Essays on Trade Policy and Labor Mobility

\author{
Erhan Artuç \\ Denizli, Turkey
}

Bachelor of Arts, Bilkent University, 2001

Master of Arts, University of Virginia, 2003

\begin{abstract}
A Dissertation presented to the Graduate Faculty of the University of Virginia in Candidacy for the Degree of Doctor of Philosophy
\end{abstract}

Department of Economics

University of Virginia

August, 2006

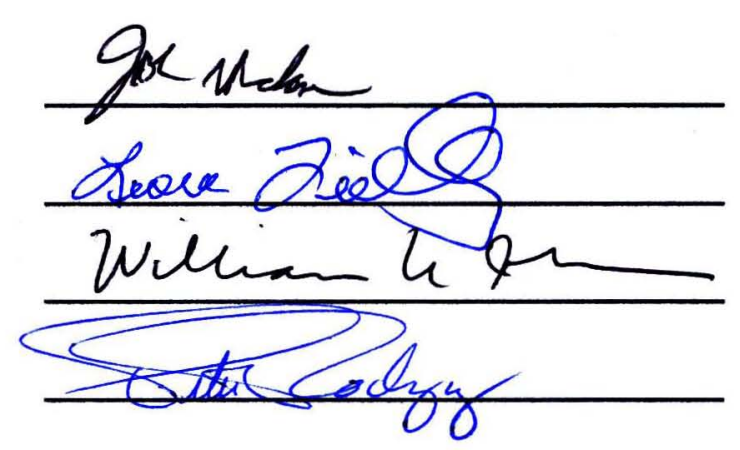




\title{
Chapter List
}

\author{
Chapter 1 \\ Delay and Dynamics in Labor Market Adjustment \\ Coauthored with Shubham Chaudhuri and John McLaren
}

\begin{abstract}
Chapter 2
Intergenerational Effects of Trade Liberalization: Structural
\end{abstract} Estimation of a Dynamic Model of Labor Mobility

\section{Chapter 3}

Intergenerational Effects of Trade Liberalization: General Equilibrium Simulation of the Dynamic Model of Labor Mobility 


\begin{abstract}
Chapter 1. We simulate numerically a trade model with labor mobility costs added, modeled in such a way as to generate gross flows in excess of net flows. Adjustment to a trade shock can be slow with plausible parameter values. In our base case, the economy moves $95 \%$ of the distance to the new steady state in approximately eight years. Gross flows have a large effect on this rate of adjustment and on the normative effects of trade. Announcing and delaying the liberalization can build - or destroy - a constituency for free trade. We study the conditions under which these contrasting outcomes occur.
\end{abstract}

Chapter 2. The effects of trade liberalization depend on the sectoral mobility of workers. For example, if workers were perfectly mobile they would be unanimous and if they were immobile they would be split in seeing free trade as good or bad. This paper provides US estimates of a dynamic longitudinal model of sectoral choice with mobility costs in an open economy subject to trade shocks. The results suggest that moving costs are large (more than one year's wage) and increase with age. We show that decreased mobility with age can be attributed to both sectoral experience and age. Therefore, workers' gains and losses from free trade should be correlated with their age and experience.

Chapter 3. Parameter estimates from Chapter 2 are used for simulations of the dynamic model in a general equilibrium framework, that show: 1. Differences in 
sectoral mobility of younger versus older workers, 2 . The speed with which workers can find new jobs in other sectors if they lose their jobs because of free trade, 3 . Gradual adjustment of wages and labor in response to a trade shock, and 4. The welfare effects of a hypothetical trade liberalization in the metal manufacturing sector (which has been especially vulnerable to trade shocks in the past, the steel industry in particular). We find that older workers' distribution of gains and losses from trade liberalization has a very large variance, while young workers are more unanimous in seeing trade liberalization as good or bad. 


\section{Acknowledgments}

I am truly grateful to John McLaren and Leora Friedberg for their continuous help and support. They have been supporting me in many ways too long to list; without their help I would not be able to write this dissertation. I thank members of my dissertation committee, William Johnson and Peter Rodriguez. I would also like to thank Chris Otrok, Steve Stern, Shubham Chaudhuri, Marco Cagetti, Wake Epps and Faruk Selçuk who had major influence on my academic development.

I acknowledge helpful comments from Simon Anderson, Frederico Ciliberto, Bob Flood, Emily Blanchard, Maxim Engers, Sanjay Jain, Luca Bossi, Oscar Mitnik, İnsan Tunalı, Kamil Yılmaz, Kuzey Yılmaz, Mehmet Yörükoğlu, Refet Gürkaynak, Byeongju Jeong, Stepan Jurajda, Eddie Summers, Luljeta Shani and seminar participants at University of Virginia, University of Miami, Koç University, Sabanc1 University, Bilkent University and Cerge-Ei.

I would like to thank my fellow graduate students and friends; Marc Santugini, Panayiotis Pourpourides, Chul Hee Kim, Sung Park, Jose Fernandez, Yakup Asarkaya, Ganesh Seshan, Devrim Demirel, Bilgehan Karabay, Paul Sullivan and all others I can not list here who helped me with my dry-runs.

Finally, I would like to acknowledge the support of my wife, I am very grateful for the sacrifices she made for me. I also want to thank my family: Anneciğım, Babacağım, Ayhan Abi ve Serhan Abi, hepinize çok teşekkürler ederim. 
The first chapter is supported by NSF grant 0080731 (given to my coauthors); the second and third chapters are supported by the Bankard Fund for Political Economy at the University of Virginia and the Dissertation Year Fellowship of the Graduate School of Arts and Sciences.

All errors are mine. 
Emre, Halide, Annem ve Babam için ... 


\title{
Chapter 1
}

\section{Delay and Dynamics in Labor Market Adjustment}

\author{
Coauthored with Shubham Chaudhuri and John McLaren
}

\subsection{Introduction}

Despite its importance, the imperfect mobility of workers within their economy has usually been ignored in research on international trade. Familiar workhorse models assume either perfect mobility or (less often) perfect immobility of workers across sectors.

This paper studies a recent theoretical model that has been designed to address this gap, by simulating the model numerically to generate answers to questions that are difficult to resolve analytically. Cameron, Chaudhuri and McLaren (2003) present a model of a small open economy with workers who face moving costs to switch sectors or to move geographically within the country. These costs have a common component and a time-varying idiosyncratic component. Workers must choose their location at each date, which amounts to a problem of investment under uncertainty with rational expectations. The presence of the idiosyncratic shocks means that the model produces 
gross flows in excess of net flows, gradual adjustment of the economy to a trade shock, anticipatory adjustment to an expected future shock, and long-run wage differentials across sectors and locations, all of which are important empirically. Chaudhuri and McLaren (2003a) studies a simple special case of this model in which there are two sectors, each in one geographic location. This is essentially a dynamic version of the familiar Ricardo-Viner model (see Mussa (1975)). Chaudhuri and McLaren (2003b) study another simple variant with two types of imperfectly mobile worker, skilled and unskilled, and no other factor of production. This is essentially a dynamic version of a Heckscher-Ohlin model. Both models show great differences from their static analogues, even in the steady state. This paper studies properties of the model in Chaudhuri and McLaren (2003a) (henceforth CM) .

Specifically, we consider an economy initially in a steady state with a tariff that is then opened to free trade, in two possible ways: first, sudden, unannounced liberalization, and then delayed, pre-announced liberalization. We study the time-path of the economy's adjustment, the evolution of wages, and the welfare of workers in exporting and import-competing sectors. We find that both the positive and the normative effects of trade can be very different for an anticipated and an unanticipated liberalization, and also for different parameter values that yield different levels of gross flows.

Various approaches have been used to incorporate imperfect labor mobility into trade models. One approach has been to adapt the convex adjustment cost assumed 
for capital in Mussa (1978) to labor, reinterpreting it perhaps as a retraining cost. Examples of this are Karp and Thierry (1994) and Dehejia (2003). Another is to assume that each worker must pay a fixed cost to switch sectors. Examples include Dixit (1993) and Dixit and Rob (1994) in a dynamic model with stochastic shocks to labor demand across sectors, and Feenstra and Lewis (1994) in a static model. These all have in common the property that if labor moves across sectors, it all moves in the same direction at any one time, or in other words, gross flows are equal to net flows.

An approach that allows for gross flows in excess of net flows is explored in Davidson, Martin and Matusz (1999) and Davidson and Matusz (2001). This approach is based on search theory; workers may leave one sector to find a job in another, but at the cost of temporary unemployment while looking for a vacancy. The approach pursued in the current paper differs from that series in a variety of ways, but most crucially it has been designed to be as close as possible to familiar trade models. For example, Davidson, Martin and Matusz (1999) show that in a model with the usual sources of comparative advantage shut down, a country can still have gains from trade due to differences in search technology across countries. In our model, by contrast, the gains from trade stem from the same sources as in a Ricardo-Viner model.

A major focus of this paper is the effect of delay in trade liberalization, or the practice of government announcing a future elimination of trade barriers in order to allow private agents time to adjust. This is a special case of 'gradualism,' or 
liberalization through scheduled progressive stages, which is an extremely common practice in real-world trade reform. Mussa (1978) showed that in a neoclassical model there is no strictly economic argument for gradualism. Staiger (1995) and Bond and Park (2002) examine different reasons that gradualism can be useful in loosening incentive-compatibility constraints in bilateral liberalization without commitment. Dehejia (2003) shows in a labor-rich Heckscher-Ohlin economy with convex moving costs for labor, gradualism can make the import-competing workers net beneficiaries from trade reform, instead of net losers. This can make the liberalization politically feasible, while a 'shock therapy' liberalization would have been infeasible. In this paper, we will explore the Dehejia argument with a different model, one featuring gross flows, and arrive at quite different results.

The next section lays out the model, the following one some baseline simulations showing how changes in the moving cost parameters change the economy's dynamic adjustment, and the following section studies in detail the possible attractiveness of delayed liberalization as a way of spreading the benefits of trade more widely.

\subsection{The Model}

Consider a small open economy that can produce two goods, $X$ and $Y$. Good $Y$ is the numeraire, and the price of $X$ is denoted by $p$. Both goods are produced under competitive conditions with constant-returns-to-scale technology $q^{i}=Q^{i}\left(L^{i}, K^{i}\right)$, 
where $q^{i}$ denotes output in sector $i, L^{i}$ and $K^{i}$ denote labor and capital employed in sector $i$ respectively. Capital in each sector is inelastically supplied, and is specific to its sector. The total supply of labor in the economy is exogenously given at a value $\bar{L}$, so at all points the adding-up condition for labor must hold:

$$
L^{X}+L^{Y}=\bar{L}
$$

Workers can move from one sector to another over time, but at each date the supply of labor to each sector is fixed by location decisions in previous periods. Wages in each sector adjust to clear the spot market for labor at each date:

$$
\begin{aligned}
& \tilde{w}_{t}^{X}=\frac{p \partial Q^{X}\left(L_{t}^{X}, K_{t}^{X}\right)}{\partial L_{t}^{X}} \\
& \tilde{w}_{t}^{Y}=\frac{\partial Q^{Y}\left(L_{t}^{Y}, K_{t}^{Y}\right)}{\partial L_{t}^{Y}}
\end{aligned}
$$

where a subscript indicates time and $\tilde{w}_{t}^{i}$ is the wage in sector $i$ in period $t$, denominated in terms of the numeraire.

\section{Workers}

All workers discount the future at the common rate $\beta<1$. Workers are infinitelylived and risk-neutral. They all have an identical and homothetic utility function, yielding an indirect utility function given by $I / \phi(p)$, where $I$ is income and $\phi(p)$ is a consumer price index. The location decisions of workers are characterised as follows. 
In each period, each worker receives an idiosyncratic benefit, $\varepsilon_{t}^{j}$ if that worker is in sector $j$ at the end of the period. We can denote the pair of benefits by , $\varepsilon_{t}=\left(\varepsilon_{t}^{i}, \varepsilon_{t}^{j}\right)$. These benefits are realized from a continuous distribution with probability density function $f$ and cumulative distribution function $F$, where $E\left[\varepsilon_{t}^{j}\right]=0$. These shocks are independently distributed across workers and across time. It is most convenient to think of these benefits as non-pecuniary. For example, a worker in sector $i$ may have tired of his/her existing job, and want to switch (indicating a negative $\varepsilon_{t}^{j}$ ); or develop a romantic attachment that requires him/her to move to another part of the country, where the workers current sector does not operate but the other sector does (indicating a large positive, $\left.\varepsilon_{t}^{j}\right){ }^{1}$

There is, then, an idiosyncratic cost to switching sectors, as a worker who leaves $i$ in order to enter sector $j$ at time $t$ forgoes the $i$ benefit and reaps the $j$ benefit instead. This implies an idiosyncratic moving cost of:

$$
\mu_{t}^{i}=\varepsilon_{t}^{j}-\varepsilon_{t}^{i}
$$

The cdf for this moving cost is derived from $F$ and denoted $G$; similarly, the pdf is

\footnotetext{
${ }^{1}$ The assumption that the idiosyncratic shocks are iid is, of course, for illustrative purposes and is not terribly realistic. There are many reasons that the shocks may be serially correlated in the real world, as when mobility is hampered by the cost of children switching schools, and there are many reasons the shocks could have different variances. If the example cited above of a worker falling in love with a worker in another sector were taken literally, that would imply that a positive shock was more likely to draw the worker to a larger sector than a smaller one, simply because there are more potential romantic matches in a larger sector. We have chosen to eliminate all of these effects by fiat in order to concentrate on the questions of greatest concern to us. We are grateful to an anonymous referee for clarifying our thinking on this.
} 
denoted $g$.

In addition to the idiosyncratic moving cost, a worker who changes sectors will also incur a common cost equal to $C \geq 0$.

\section{Worker optimization}

Let $V^{i}\left(L_{t}\right)$ stand for the expected utility of a worker in sector $i$ at time $t$ (before learning idiosyncratic shocks $\varepsilon_{t}$ ). Worker optimization implies the Bellman equation:

$$
E V_{t}^{i}=w_{t}^{i}+E \max \left\{\varepsilon_{t}^{i}+\beta V^{i}\left(L_{t+1}\right), \varepsilon_{t}^{j}+\beta V^{i}\left(L_{t+1}\right)-C\right\}
$$

where $i, j \in\{X, Y\}$ and $i \neq j$, and $w_{t}^{i}=\frac{\tilde{w}_{t}^{i}}{\phi(p)}$ is the real utility wage. It is easy to see that at any date $t$ there is a threshold value of $\mu_{t}^{i}$, say $\bar{\mu}_{t}^{i}$, such that the worker will stay in $i$ if $\mu_{t}^{i}>\bar{\mu}_{t}^{i}$, and will move to $j$ if $\mu_{t}^{i}<\bar{\mu}_{t}^{i}$. Put differently, $\bar{\mu}_{t}^{i}$ is the net value of being in $j$ rather than $i$ next period, net of non-idiosyncratic moving costs. This enables us to write:

$$
\begin{aligned}
& \bar{\mu}_{t}^{X}=\beta\left[V^{X}\left(L_{t+1}\right)-V^{Y}\left(L_{t+1}\right)-C\right], \\
& \bar{\mu}_{t}^{Y}=\beta\left[V^{Y}\left(L_{t+1}\right)-V^{X}\left(L_{t+1}\right)-C\right],
\end{aligned}
$$

and so

$$
\bar{\mu}_{t}^{X}=-\bar{\mu}_{t}^{Y}-2 C
$$


Using this notation, the Bellman equation becomes:

$$
\begin{aligned}
E V_{t}^{i} & =w_{t}^{i}+\beta E V^{i}\left(L_{t+1}\right)+E \max \left\{0, \bar{\mu}_{t}^{i}-\mu_{t}\right\} \\
& =w_{t}^{i}+\beta E V^{i}\left(L_{t+1}\right)+\Omega\left(\bar{\mu}_{t}^{i}\right),
\end{aligned}
$$

where $\Omega\left(\bar{\mu}_{t}^{i}\right)=E \max \left\{0, \bar{\mu}_{t}^{i}-\mu_{t}\right\}=G\left(\bar{\mu}_{t}^{i}\right) \bar{\mu}_{t}^{i}-\int_{-\infty}^{-\bar{\mu}_{t}^{i}} \mu g(\mu) d \mu$ is the option value of worker in sector i. In addition, the law of motion for labor allocations can be written:

$$
L_{t+1}^{i}=\left(1-G\left(\bar{\mu}_{t}^{i}\right)\right) L_{t}^{i}+G\left(\bar{\mu}_{t}^{j}\right) L_{t}^{j}
$$

since the fraction of workers in $i$ who move to $j$ in any period is equal to $G($ ).

Thus, the steady-state values of $L^{X}$ and $L^{Y}$ are determined by the steady-state value of $\bar{\mu}_{t}^{x}$, which we denote $\bar{\mu}^{x}$. This, then, determines the steady-state values of $w^{X}$ and $w^{Y}$ as a function of $\bar{\mu}^{x}$ through (1), so condition (3) can be used to compute the steady-state values of $V^{i}$ as a function of $\bar{\mu}^{x}$, which can then be substituted into (2) to obtain one equation in one unknown, $\bar{\mu}^{x}$. This, then, allows us to compute the steady state easily. ${ }^{2}$

CM derive a number of results. First, in the steady state, the larger sector must have a higher wage, and the steady-state allocation of labor is in between the RicardoViner equilibrium and equal division. ${ }^{3}$ In addition, the dynamic equilibrium maxi-

\footnotetext{
${ }^{2}$ It is easy to see that this steady state is unique. In addition, note that the steady state features positive gross flows but zero net flows.

${ }^{3}$ According to the model there should be a positive correlation in the long run between industry
} 
mizes the present discounted value of aggregate real revenue net of (common plus idiosyncratic) moving costs. ( This is the dynamic analogue of the static revenue function, as used in Dixit and Norman (1980).) The optimization problem can be implemented as a straightforward dynamic programming problem. Because the value function is strictly concave, the solution to this optimization problem, and hence the equilibrium, is unique. This optimization approach could be useful in computing the equilibrium numerically, although we use a different method in this paper. A few properties of the equilibrium dynamics are also derived. If trade is suddenly opened up in an economy that had been closed, the economy adjusts gradually and monotonically to the new steady state as the import-competing sector shrinks.

Further, if a future opening of trade is credibly announced in advance, labor begins to reallocate immediately from the import-competing sector in anticipation of the policy change. This implies that such an announcement will raise wages in the import-competing sector in advance of the policy change and lower them in the export sector during the same period. This raises questions regarding the incidence of trade policy and how it may be affected by delay in liberalization. Under what conditions are workers in the import-competing sector net beneficiaries of trade? Workers in the export sector? And how are these welfare effects affected by delay of liberalization of the type just described?

size and industry average wages. We have confirmed this by calculating the correlation coefficients between wages and size of industries in the Current Population Survey data. Our results show that correlation coefficients are positive and significant at more than $95 \%$ confidence level for all years between 1981 to 2000. Details are available from the authors on request. 
A number of local results are derived regarding this in $\mathrm{CM}$, that is, results that are valid if the world price is close enough to the domestic autarkic price. First, starting from an autarkic steady state, it is shown that it is possible for all workers to benefit from a surprise opening of trade (in terms of lifetime expected utility, $V^{i}\left(L_{t}\right)$ ). It is also possible for all workers to be hurt, and it is possible for workers initially in the export sector to benefit and workers in the import-competing sector to be hurt. (The benefit to export-sector workers always exceeds the benefit to import-competing workers.) Refer to the first two cases as cases in which workers are 'unanimous,' and the last case as one in which workers are 'split.' In cases in which the workers are unanimous without delay, delay does nothing to change their minds, but in cases in which they are split a sufficiently long delay will guarantee unanimity. However, it could be a pro-trade or an anti-trade unanimity. CM derive a condition that determines which of the two cases occurs, in the local case. It essentially says that if export-sector labor demand is responsive enough compared to import-competingsector labor demand, delay leads to pro-trade unanimity, and otherwise it leads to an anti-trade unanimity. In this paper, we explore these questions numerically to try to quantify these effects and to map out the portions of the parameter space in which these outcomes occur without relying on the assumption of the nearness of the world price to the autarkic price. 


\subsection{Parameters and simulation method}

We will study an economy that is initially in a steady state with a tariff, but then has the tariff removed either abruptly or with some warning. Here we will lay out the functional form and parameter assumptions and the method for computing equilibrium responses to these policy changes.

The economy has 1 unit of specific capital in each of the two sectors and 2 units of labor in total. We adopt the following functional-form assumptions. Production functions are of the constant-elasticity-of-substitution (CES) variety:

$$
\begin{aligned}
Q^{i}\left(L_{t}^{i}, K_{t}^{i}\right) & =\left(2^{-1 / \rho_{i}}\right)\left[\left(L_{t}^{i}\right)^{\rho_{i}}+\left(K_{t}^{i}\right)^{\rho_{i}}\right]^{1 / \rho_{i}} \text { if } \rho_{i} \neq 0, \text { and } \\
& =\left(L_{t}^{i}\right)^{1 / 2}\left(K_{t}^{i}\right)^{1 / 2} \text { otherwise, }
\end{aligned}
$$

where $\rho_{i} \in(-\infty, 1)$ is a parameter. The elasticity of substitution between labor and capital in sector $i$ is then $\sigma_{i}=1 /\left(1-\rho_{i}\right)$. Note that the production functions have been normalized so that regardless of the elasticity of substitution chosen, the unit isoquant will always go through the point $(1,1)$. Preferences are given by the CobbDouglas utility function $U\left(C^{X}, C^{Y}\right)=\left(C^{X} C^{Y}\right)^{1 / 2}$, where $C^{i}$ represents consumption of good $i$, yielding the indirect utility function $I /\left(p^{X} p^{Y}\right)^{1 / 2}$, where $p^{X}$ and $p^{Y}$ are the product prices and $I$ is income. Given that $Y$ is the numeraire, the indirect utility function becomes:

$$
I / \phi(p)
$$


for given income $I$ and price $p$ for good $X$, where $\phi$ the consumer price index is given by $\phi(p)=p^{1 / 2}$.

It is straightforward to see that as a result of these production and consumption assumptions the value $p=1$ is always the steady-state equilibrium price in autarky, regardless of the substitution elasticities, with equal wages in the two sectors (equal to $\frac{1}{2}$ ) and an equal division of labor between the sectors. This is a useful benchmark. We will assume that the world relative price of $X$ is $p^{W}=0.7$, and that before the liberalization the tariff is set just high enough that the domestic relative price is equal to unity (an ad valorem rate of approximately 43 per cent). In other words, the government has imposed the minimal prohibitive tariff. This makes for a convenient thought experiment, because it facilitates easy comparison of the pre-liberalization situation across different parameter values. Note that since the autarkic relative price of $\mathrm{X}$ exceeds the corresponding world price, the economy exports $\mathrm{Y}$.

We assume that the,$\varepsilon_{t}^{i}$ 's have the extreme-value distribution, with cumulative distribution function

$$
F(\varepsilon)=\exp (-\exp (-\varepsilon / \nu-\gamma))
$$

where $\gamma=0.5772$ is Eulers constant. The means of $\varepsilon$ is then zero, and its variance is then equal to $\left(\pi^{2} \nu^{2}\right) / 6$ (Patel, Kapadia, and Owen (1976, p.35)). It can be shown that in this case

$$
G(\mu)=\frac{\exp (\mu / \nu)}{1+\exp (\mu / \nu)},
$$


and that

$$
\Omega(\mu)=\nu \log (1+\exp (\mu / \nu))
$$

(Derivations are available from the authors on request.)

The trade liberalization proceeds as follows. Suppose that the economy is in a steady state with tariff at date $t=0$, and then it is announced that at date $T \geq 0$ and from that date forward, free trade will prevail. Thus, we have $p_{t}=1$ for $t<T$, and $p_{t}=p^{W}$ for $t \geq T$. If $T=0$, this simply means simulating forward adjustment under free trade from a starting point of $L^{X}=L^{Y}=1$, otherwise we simulate an anticipatory adjustment.

We compute equilibrium by the following method. First, use steady-state versions of (1), (2), (3) and (4) to compute the free-trade steady state. Next, choose a value for $T^{S S}$, say, $T^{S S}=30$, and conjecture that the system will come to within a given tolerance level of the steady state by date $T^{S S}$. Then, for each date from $t=0$ to $T^{S S}$, we conjecture a value $z_{t}^{X}$ for $V^{X}\left(L_{t}+1\right)$ and a value $z_{t}^{Y}$ for $V^{Y}\left(L_{t}+1\right)$. Denote these vectors by $z^{j}=\left\{z_{t}^{j}\right\}$ for $j=X, Y$. By (2), these values can be used to calculate the implied values of and for $t=0$ to $T^{S S}$. This then, through (4), implies a time path for $L_{t}^{X}$ for $t=0$ to $T^{S S}$, starting from $L^{X}=L^{Y}=1$, which, then, by (1), implies a time path for wages from $t=1$ to $T^{S S}+1$. (Of course, in using (1), we substitute in the current value of $\mathrm{p} t$ at each date.) The nominal wages are then converted to real wages using the consumer price index $\phi\left(p_{t}\right)$. We then use the 
workers' Bellman equation (3) to compute updated values $\tilde{z}^{j}$ of the vectors $z^{j}$. Thus, we set $z_{t}^{j}=w_{t+1}^{j}+\Omega\left(\bar{\mu}_{t+1}^{j}\right)+\beta z_{t+1}^{j}$ for $t=0$ to $T^{S S}-1$, and using the assumption that the system is in steady state by date $T^{S S}$, we set $z_{T^{S S}}^{j}=w_{T^{S S}}^{j}+\Omega\left(\bar{\mu}_{T^{S S}}^{j}\right)+\beta z_{T^{S S}}^{j}$. We then compare $\left\{z^{X}, z^{Y}\right\}$ to $\left\{\tilde{z}^{X}, \tilde{z}^{Y}\right\}$ and if they match to within our convergence tolerance, we stop, otherwise the process is repeated with an updated initial guess. We then confirm that the system is within our tolerance of steady state by date $T^{S S}$; if not, a higher value of $T^{S S}$ is chosen and we start the algorithm from the beginning. This algorithm is similar to the multiple-shooting technique of Lipton et. al. (1982). Program code and details are available from the authors on request. The process converges quickly to a high degree of precision.

Once the equilibrium transition path has been computed, it is straightforward to compute the welfare of a worker currently in sector $i$ at the date of the policy announcement as $\sum_{t=0}^{\infty} \beta^{t}\left(w_{t}^{i}+\Omega\left(\left(\bar{\mu}^{i}\right)\right) .{ }^{4}\right.$ We compare this to the utility of a worker in the tariff-affected steady-state $\left(\frac{1}{2}+\Omega((-C)) /(1-\beta)\right.$, to evaluate whether the given worker is made better or worse off by the announced policy. The welfare of owners of fixed factors can be computed in analogous fashion, as the present discounted value of their marginal products, deflated by the consumer price index. We set $\beta$ equal to 0.97, which seems reasonable for an annual discount factor and allows us to interpret

\footnotetext{
${ }^{4}$ There will be no tariff revenues in the initial steady state, because there will be no imports. There will certainly be no tariff revenues after the tariff has been eliminated. In between, there will generally be positive tariff revenue. In order to work out who the net gainers from trade are, we need to make an arbitrary assumption about how the government disposes of the tariff revenue. We assume that all of these revenues are captured by the owners of the fixed factors, conjecturing that alternative assumptions would not make much difference to the results.
} 
the 'periods' in our simulations as 'years.'

It should be noted that our focus is on workers, so we ignore the welfare effects on specific factors. Given that this is a rational-expectations economy with no externalities, total welfare is always higher with trade than under autarky, so if worker welfare declines as a result of trade, there is necessarily a corresponding and larger increase in the welfare of specific factors as a whole. Further, it is straightforward to confirm that in these simulations the welfare of owners of import-competing specific factors is always lowered by trade, with the opposite effect on owners of factors specific to the export sector.

To sum up, the fixed parameters are $\beta=0.97 ; K^{X}=K^{Y}=1 ; \bar{L}=2$; and $p^{F T}=0.7$. The pre-liberalization relative price is equal to unity. The free parameters are the two substitution elasticities $\sigma^{X}$ and $\sigma^{Y}$; the parameter $\nu$ that governs the variance of idiosyncratic shocks; the common value of moving costs, $C$; and $T$, the length of delay in trade liberalization. We will now show two sets of simulation results: One to study the dynamics of some base-case liberalizations, and show the effect of the idiosyncratic variance parameter $\nu$, and then a second set to identify the conditions under which delay can improve the distributional effects of liberalization.

\subsection{Dynamics in base case simulations}

We need to choose values of $C$ and $\nu$ for a base case simulation. We turn to esti- 
mates in Chapter 2, where a similar model is estimated with data from the National Longitudinal Study of Youth. For the base case in those estimations, the moving cost is between two and three times average annual wages, so we will set $C$ equal to 1.0 for the base case (recalling that steady-state wages before liberalization are equal to 0.5 in each sector). This is, of course, a high value. In interpreting these parameters, it should be kept in mind that the inertia in labor flows exhibited in the data reflects the full costs of moving, psychic as well as pecuniary, plus any unmodelled frictions that may impede movement. We also contrast the base case with simulations based on a much lower moving cost, with $C=0.33$. In both cases, we set $\nu$ so that the steady-state rate of gross flows with the tariff is approximately equal to 4 per cent per year. ${ }^{5}$ Thus, in the Benchmark Case we have $C=1$ and $\nu=0.31$, and in the Low-Cost Case we have $C=0.33$ and $\nu=0.10$.

Figure 1.1 shows the time path of $X$-sector employment $L^{X}$ under four situations, a sudden removal of the tariff at date 0 for the Benchmark and Low-Cost cases, and an announcement at date 0 that the tariff will be removed at date 10 for the Benchmark and the Low-Cost cases.

Note that the adjustments for both delayed and sudden liberalization cases are gradual, as in each period import-competing workers who have high current moving costs wait to see if their moving costs will be more favorable in the near future. In

\footnotetext{
${ }^{5}$ Recalling that in the tariff-affected steady state, wages are equalized across the sectors, $\bar{\mu}^{X}=$ $\bar{\mu}^{Y}=-C$, and so gross flows are equal to $G(-C)$ in both sectors, which takes a value of about 4 per cent per year with $C=1$ and $\nu=0.31$.
} 
the case of the surprise liberalization with Benchmark parameters, it takes about 8 years for the economy to move $95 \%$ of the distance to the new steady state, while in the case of delayed liberalization the adjustment is even slower. This suggests a possible problem for application of steady state models to data, unless one is willing to assume that trade shocks occur very infrequently.

Note as well that in the case of delayed liberalization, workers begin to move at the date of the policy announcement, as import-competing workers who have very low current moving costs take advantage of them rather than risk being stuck with high moving costs later. In fact, more than three quarters of the adjustment occurs before the policy change. This suggests a possible problem for empirical approaches that are based on comparison of sectoral employment before and after the elimination of the tariff.

In the event of a sudden liberalization, $X$ - sector real wages drop immediately and gradually climb as labor leaves the sector (Figure 1.2, broken line), while Y-sector real wages jump up due to the reduced cost of living, then gradually fall as workers enter the sector (Figure 1.3, broken line). The steady-state wage is slightly higher for workers in the export sector (0.520) than for workers in the import-competing sector (0.508). For all of these reasons, the $Y$ workers benefit more from the liberalization than the $X$ workers do, although welfare of workers in both sectors rises when the liberalization is announced (by about $1.7 \%$ for import-competing workers and $3.7 \%$ for export workers). 
On the other hand, in the event of delayed liberalization, the $X$ - sector wage begins to rise during the interval between announcement and actual removal of the tariff, as workers leave the sector in anticipation (Figure 1.2, solid line). The wage drops abruptly when the tariff is removed. At the same time, the wage in the export sector is pushed down as workers enter, and jumps up abruptly when the tariff is removed (Figure 1.3, solid line). As a result, the net benefit to import-competing workers is greater, and the net benefit to export workers is less, than in the case with no delay. In this case, both groups of worker now see a rise in welfare from the liberalization of about $2 \%$. Thus, this is a case in which delay unifies workers in favor of free trade.

For the Low-Cost case, the adjustment of workers is faster than in the Benchmark case (see Figure 1.1). However, note that in the case of delay, the bulk of the labor adjustment takes place close to the actual trade liberalization date rather than right after the announcement date. In the limit with zero moving costs, the model would imitate a static Ricado-Viner model.

In the last two cases examined in this section, we vary $\nu$, holding $C=1.0$, in order to see how important idiosyncratic shocks and gross flows are to the system's dynamics. In general, the higher is $\nu$, the more important are idiosyncratic shocks and the larger will be gross flows. Here, we consider a 'high variance case,' in which $\nu^{2}$, and therefore the idiosyncratic variance, is ten times what it was in the base case; and a 'low variance case,' in which the idiosyncratic variance is one-tenth what it 
was in the base case. ${ }^{6}$ As can be seen from Figure 1.4, in the high variance case the new steady-state employment in $X$ is only $15 \%$ less than that in the old steady state, compared with $32 \%$ in the benchmark case. The reason is that in the high variance case idiosyncratic non-pecuniary factors are much more important to workers relative to wages than was the case in the benchmark case. Thus, the supply side of the economy responds less vigourously to price signals, in the short and long runs. As a consequence, wages do most of the adjustment, and indeed, in this case without delay real import-competing wages fall, in the short run and the long run, while export sector wages do the opposite.

Thus, we see a paradoxical result: Although the high-variance case is a case with very high labor mobility, ${ }^{7}$ in the aggregate it looks like a model with very unresponsive labor adjustment, with labor quantities moving very little even in the long run, and wages absorbing the brunt of the effect of trade liberalization. Casual interpretation without taking gross flows into account would suggest that import-competing workers are hurt by the liberalization while export-sector workers benefit, but in fact both groups of worker benefit, even without delay in the tariff removal. The reason is that with such high rates of gross flow, workers do not think of themselves as attached to their current sector, and are cheered by news of higher wages in the other sector because they know that they will likely spend time in that sector soon.

\footnotetext{
${ }^{6}$ The high-variance case has $\nu=0.94$, and the low-variance case has $\nu=0.10$.

${ }^{7}$ Gross flows in the tariff-affected steady state are equal to $G(-1) \cong 26 \%$ per year with $\nu=0.94$.
} 
By contrast, in the low-variance case the economy is sluggish but has more reallocation in the steady state; once again, see Figure 1.4. In the low-variance case, the economy achieves $95 \%$ of its adjustment in 31 years, while in the high-variance case it takes only 3 years. In the high variance case with delay, $61 \%$ of the adjustment is completed by the date the tariff is removed, while in the low variance case $39 \%$ is completed by that date.

A surprising fact about long-run wages emerges from the low-variance case. The long-run wage the export sector is 0.517 , while in the import-competing sector it is 0.513. Thus, the long-run wage differential between the two sectors is much narrower than it is in the other two parametric cases, despite the sluggishness of labor movements. This is an illustration of a general result shown in Cameron, Chaudhuri, and McLaren (2003), that as the idiosyncratic variance becomes vanishingly small, the long-run wage differential across sectors also becomes vanishingly small (even if $C$ does not become small itself). The point is that although labor adjustment is very sluggish, the long run elasticity of intersectoral labor supply with respect to wage differentials is very large when the idiosyncratic variance is small. Thus, even though this is a model with very low mobility of labor, ${ }^{8}$ if one focusses on steady state wage differentials, one may be deceived into thinking it is a model with a very high degree of mobility; the steady state is close to the equilibrium of a static frictionless

\footnotetext{
${ }^{8}$ Gross flows in the tariff-affected steady state are equal to $G(-1.0) \cong 7 \times 10^{-5}$ per year with $\nu=0.10$.
} 
model. At the same time, obviously, because adjustment is slow, the steady state is not sufficient for welfare analysis.

A final point about all three cases is that the short run behaviour of wages is very different from the long-run behaviour. In each case, with an unannounced tariff removal, the real wage in the import-competing sector falls on impact, and the wage in the export sector rises. However, as we have seen in the discussion of the results, this is very different from the behaviour both of long-run wages and of worker welfare. For example, for the benchmark and low variance cases the long run wage is higher for import-competing workers than the original steady state wage, and in the highvariance case, although import-competing wages never recover, the import-competing workers are better off. As a result, results from an empirical approach focussed only on comparing wages in the two sectors immediately before and after the tariff reduction must be interpreted with care.

\subsection{Delay and Worker Unity.}

A point that emerges from the simulations above is that delaying the liberalization tends to increase the gains (or reduce the losses) to import-competing workers, by temporarily raising their wage, and tends to reduce the gains (or increase the losses) to export workers, by temporarily lowering their wages. This can have important

effects on the pattern of net beneficiaries from the liberalization. In particular, in 
cases in which import-competing workers would have been opposed to an immediate liberalization, it is possible that a delayed liberalization would unite all workers, either in favor of or in opposition to free trade. In this section, we examine this argument in more detail.

In $\mathrm{CM}$, it is shown that locally the determinant of whether delay will tend to unite workers in favor of or in opposition to free trade is the relative long-run responsiveness of $X$ - and $Y$ - sector output to a change in total labor supply. Essentially, if the demand for labor in the import-competing sector is very inelastic, delay will unite workers in favor of trade, while if the demand for labor in the export sector is very inelastic, delay will unite workers against trade. A natural way to parametrize this is by varying the sectoral elasticities of factor substitution $\sigma(X)$ and $\sigma(Y)$. Of course, if $\sigma(i)$ is close to zero, then the output response of sector i must be close to zero, and the higher is the elasticity the better the sector would be able to absorb and make use of additional supplies of labor.

We have performed the following experiment. For each point in a grid of $(\sigma(X), \sigma(Y))$ values ranging between 0 and 5 , we have solved and simulated the model for $T=0$, in other words, for an unannounced immediate tariff removal. All other parameters are as in the base case of the previous section. Figure 1.5 represents the grid, with $\sigma(X)$ measured along the horizontal axis and $\sigma(Y)$ along the vertical. If the welfare of workers in both sectors increases as a result of the removal, we record this in Figure 1.5 as a point for which 'Sudden liberalization benefits all workers.' If the welfare of 
workers in both sectors falls, we record the point as one for which 'Sudden liberalization hurts all workers.' On the other hand, if the workers are split, meaning that export workers benefit from the liberalization while import-competing workers are hurt, then we solve the model again for $T=1$, or a one-period delay. If this policy brings about an increase in welfare (measured at the announcement date $t=0$ ) for workers in both sectors, we record that point as one for which 'Delayed liberalization benefits all workers.' If the workers are still split, we add 1 to $T$ and repeat. If all workers are hurt by the delayed liberalization, then we record the point in the figure accordingly.

In other words, we search for the minimal delay required to achieve unanimity among the workers regarding their support for free trade.

Note that if $\sigma(X)$ is low enough, then all workers will benefit from free trade even if it is sprung by surprise, as reflected in the fact that the 'Sudden liberalization benefits all workers' region lies against the vertical axis. This is because free trade will raise the demand for export-sector workers; if labor demand in the import-competing sector is very inelastic (as would be the case with Leontieff technology), this will result in a sharp increase in import-competing sector wages, which will dominate other effects. Similarly, if $\sigma(Y)$ is low enough, then all workers will be hurt by free trade if it is sprung by surprise, as reflected in the fact that the 'Sudden liberalization hurts all workers' region lies against the horizontal axis. This is because free trade will lower the demand for import-competing-sector workers; if labor demand in the 
export sector is very inelastic, this will result in a sharp decrease in export-sector wages, which will dominate other effects. It is the region in between in which the workers are split.

A broken line divides that region of worker disunity into two sections. The section above the broken line contains parameter values for which a sufficient delay makes all workers net beneficiaries from liberalization. For these points, labor demand in the import-competing sector is sufficiently inelastic relative to the export sector that the rise in import-competing wages during the period of anticipation is the dominant effect, converting import-competing workers into net beneficiaries of the process. The section below the broken line contains parameter values for which a sufficient delay makes all workers net losers from liberalization. This is the paradoxical case in which giving private agents time to adjust to the new trade regime unites all workers in opposition to free trade. For these points, labor demand in the export sector is sufficiently inelastic relative to the export sector that the fall in export sector wages during the period of anticipation is the dominant effect, converting export workers into net victims of the process.

Thus, in contrast to Dehejia (2003), we find that the use of delay to soften political resistance to liberalization is rather treacherous. In this framework, it creates constituencies for liberalization only in a small portion of the parameter space, which is right adjacent to a portion of the parameter space where delay destroys constituencies for liberalization. There are a number of key differences between our model and 
Dehejia's: for example, we examine delayed liberalization, rather than gradualism; our model of adjustment costs allows for gross flows and long-run wage differentials, while his does not. However, the difference that is most likely salient for understanding this contrast in results is the underlying structure of the economy (see Chaudhuri and McLaren (20003a) for a formal analysis of this in the case of the present model). Dehejia's is a labor-rich Heckscher-Ohlin model with added adjustment costs; in the absence of adjustment costs, workers would gain from liberalization unambiguously. Our model is a specific-factors model with added adjustment costs; in the absence of adjustment costs, workers can gain or lose from trade depending on parameters. For example, in the limit, as the elasticity of substitution between capital and labor in the export sector becomes very low, workers will be unambiguously hurt (in effect, labor demand in the import-competing sector falls, while labor demand in the export sector is unchanged). On the other hand, if the elasticity is very low in the importcompeting sector, workers will unambiguously benefit (labor demand in the export sector rises, while labor demand in the import-competing sector is unchanged). See Mussa (1974)) for a full discussion of the static model.

These forces at work in the static model also drive the direction of workers' welfare effects in the case of delay. We conjecture that, for the same reasons, in a capital-rich version of the Dehejia model, we would find workers unanimous in opposition to a gradual trade liberalization, for the same reasons.

The minimum delay required to achieve worker unanimity varies widely over the 
parameter space, and is plotted in the shark's fin diagram of Figure 1.6. The horizontal axes measure the elasticities of substitution in the two sectors, and the vertical axis measures the number of periods of delay required to reach unanimity. The flat water surrounding the fin shows the zero delay required to achieve unanimity either for or against trade if one sector has a much lower elasticity than the other. The face of the fin facing the $\sigma(X)$ axis corresponds to the points in Figure 1.5 for which delayed liberalization hurts all workers, and the other face corresponds to the points for which delayed liberalization benefits all workers. The ridge joining the two faces corresponds to the points along the broken curve in Figure 1.5.

Not surprisingly, the points near the regions in which workers are unanimous without delay are the ones for which the shortest delay is required. As we move farther from those boundaries, the delay required becomes longer, thus reducing the aggregate benefit from liberalization. Thus, delay is most attractive the closer the economy is to the upper solid curve in Figure 1.5 (while still being below it). It is least attractive near the broken curve in Figure 1.5, where not only is a very long delay necessary to win the support of import-competing workers, but a small perturbation in parameter values would lead to the paradoxical case in which the support of export workers would be destroyed. Thus, if there was any uncertainty about parameter values, the delay strategy could be very risky.

A fuller analysis of policy options would include the possibility of compensatory transfers or direct labor market interventions rather than, or in addition to, delay. 
Such policies are studied in detail in Feenstra and Lewis (1994) and Davidson and Matusz (2002). It seems sensible to speculate that delay would be more attractive relative to those other options the closer the parameters are to the upper solid curve. However, analysis of this question is beyond the scope of this paper.

\subsection{Conclusion.}

We have studied numerical simulations of a standard trade model with labor mobility costs added, modeled in such a way as to generate gross flows in excess of net flows. Major conclusions can be summarized as follows.

(1) Adjustment to a trade shock can take a long time with plausible values of parameter values. In our base case, for the economy to move $95 \%$ of the distance to the new steady state took approximately eight years.

(2) Gross flows matter a great deal. In our model version with high gross flows (the 'high variance' model of Section 4), there was very little net movement of workers, so trade liberalization resulted in a sharp rise in wage in the one sector and a sharp drop in the other in the short run and in the long one. However, because of the high mobility of workers, actual welfare of workers even in the import-competing sector rose. On the other hand, with low gross flows (the 'low variance' model), long-run net movement of workers is large, but the adjustment takes more than 40 years. Thus, empirical estimates of the parameters that govern rates of gross flow would be 
valuable in studying hypothetical policy changes through simulation.

(3) Announcing and delaying the liberalization can build a constituency for free trade, but it can also destroy one. We have studied the conditions under which these two different outcomes occur.

In addition, we have shown how equilibrium in this model can be computed and a variety of policy experiments simulated. 


\section{Chapter 2}

\section{Intergenerational Effects of Trade Liberalization: Structural Estimation of a Dynamic Model of Labor Mobility}

\subsection{Introduction}

In order to analyze the welfare effects of trade liberalization, it is crucial to know how mobile workers are. If all workers were assumed to be perfectly mobile across sectors, then all of them would be unanimously better off or worse off after the liberalization. If all workers are absolutely immobile, then there would be clearly distinct winners and losers from free trade. In reality, mobility costs probably lie between these two extremes and vary across groups. One important source of variation has to do with the age of affected workers. In this paper, I analyze how trade liberalization affects younger and older workers using estimates from a dynamic sectoral choice model with intersectoral mobility costs. The model includes a careful modelling of labor markets in a way similar to the labor economics models. However, my primary objective is to study crucial questions about the welfare effects of trade policy that could not be investigated otherwise. I will use estimates of labor mobility parameters from this chapter for calibration purposes in the next chapter. There I simulate a hy- 
pothetical trade liberalization in the metal manufacturing industry using calibrated labor demand equation parameters in addition to the estimates of the structural ones. I compute the speed with which workers can find new jobs in other sectors and the overall welfare effects on younger and older workers. Therefore, the structural model that will be introduced in this chapter will be less complicated compared to other labor mobility models since the main purpose will be to obtain parameter values for the general equilibrium simulations.

Although it has been discussed in the popular media, the intergenerational effects of trade liberalization have not been explored previously by economists. For example, according to opinion polls conducted in 2002 by the Pew Global Attitudes Project, older people in 36 out of 44 countries surveyed, including the USA, are less enthusiastic about free trade compared to the young. ${ }^{9}$ In this research, the attitudes of younger and older workers towards free trade are explained by mobility differences. Older workers, who are less mobile compared to the young, should be more divided in seeing free trade as good or bad depending on their sector.

Unlike this research, most studies of the distributional effect of trade focus on static models without mobility costs. I prefer to use a dynamic model because limited

\footnotetext{
${ }^{9}$ Countries where young workers are more enthusiastic about increasing trade with other countries: Angola, Argentina, Bangladesh, Bolivia, Brazil, Bulgaria, Canada, China, Czech Republic, Egypt, Germany, Ghana, Great Britain, India, Indonesia, Italy, Ivory Coast, Japan, Jordan, Kenya, Mexico, Nigeria, Peru, Philippines, Poland, Russia, Senegal, Slovak Republic, South Africa, Tanzania, Turkey, Ukraine, United States, Uzbekistan, Venezuela, Vietnam. In the following 8 countries the opposite is observed: France, Guatemala, Honduras, South Korea, Mali, Pakistan, Uganda, Lebanon.
} 
worker mobility implies gradual adjustment after trade liberalization, causing long run and short run effects to differ. The importance of mobility costs and gradual adjustment was recently emphasized by Cameron, Chaudhuri and McLaren (2002) (henceforth CCL). They illustrate this importance with a dynamic model of labor mobility, where workers choose a sector by considering idiosyncratic random moving costs and average wages. The Keane and Wolpin (1997) model from the labor economics literature (henceforth $\mathrm{KW}$ ) is also relevant, since it is an occupational choice model where workers choose between blue collar or white collar occupations, going to school, or staying at home. KW model how workers, who are heterogeneous, accumulate occupation-specific human capital. In this work, I extend previous international trade research by incorporating human capital accumulation and heterogeneous workers similar to KW. Unlike them, I focus on sectoral choice because sectors, rather than occupations, are directly affected by trade policy.

Most of the previous research, such as Borjas and Rosen (1980), attributed decreases in mobility with age to increases in wages with tenure. The decrease in mobility with age can be attributed to specific human capital as in Topel (1991), better job match as in Jovanovic (1979) or implicit contracts as in Lazear (1979). Groot and Verberne (1997) suggested that the decrease in mobility with age can be partially attributed to non-financial reasons as well. Mortensen and Neumann (1989) reported that roughly $30 \%$ of inter-firm transitions involve a worker voluntarily moving to a firm offering a lower wage than his current job, suggesting that unobservable factors 
contribute significantly to labor mobility; these might be dominating pecuniary factors. Consistent with previous research, there are three factors in the model that cause mobility differences: first, sector-specific experience increases wages so older workers lose more if they quit their sector; second, workers face a non-pecuniary moving cost with a component that increases with age; third, the time horizon for older workers is shorter than for younger ones, which mutes both positive and negative effects of free trade.

In the model I focus on workers who differ by sectoral experience and by market experience. As workers get older, their market experience (defined as age minus schooling) increases. Sectoral experience (defined as number of years spent in the current sector) is also positively correlated with age, however it is endogenous in the model, unlike market experience. In the simulations, I will also consider retired workers with a fixed endowment who only care about prices and their purchasing power. Workers choose among five aggregate sectors (Agriculture/Construction, Manufacturing, Metal, Service, Trade) or "stay at home" considering wage offers, preference shocks and mobility costs. I estimate different versions of the model with alternative simplifying assumptions to show which modifications are most important, such as serially correlated preference shocks and a log-linear wage equation. As far as I know, exploring these alternative models of intersectoral mobility represents a contribution to the labor literature as well as the trade literature.

Previous literature on displaced workers is relevant, but very different in terms of 
formulating research questions. Studies on displaced workers analyze the wage effects of displacement on workers who lose their jobs mostly because of free trade. There are two major differences between them and my study: first, I look at welfare effects rather than wage effects; second, with a general equilibrium approach I can analyze the effect of trade liberalization in metal sector on other sector workers as well. I recognize that most of the studies on displaced workers formulate more sophisticated wage tenure profiles, since they are partial equilibrium models unbounded by the size of state space.

The estimates show that the monetary equivalent of workers' costs of changing sector is more than one year's average real wage. The calculated cost includes all monetary and psychological costs except a possible wage decrease. In addition, the non-random component of the moving cost increases rapidly with age, reducing the mobility of older workers. Experienced workers with sector-specific human capital will incur an additional wage drop.

I use a method which can be described as a combination of multinomial logit and numerical integration to estimate the basic version of my model. For more complicated versions, such as the case of serially correlated shocks, I use the Indirect Inference method introduced by Smith (1993) and Keane and Smith (2003).

In the next section, the basic model and its variations will be described. In the third section, the data set will be briefly analyzed. The fourth section will present the estimation results. The fifth section will discuss the simulation results and its 
economic implications. Detailed explanations of the solution methods are available in the appendix.

\subsection{Models}

In this section, I will present the basic estimation model with linear wage equation and iid preference shocks. Then I will discuss extensions which simplify the state space in certain ways that allow me to explore log linear wage equation and serially correlated preference shocks.

\subsubsection{Basic Model}

Assume that there are 6 sectors $^{10}$ in the economy with a total of $N$ workers. Workers choose a sector in which to work in each period. If a worker indexed by $n$ decides to work in sector $i$ then $d_{t}^{n}=i$ where

$$
d_{t}^{n} \in\{1,2,3,4,5,6\}
$$

I will define the sectors below. A worker, $n$, receives wage $w_{t}^{n i}$ from working in sector

\footnotetext{
${ }^{10} 1$. Agriculture, Construction and Mining, 2. Manufacturing except Metal, 3. Metal, 4. Service $\{$ Transportation, Public Utilities, Communication, Finance, Insurance, Real Estate, Repair, Personal, Entertainment, Professional Service, Public,etc.\} 5. Trade \{Wholesale and Retail\}. 6. Staying at Home.
} 
$i$, with the wage equation ${ }^{11}$ given by

$$
\begin{aligned}
& h_{t}^{n i}=\phi_{1}+\phi_{2} H i g h S c h^{n}+\phi_{3} \text { College }^{n}+\phi_{4} \operatorname{SecExp}_{t}^{n i}+\phi_{5} M k t E x p_{t}^{n}+z_{t}^{n i}, \\
& w_{t}^{n i}=\frac{\bar{w}_{t}^{i}}{\bar{h}_{t}^{i}} h_{t}^{n i}
\end{aligned}
$$

where $h_{t}^{n i}$ is the human capital level for individual $n, \bar{w}_{t}^{i}$ is the average wage in sector $i$ and $\bar{h}_{t}^{i}$ is the average human capital level in the sector, $z_{t}^{n i}$ is a mean-zero random shock distributed "normal" with variance $\sigma_{z}^{2}, \operatorname{SecExp} p_{t}^{n i}$ is the sector specific experience, ${ }^{12}$ and $M k t \operatorname{Exp}_{t}^{n}$ is market experience (defined as age minus schooling). The workers who stay at home do not receive any wage, $w_{t}^{n 6}=0$. See the Appendix for details on deriving the wage equation. Different from KW, I assume that all sector specific experience is lost if a worker changes her sector. Even if she returns to her initial sector she has to start over from zero sectoral experience. Without this assumption the state space would be extremely large. ${ }^{13}$ Attending high school as final degree is denoted as HighSch and college is denoted as College. ${ }^{14}$ Sectoral experience evolves

\footnotetext{
${ }^{11}$ Although my formulation of the wage equations is different from the previous literature it yield to a wage tenure profile consistint with the previous literature, such as Topel (1991).

${ }^{12}$ Neal (1995) shows that firm specific experience contributes little to the observed slope of wage tenure profiles when sectoral experience is accounted for.

${ }^{13}$ In the next subsections, I improve the model from other aspects such as time persistent preference shocks, which also makes the state space large. It would be infeasible to consider complicated history of choices, as in $\mathrm{KW}$, and time persistent shocks at the same time.

${ }^{14}$ In the next version, I will consider different returns for schooling for different sectors, which will increase the number of parameters to estimate. Note that these options are mutually exclusive since they are defined as final degree. Unlike KW, I do not model how workers decide how much schooling to obtain, therefore I do not use individuals who did not complete their education to prevent bias in the estimation.
} 


$$
\begin{aligned}
\text { if } d_{t}^{n} & =d_{t-1}^{n} \Longrightarrow \operatorname{SecExp} p_{t}^{n i}=\operatorname{SecExp} \operatorname{Ex}_{t-1}^{n i}+1, \\
\text { else if } d_{t}^{n} & \neq d_{t-1}^{n} \Longrightarrow \operatorname{SecExp} p_{t}^{n i}=0 .
\end{aligned}
$$

In addition to the wage, each worker $n$ receives an idiosyncratic random utility $u_{t}^{n i}$, and a fixed utility $v^{i}$ from working in sector $i$. Hence the total utility of being in sector $i$, is

$$
U_{t}^{i}\left(s_{t}\right)=w_{t}^{i}\left(s_{t}^{n}, z_{t}^{n}\right)+v^{i}+u_{t}^{n i}
$$

where wage, $w_{t}^{i}\left(s_{t}^{n}, z_{t}^{n}\right)$ is a function of the state variables and a random shock for the worker. The state vector $s_{t}$ depends on education and experience such that

$$
s_{t}=\left[\begin{array}{lllll}
d_{t-1}^{n} & H_{i g h S c h}^{n} & \text { College }^{n} & \operatorname{SecExp}_{t}^{n d_{t-1}^{n}} & M k t \operatorname{Exp}_{t}^{n}
\end{array}\right]^{\prime} .
$$

The fixed utility $v^{i}$ is the same for all workers in an industry while the random variables $z_{t}^{n i}$ and $u_{t}^{n i}$ vary across workers. ${ }^{15}$ Linearity of components of the utility function ensures agents will be risk neutral so that I do not need to model savings. I assume that random component of utility, $u_{t}^{n i}$, is distributed as "extreme value" with

\footnotetext{
${ }^{15}$ I incorporated random effects to the model in another version which increases the state space significantly. The new version of the model is currently being estimated, and the results will be presented in the next version of the paper.
} 
variance $\sigma_{u}^{2}$ :

$$
\begin{aligned}
& u_{t}^{n i} \sim E V\left(0, \sigma_{u}\right), \\
& z_{t}^{n i} \sim N\left(0, \sigma_{z}\right) .
\end{aligned}
$$

Workers will incur a moving cost, $C$, if they change their sectors, so $C^{d_{t}^{n}}, d_{t+1}^{n}>0$ if $d_{t}^{n} \neq d_{t+1}^{n}$ and $C^{d_{t}^{n}, d_{t+1}^{n}}=0$ if $d_{t}^{n}=d_{t+1}^{n}$. In this version of the model I will include "Staying at Home" as a non-market sector and assume that it is costless to chose the non-market sector, so $C^{d_{t}^{n}, d_{t+1}^{n}}=0$ if a worker chooses to stay at home in period $t+1$. I model the moving cost as a linear function of age ${ }^{16}$ :

$$
\begin{aligned}
C^{d_{t}^{n}, d_{t+1}^{n}\left(s_{t}^{n}\right)}=0, \text { if } d_{t}^{n}=d_{t+1}^{n} \text { or } d_{t+1}=6, \\
\text { else } C^{d_{t}^{n}, d_{t+1}^{n}\left(s_{t}^{n}\right)}=C_{0}+C_{1}\left(A g e_{t}^{n}-14\right) .
\end{aligned}
$$

The utility and costs associated with each option are summarized in Table 2.1.

All workers are expected to live for a fixed amount of time, $T$. Hence the objective of an individual for any time $t=1, \ldots, T$ is to maximize her present discounted total

\footnotetext{
${ }^{16}$ For estimation and simulation purposes we assume that the linear increase in the non-pecuniary moving cost, $C$, stops after the age of 32 . We found that this assumption is consistent with the implied probabilities of sector change for different age groups from CPS. See the data section (2.3) for more details.
} 
utility as in Bellman (1957):

$$
V_{t}\left(s_{t}^{n}\right)=\max _{i}\left(V_{t}^{i}\left(s_{t}^{n}\right)\right)
$$

where sector (alternative) specific value functions are:

$$
\begin{aligned}
V_{t}^{i}\left(s_{t}^{n}, u_{t}^{n}, z_{t}^{n}\right) & =U_{t}^{i}\left(s_{t}^{n}, u_{t}^{n}, z_{t}^{n}\right)+E \max _{j} \beta\left\{V_{t+1}^{j}\left(s_{t+1} \mid s_{t}\right)-C^{i, j}\left(s_{t}^{n}\right)\right\} \\
& =U_{t}^{i}\left(s_{t}^{n}, u_{t}^{n}, z_{t}^{n}\right)+\beta \Omega_{t}^{i}\left(s_{t}^{n}\right)+\beta E_{u, z} V_{t+1}^{i}\left(s_{t+1}^{n}, u_{t+1}^{n}, z_{t+1}^{n}\right),
\end{aligned}
$$

for all periods except $T$, and

$$
V_{T}^{i}\left(s_{T}^{n}, u_{T}^{n}, z_{T}^{n}\right)=U_{T}^{i}\left(s_{T}^{n}, u_{T}^{n}, z_{T}^{n}\right)
$$

for the last period, where $\beta$ is the discount factor. Thus I can write the option value of moving as

$\Omega_{t}^{i}\left(s_{t}^{n}\right)=E_{u, z}\left(\max _{j}\left\{V_{t+1}^{j}\left(s_{t+1}^{n}, u_{t+1}^{n}, z_{t+1}^{n}\right)-V_{t+1}^{i}\left(s_{t+1}^{n}, u_{t+1}^{n}, z_{t+1}^{n}\right)-C^{i, j}\left(s_{t}^{n}\right)\right\} \mid s_{t}^{n}\right)$

and can be calculated numerically. For further discussion refer to the appendix.

\section{Timing:}

At any given time period $t$ the order of events for a worker is as follows: 1 . Pays the moving cost $C>0$ if her previous sector is different. 2. Works and enjoys her 
utility: $w_{t}^{n i}+v^{i}+u_{t}^{n i}, 3$. Learns the next period's random shocks $\left\{z_{t+1}^{n j}, u_{t+1}^{n j}\right\}_{j=1}^{6} .4$.

Chooses her sector. 5. Enters the next period $t+1$ and repeats steps $1-5$ for $t+1$.

\subsubsection{Simplified Benchmark Model}

In this version (Model 2.2.2) and later versions (Models 2.2.3, 2.2.4 and 2.2.5) I assume that the moving cost is constant

$$
\begin{aligned}
C^{d_{t}^{n}, d_{t+1}^{n}}\left(s_{t}^{n}\right) & =0, \text { if } d_{t}^{n}=d_{t-1}^{n}, \\
\text { else } C^{d_{t}^{n}, d_{t+1}^{n}}\left(s_{t}^{n}\right) & =C_{0} .
\end{aligned}
$$

So (10) is replaced with (14) and workers are not allowed to choose "Staying at

Home." Therefore,

$$
d_{t}^{n} \in\{1,2,3,4,5\}
$$

and the decision set (5) is replaced with (15). The wage equation is given as:

$$
w_{t}^{n i}=\bar{w}_{t}^{i}+\phi_{1}+\phi_{2} H i g h S c h^{n}+\phi_{3} \text { College }^{n}+\phi_{4} S e c E x p_{t}^{n i}+\phi_{5} M k t E x p_{t}^{n}+z_{t}^{n i} .
$$

instead of (6) where

$$
\begin{aligned}
& u_{t}^{n i} \sim E V\left(0, \sigma_{u}\right), \\
& z_{t}^{n i} \sim E V\left(0, \sigma_{z}\right) .
\end{aligned}
$$


All other equations are the same. These assumptions decrease the size of state space and allow me to work on other extensions in Models 2.3-2.5. Comparing those extensions to Model 2.2 will show how different assumptions about the structure of the model and the error terms change the estimates. This version also serves as the auxiliary model for Indirect Inference estimations of Models 2.3-2.4.

\subsubsection{Log Linear Wage Equation Model}

Wage equations are log linear by convention, as in the Mincer (1958) wage equation, not linear as I assumed in the Basic Model. I extended the benchmark model (Model 2.2.2) by converting the wage equation to a log linear form and considering a normal error term instead of "extreme value,"

$\log w_{t}^{n i}=\log \bar{w}_{t}^{i}+\phi_{1}+\phi_{2} H_{i g h S c h}^{n}+\phi_{3}$ College $^{n}+\phi_{4} \operatorname{SecExp} p_{t}^{n i}+\phi_{5} M k t E x p_{t}^{n}+z_{t}^{n i}$,

where $z_{t}^{n i}$ is a iid normal shock with mean zero,

$$
\begin{aligned}
& u_{t}^{n i} \sim E V\left(0, \sigma_{u}\right) \\
& z_{t}^{n i} \sim N\left(0, \sigma_{z}\right)
\end{aligned}
$$

Therefore equation (16) is replaced with (18) and (9) is replaced with (19). The model is otherwise identical to the benchmark (Model 2.2.2). I find that assuming a log-linear model does not help with estimating the moving costs and is much more 
time consuming to estimate. Thus I conclude that assuming linearity in the model does not cause noticeable bias. I use Indirect Inference (II), which is a generalized version of Simulated Method of Moments (SMM), to estimate Models 2.2.3 and 2.2.4. Different from SMM, II involves using an auxiliary model as a norm to compare actual and simulated data sets instead of moments. The auxiliary model is based on Model 2.2.2. See the appendix for details.

\subsubsection{Time Persistent Preference Shocks Model}

In real life there is probably some additional heterogeneity among workers that is unobserved by econometricians. Some workers, for example, like certain sectors better than others. The idiosyncratic preference shocks assumed above give a new mean zero shock in each period. This is not very realistic because we would not expect people's opinions to fluctuate randomly over time without showing any persistence. Therefore I changed the structure of $u_{t}^{n i}$ from iid mean zero to a process similar to $\operatorname{AR}(\mathrm{I})$.

$$
\begin{aligned}
& u_{t}^{n i}=\rho u_{t-1}^{n i}+\xi_{t}^{n i}, \\
& \xi_{t}^{n i} \sim E V\left(0, \sigma_{\xi}\right) \\
& z_{t}^{n i} \sim E V\left(0, \sigma_{z}\right)
\end{aligned}
$$

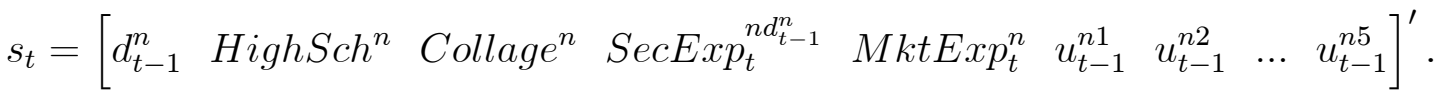


As a result, I consider (20) instead of (9) and (21) instead of (8). All the other equations are identical to the Benchmark model (Model 2.2.2). By inserting time persistence in the preferences, I added more friction in the model along with moving cost and sector specific experience that were included above, which caused moving costs to become smaller. To calculate the value functions associated with this version, I assume that $u_{t-1}^{n i}$ can take only three discrete values and I use a discrete Markov chain for that, similar to Tauchen and Hussey (1991). Hence there are three different types of workers with respect to the magnitude of the idiosyncratic shock.

I do not estimate value of the correlation coefficient $\rho$, but instead use a fixed number, 0.8 , for estimation. It is not possible to identify $\rho$ since II estimation requires the auxiliary model (the Benchmark - model 2.2.2 in this case) to have at least as many parameters as the actual model. Still, this will satisfy my goal of showing how serial correlation in preference shocks changes estimated moving cost.

\subsubsection{No Idiosyncratic Preference Shocks Model}

Some models of occupational choice, (e.g., KW), do not consider idiosyncratic shocks to workers' preferences. For the sake of comparability, this version shows how the estimates would change without preference shocks such that $u_{t}^{n i}=0$ for all $n$ and $i$ :

$$
\begin{aligned}
u_{t}^{n i} & =0 \\
z_{t}^{n i} & \sim E V\left(0, \sigma_{z}\right),
\end{aligned}
$$


The only difference from the Benchmark model (Model 2.2.2) is, (9) is replaced with (22). Solution methods are described in the appendix. Note that the only source of randomness is fluctuations in the wages in this version, which is easily identifiable since the wages are observable. The fluctuations in the wages are relatively small and they can not explain the large labor mobility observed in the data. Therefore this model implies small moving costs, and workers should be moving to sectors with larger wage offers almost all times, which is not the case as explained in the previous research such as Mortensen and Neumann (1989).

\subsection{Data}

I use 10 periods of the 1979 cohort of the National Longitudinal Survey of Youth (NLSY79) data on labor markets from 1985 to 1994 for estimation. In addition to NLSY79, I use 17 years of sectoral average wage data from the Current Population Survey (CPS) in order to calculate the value functions (not directly for estimation). There are two reasons for this: first, it is not possible to calculate the average wages accurately using NLSY79 since the sample size is very small; second, expected future wages affect workers' mobility decisions according to the model, so by using seven additional years, I make sure that the forward looking property of the model is not underestimated. ${ }^{17}$

\footnotetext{
${ }^{17}$ Assume that the set of parameters of the model is $\theta=\left\{C_{0}, C_{1}, C_{0} / \sigma_{e}, \sigma_{z}, v^{1}, \ldots, v^{6}, \phi^{1}, \ldots, \phi^{5}\right\}$.
} 


\section{Sample Selection}

Initially, we have 12,686 people in the sample, consisting of 6,403 males and 6,283 females. Like most of the other mobility models, we only pick males for our sample (such as Keane and Wolpin 1997). Moreover, we take out of our sample blacks and Hispanics, who are over-sampled by the NLSY survey, again following the previous research. This reduces our sample size by approximately $40 \%$, so we are left with 3,790 individuals. Thus, our analysis is based only on white males. The individuals in our sample are between ages of 14 and 21 as of year 1979. In addition, we also exclude individuals who are less than 20 as of 1985, because we want to focus on those who are working, i.e. not going to school. This reduces our sample size from 3,790 to 3,492 . The individuals in our sample are between 20 and 28 in starting year 1985; thus between 30 and 38 in the final year 1994. The distributions of workers by age is illustrated in Figure 2.1.2.

We also take out people who are continuing their education, because we do not model educational choice. It further reduces our sample size to 3,259. A person who reports that she is attending school but does not report a sufficient increase in highest grade completed towards a degree, is considered as not continuing her education, because such individuals are most likely working. The individuals who

To calculate expected value functions we only need $\theta$ and average wages $\left\{\left\{\bar{w}_{t}^{i}\right\}_{i=1}^{5}\right\}_{t=1}^{17}$. However to calculate probability of moving we need choices, $d_{t}^{n}$, and wages, $w_{t}^{n i}$, in addition to expected values. Therefore it is possible to calculate the expected value functions for future time periods as long as the average wage data is available. 
have gaps in their interviews are also taken out of the sample. The sample size is 1,405 after this step. Finally, workers who make less than $10 \%$ of average real wage and those who are in the military are excluded from the sample. NLSY over-samples both poor individuals and members of military. The number of individuals in our final sample is 969, which is less than the size of Keane and Wolpin (1997). They end up with 1,373 workers; the reason for this difference is the exclusion of military officers and students.

\section{Sectoral Choice}

In each interview, individuals report their current industry. We have chosen 6 general groups of aggregate industries defined as sectors: 1. Agriculture, Construction and Mining, (12\% of the workers); 2. Manufacturing except Metal (22\% of the workers); 3. Metal, (3\% of the workers); 4. Service, including Transportation, Public Utilities, Communication, Finance, Insurance, Real Estate, Repair, Personal, Entertainment, Professional Service, Public, etc. (42\% of the workers); 5. Trade, Wholesale and Retail ( $16 \%$ of the workers); 6 . Staying at Home (5\% of the workers). Workers who do not work or are unemployed for more than 25 weeks are considered to be staying at home for that year. Note that, we already excluded students from our analysis.

Workers gain one year of market experience if they stay in the market for one more year, even if they were unemployed that year. Market experience is defined as age minus time spent for schooling, where time spent for schooling is defined as 
the education level of a worker (college, high school, or other) times years required to finish that degree. Possible education levels will be explained later on in detail. Workers gain sectoral experience if they stay in the same sector for one more year; whenever a worker changes her sector she loses all of her sectoral experience. All workers are assumed to start with zero sectoral experience in 1985. Distributions of workers by market and sectoral experience are illustrated in Figures 2.1.5 and 2.1.3.

Percent of workers moving from one sector to another one is given in Table 2.3.1. Note that, the percentage of workers who are staying in their sector (diagonal elements) is correlated with the size of sector in steady state. Percent of workers who change sectors in each age group given their sectoral experience, initial sector and education are given in Tables 3.2.2, 3.2.3 and 3.2.4. In all these tables we see that the probability of changing sectors is negatively correlated with age, sectoral experience and size of sector. We can not see a pattern regarding education level.

The annual rate of changing sectors is decreasing with age (see Figure 2.1.1): it is $20 \%$ when a worker is 20 years old and it drops gradually as a worker gets older. By the time a worker is 35 years old the rate of sector change is around $4 \%$. According to CPS data, it stays about the same for older workers.

\section{Real Wages}

Individuals report total income earned the previous year, as opposed to reporting their current wage. In order to calculate their equivalent hourly wage, we divide their income by the total number of hours worked the past year. Then, we find the real 
Table 2.3.1: Annual Flows $(*)$

\begin{tabular}{|l|l|l|l|l|l|l|}
\hline & Constr & Manuf & Metal & Service & Trade & Home \\
\hline Constr & 84 & 03 & 05 & 06 & 04 & 03 \\
\hline Manuf & 02 & 90 & 00 & 04 & 03 & 02 \\
\hline Metal & 04 & 04 & 85 & 03 & 02 & 02 \\
\hline Service & 02 & 03 & 00 & 90 & 03 & 01 \\
\hline Trade & 03 & 03 & 00 & 09 & 84 & 01 \\
\hline Home & 10 & 04 & 01 & 09 & 06 & 71 \\
\hline
\end{tabular}

*Percent of workers moving from row sector to column sector.

Table 2.3.2 Percent of Workers Changing Sectors by Age (rows) and Sectoral Experience (columns)

\begin{tabular}{|l|l|l|l|l|l|l|l|l|l|}
\hline & 1 & 2 & 3 & 4 & 5 & 6 & 7 & 8 & 9 \\
\hline 20 & 26 & & & & & & & & \\
\hline 21 & 30 & 16 & & & & & & & \\
\hline 22 & 27 & 21 & 16 & & & & & & \\
\hline 23 & 25 & 22 & 22 & 14 & & & & & \\
\hline 24 & 22 & 13 & 14 & 09 & 10 & & & & \\
\hline 25 & 25 & 13 & 15 & 11 & 03 & 04 & & & \\
\hline 26 & 20 & 15 & 08 & 05 & 04 & 06 & 09 & & \\
\hline 27 & 28 & 11 & 04 & 11 & 10 & 06 & 02 & 02 & \\
\hline 28 & 26 & 21 & 08 & 09 & 09 & 04 & 08 & 05 & 08 \\
\hline 29 & 21 & 14 & 11 & 06 & 06 & 03 & 02 & 09 & 02 \\
\hline 30 & 17 & 19 & 11 & 04 & 06 & 00 & 05 & 02 & 04 \\
\hline 31 & 22 & 19 & 17 & 05 & 07 & 01 & 06 & 04 & 06 \\
\hline 32 & 24 & 06 & 14 & 04 & 04 & 05 & 03 & 03 & 03 \\
\hline
\end{tabular}


Table 2.3.3 Percent of Workers Changing Sectors (by Age and Sector)

\begin{tabular}{|l|l|l|l|l|l|l|}
\hline & Constr & Manuf & Metal & Service & Trade & Home \\
\hline 20 & 33 & 27 & 33 & 26 & 17 & 31 \\
\hline 21 & 15 & 20 & 38 & 23 & 26 & 53 \\
\hline 22 & 28 & 18 & 29 & 24 & 22 & 29 \\
\hline 23 & 29 & 16 & 26 & 18 & 27 & 36 \\
\hline 24 & 18 & 14 & 21 & 10 & 20 & 28 \\
\hline 25 & 22 & 11 & 22 & 11 & 20 & 23 \\
\hline 26 & 14 & 08 & 19 & 08 & 18 & 26 \\
\hline 27 & 15 & 09 & 13 & 09 & 13 & 28 \\
\hline 28 & 14 & 09 & 06 & 12 & 10 & 31 \\
\hline 29 & 17 & 06 & 13 & 04 & 10 & 14 \\
\hline 30 & 09 & 11 & 03 & 04 & 07 & 04 \\
\hline 31 & 15 & 05 & 07 & 05 & 06 & 30 \\
\hline 32 & 08 & 04 & 00 & 04 & 08 & 31 \\
\hline
\end{tabular}

Table 2.3.4 Percent of Workers Changing Sectors by Age and Education

\begin{tabular}{|l|l|l|l|}
\hline & Middle School & High School & College \\
\hline 20 & 19 & 30 & 23 \\
\hline 21 & 33 & 23 & 27 \\
\hline 22 & 11 & 20 & 28 \\
\hline 23 & 29 & 21 & 22 \\
\hline 24 & 26 & 28 & 23 \\
\hline 25 & 16 & 14 & 16 \\
\hline 26 & 18 & 11 & 11 \\
\hline 27 & 18 & 11 & 10 \\
\hline 28 & 16 & 11 & 11 \\
\hline 29 & 20 & 08 & 07 \\
\hline 30 & 06 & 09 & 06 \\
\hline 31 & 15 & 06 & 08 \\
\hline 32 & 10 & 06 & 05 \\
\hline
\end{tabular}


Table 2.3.5 Wages by Age (rows) and Sectoral Experience (columns)

\begin{tabular}{|l|l|l|l|l|l|l|l|l|l|l|l|}
\hline & & 1 & 2 & 3 & 4 & 5 & 6 & 7 & 8 & 9 & 10 \\
\hline $20-24$ & Mean & 0.52 & 0.62 & 0.66 & 0.73 & 0.73 & & & & & \\
\hline & StdDev & 0.19 & 0.14 & 0.13 & 0.14 & 0.10 & & & & & \\
\hline $25-29$ & Mean & 0.56 & 0.74 & 0.81 & 0.85 & 0.84 & 0.85 & 0.84 & 0.83 & 0.86 & 0.90 \\
\hline & StdDev & 0.18 & 0.13 & 0.16 & 0.16 & 0.13 & 0.14 & 0.13 & 0.11 & 0.14 & 0.24 \\
\hline $30-34$ & Mean & 0.37 & 0.72 & 0.79 & 0.79 & 0.95 & 0.98 & 0.98 & 0.95 & 0.97 & 0.99 \\
\hline & StdDev & 0.19 & 0.12 & 0.20 & 0.11 & 0.23 & 0.26 & 0.20 & 0.18 & 0.26 & 0.23 \\
\hline
\end{tabular}

Table 2.3.6 Wages by Age and Sector

\begin{tabular}{|l|l|l|l|l|l|l|}
\hline & & Constr & Manuf & Metal & Service & Trade \\
\hline $20-24$ & Mean & 0.60 & 0.65 & 0.74 & 0.65 & 0.55 \\
\hline & StdDev & 0.13 & 0.09 & 0.15 & 0.21 & 0.14 \\
\hline $25-29$ & Mean & 0.72 & 0.86 & 0.95 & 0.81 & 0.71 \\
\hline & StdDev & 0.12 & 0.14 & 0.19 & 0.15 & 0.11 \\
\hline $30-31$ & Mean & 0.84 & 0.99 & 0.93 & 0.94 & 0.77 \\
\hline & StdDev & 0.16 & 0.23 & 0.13 & 0.25 & 0.17 \\
\hline
\end{tabular}

wage by dividing the nominal wage by the consumer price index reported for that year. Then, we normalize the wages in such a way that the average annual real wage is approximately one, so that all our results can be considered relative to average annual real wage. Note that we use the same denominator to normalize for the entire sample - all years and sectors. Distribution of workers by wage is illustrated in Figure 2.1.6. Mean and standard deviation of wages of different age groups by sectoral experience, sector and education are given in Tables 2.3.5, 2.3.6 and 2.3.7. Wages generally increase with age, sectoral experience and education.

\section{Education}

Individuals who go through 16 years or more of schooling are considered college graduates, who count for approximately $45 \%$ of the final sample. Similarly people 
Table 2.3.7 Wages by Age and Education

\begin{tabular}{|l|l|l|l|l|}
\hline & & Middle School & High School & College \\
\hline $20-24$ & Mean & 0.47 & 0.56 & 0.63 \\
\hline & StdDev & 0.10 & 0.12 & 0.22 \\
\hline $25-29$ & Mean & 0.55 & 0.69 & 0.89 \\
\hline & StdDev & 0.13 & 0.11 & 0.18 \\
\hline $30-34$ & Mean & 0.51 & 0.78 & 1.03 \\
\hline & StdDev & 0.09 & 0.15 & 0.30 \\
\hline
\end{tabular}

who have at least 12 years but less than 16 years of education are classified as high school graduates and they are approximately $47 \%$ of the final sample. The rest are assumed to be middle school graduates. The histogram of distribution of educational attainment is presented in Figure 2.1.4.

\section{Coding Errors}

Neal (1999) reports that there are coding errors in NLSY79 regarding occupations. A similar error is also present for industry codings. In order to minimize this problem, I use the following method (as in Neal 1999): whenever a sector change is reported, I require that the worker has to change his employer as well, otherwise it is considered as a coding error and the original sector is kept. Tenure of workers with their current employer is reported in NLSY.

\section{CPS Data}

Sample selection process is almost identical for the CPS sample. There are only two main differences: first, we use white males between 25 and 64; second, we do not specifically look for people who are done with their education since it is safe to assume that almost everybody would be working after the age of 25 . We have a minimum of 
13,223 and a maximum of 20,055 people in our final sample between the years 1984 and 2001 (sample size changes every year).

\subsection{Estimation Results}

One year's average real wage is normalized to 1.0 and I assume that the discount factor $\beta$ is 0.96 in all models, since I was not able to identify this parameter when I tried to estimate it.

Calibration of Moving Cost Using CPS

In addition to NLSY, I use CPS to calculate the mobility of workers for different age groups and to compare predictions of my model for older workers (who are not observed in NLSY) with the actual data. I find that assuming a linear form for the non-pecuniary moving cost, $C$, is inconsistent with the data: the simulated mobility rates of older workers are below the actual rates. The mobility versus age graph has a kink at around age 32 and mobility does not decrease much after that age. When I assume that moving cost, $C$, stops increasing at the age of 32 ; I find that predictions of my model fit the data well. See Figures 2.2.1, 2.2.2, 2.2.3 and 2.2.4 for details. When we estimate the basic model with non-linear extrapolation of $C$ and an alternative version with linear extrapolation, we find that the non-linear extrapolation performs better. The likelihood ratio test is 51.94 in favor of non-linear extrapolation

and estimation results are presented in the Appendix, Tables 2.A.1, 2.A.2 and 2.A.3. 
When we estimate another version with a variable slope after the kink, we find that the slope is very close to zero under the condition that the slope is positive. Estimates of this version are almost identical to those of the basic model, therefore we will not present them.

Note that this could be an artifact coding errors in CPS. If there is roughly a $4 \%$ coding error for industries of workers then mobility of old workers would never go below that level even if they do not move at all. Unfortunately, we do not have simple tools to study these possibilities further, without losing main focus of this research. However, it is definitely a very interesting issue and recently pointed out by Kambourov and Manovskii (2004).

Basic Model (2.2.1)

See tables 2.4.1, 2.4.2 and 2.4.3 for basic model estimates. The estimated nonpecuniary moving cost $C$ is quite large and statistically significant, approximately equal to 2.5 when a worker first enters the job market and increasing significantly by 0.095 every year. Note that the moving cost is very large because it captures all psychological moving costs and all unmodelled frictions. Keane and Wolpin (1994) and Lee and Wolpin (2004) report lower moving costs, however they do not consider idiosyncratic preference shocks for sectors (or occupations). Note that when idiosyncratic shocks are omitted, the moving costs are significantly lower as in the Model 2.2.5. However, such models do not fit the data well since fluctuations in the wages alone fail to explain the gross flows when preference shocks are ignored. Sullivan (2005) 
Table 2.4.1: Basic Model (2.2.1) - Moving Cost Estimates

\begin{tabular}{|l|l|l|l|}
\hline & $C_{0}$ & $C_{1}$ & $C_{0} / \sigma_{e}$ \\
\hline Estimate & 2.536 & 0.095 & 1.805 \\
\hline Standard Error & $(0.187)$ & $(0.016)$ & $(0.052)$ \\
\hline
\end{tabular}

Table 2.4.2: Basic Model (2.2.1) - Wage Equation Estimates

\begin{tabular}{|l|l|l|l|l|l|l|}
\hline & $\sigma_{z}^{2}$ & $\phi_{1}$ & $\phi_{2}$ & $\phi_{3}$ & $\phi_{4}$ & $\phi_{5}$ \\
\hline & $\operatorname{Var}\left(\mathrm{z}_{t}\right)$ & Constant & HighSch & College & SecExp & MktExp \\
\hline Estimate & 0.160 & 0.164 & 0.215 & 0.478 & 0.034 & 0.020 \\
\hline Standard Error & $(0.001)$ & $(0.015)$ & $(0.010)$ & $(0.011)$ & $(0.001)$ & $(0.001)$ \\
\hline
\end{tabular}

also reports high moving costs which cause significant reductions in the worker utility, as a results of the estimation of a labor mobility model with idiosyncratic preference shocks.

Another factor limiting worker mobility is the sectoral experience wage premium, $\left(\phi_{4}\right)$, which increases by 0.03 annually. Since the additional moving cost is large, it shows that much of the cost is psychological (non-pecuniary) and also quite variable, since the variance of idiosyncratic shocks is large. In other words, non-pecuniary factors also play an important role in the workers' mobility decisions .

High school graduates $\left(\phi_{2}\right)$ earn more than middle school graduates and less than college graduates $\left(\phi_{3}\right)$. The wage premium for market experience $\left(\phi_{5}\right)$ is about half the size of the wage premium for sector specific experience $\left(\phi_{4}\right)$. The fixed utility associated with each sector leads to the following ranking: most popular is Trade $\left(v^{5}\right)$, then Agriculture, Mining and Construction $\left(v^{1}\right)$, Service $\left(v^{4}\right)$, Manufacturing $\left(v^{2}\right)$, and the least popular is Metal $\left(v^{3}\right)$.

Next, I discuss how the parameter estimates change when I first simplify the model 
Table 2.4.3: Basic Model (2.2.1) Utility Estimates

\begin{tabular}{|l|l|l|l|l|l|l|}
\hline & $v^{1}$ & $v^{2}$ & $v^{3}$ & $v^{4}$ & $v^{5}$ & $v^{6}$ \\
\hline & Construc. & Manuf. & Metal. & Service & Trade & Home \\
\hline Estimate & 0.508 & 0.434 & 0.262 & 0.471 & 0.574 & 0 \\
\hline Standard Error & $(0.090)$ & $(0.093)$ & $(0.080)$ & $(0.097)$ & $(0.091)$ & - \\
\hline
\end{tabular}

in the Benchmark (Model 2.2) for the purposes of comparison and then add other details in Models 2.2.3-5. See Table 2.4.4 for a detailed comparison of all the models.

\section{Log Linear Wage Equation Model (2.2.3)}

This version does not have an analytical or approximate closed form solution and must be estimated using simulations. I use Indirect Inference Estimation similar to Smith (1993). For Models 2.2.3 and 2.2.4, I simulate three data sets for each step in Indirect Inference estimation. Using more simulations would reduce the standard errors up to $25 \%$. For example, if 10 data sets were used, the standard errors would be $15 \%$ smaller. The estimated moving cost, $C$, decreases slightly but no major changes in the other coefficient estimates are observed. Note that the wage equation estimates are different compared to the benchmark (Model 2.2.2), which happens because the parameters are multiplicative. The estimates of wage equation parameters are consistent with Model 2.2.2 with respect to their relative sizes.

Time Persistent Shocks Model (2.2.4)

This version is also estimated using Indirect Inference similar to the previous version. When unobserved heterogeneity caused by time persistent shocks is incorporated into the model, the estimated moving cost, $C$, decreases approximately $50 \%$ 
Table 2.4.4: Estimation of Alternative Models

\begin{tabular}{|c|c|c|c|c|c|}
\hline & & Benc 2.2.2 & Log-Ln 2.2.3 & Time Per 2.2.4 & No Idi 2.2 .5 \\
\hline \multirow[t]{2}{*}{$C_{0}$} & Mov.Cost & 4.006 & 3.233 & 2.122 & 0.479 \\
\hline & & $(0.627)$ & $(0.094)$ & $(0.106)$ & $(0.011)$ \\
\hline \multirow{2}{*}{$C_{1}$} & Mov.Cost & - & - & - & - \\
\hline & & - & - & - & - \\
\hline \multirow{2}{*}{$\frac{C_{0}}{\sigma_{e}}$} & $\mathrm{C} / \operatorname{Stde}(\mathrm{u})$ & 2.379 & 2.340 & 2.794 & - \\
\hline & & $(0.057)$ & $(0.031)$ & $(0.082)$ & - \\
\hline \multirow[t]{2}{*}{$\rho$} & Corr.Coef & - & - & 0.8 & - \\
\hline & & - & - & - & - \\
\hline \multirow[t]{2}{*}{$v^{1}$} & Construc. & 0 & 0 & 0 & 0 \\
\hline & & - & - & - & - \\
\hline \multirow[t]{2}{*}{$v^{2}$} & Manuf. & -0.053 & -0.027 & -0.086 & -0.150 \\
\hline & & $(0.024)$ & $(0.005)$ & $(0.008)$ & $(0.004)$ \\
\hline \multirow[t]{2}{*}{$v^{3}$} & Metal & -0.250 & -0.178 & -0.217 & -0.102 \\
\hline & & $(0.036)$ & $(0.015)$ & $(0.013)$ & $(0.005)$ \\
\hline \multirow[t]{2}{*}{$v^{4}$} & Service & 0.129 & -0.071 & -0.154 & -0.187 \\
\hline & & $(0.021)$ & $(0.006)$ & $(0.008)$ & $(0.004)$ \\
\hline \multirow[t]{2}{*}{$v^{5}$} & Trade & 0.071 & 0.022 & 0.053 & 0.007 \\
\hline & & $(0.021)$ & $(0.003)$ & $(0.005)$ & $(0.004)$ \\
\hline \multirow[t]{2}{*}{$v^{6}$} & Home & - & - & - & - \\
\hline & & - & - & - & - \\
\hline \multirow[t]{2}{*}{$\sigma_{z}^{2}$} & $\operatorname{Var}(\mathrm{z})$ & 0.122 & 0.106 & 0.119 & 0.115 \\
\hline & & $(0.001)$ & $(0.002)$ & $(0.002)$ & $(0.001)$ \\
\hline \multirow[t]{2}{*}{$\phi_{1}$} & Constant & -0.708 & -1.150 & -0.749 & -1.022 \\
\hline & & $(0.014)$ & $(0.028)$ & $(0.015)$ & $(0.014)$ \\
\hline \multirow[t]{2}{*}{$\phi_{2}$} & HighSch & 0.167 & 0.271 & 0.174 & 0.251 \\
\hline & & $(0.008)$ & $(0.024)$ & $(0.011)$ & $(0.008)$ \\
\hline \multirow[t]{2}{*}{$\phi_{3}$} & College. & 0.327 & 0.526 & 0.330 & 0.465 \\
\hline & & $(0.009)$ & $(0.024)$ & $(0.013)$ & $(0.010)$ \\
\hline \multirow[t]{2}{*}{$\phi_{4}$} & SecExp & 0.027 & 0.051 & 0.037 & 0.019 \\
\hline & & $(0.001)$ & $(0.002)$ & $(0.001)$ & $(0.001)$ \\
\hline \multirow[t]{2}{*}{$\phi_{5}$} & MktExp & 0.015 & 0.021 & 0.013 & 0.031 \\
\hline & & $(0.001)$ & $(0.001)$ & $(0.001)$ & $(0.001)$ \\
\hline
\end{tabular}


compared to the results of the Benchmark (Model 2.2.2), which may be more realistic. It is also noteworthy that the estimates of other parameters are very close to the estimates of Model 2.2.2.

Another alternative I explored similar to this version is a model with random effects. In that model I assume that workers receive random shocks in the beginning of their career for each sector which do not change over the years. I find that the moving cost is about $50 \%$ of the benchmark model as well, similar to the time persistent shocks model. This result is not surprising, since allowing for random effects is another way of allowing time persistence.

As we include in the model more frictions which are observed in reality, we expect the non-pecuniary moving cost to become smaller and closer to what one might expect as the actual cost of moving.

\section{No Idiosyncratic Preference Shocks Model (2.2.5)}

When preference shocks are eliminated, a simpler solution method similar to that used in Model 2.2.2, can be used. The elimination of idiosyncratic preference shocks decreases $C$ approximately $90 \%$ compared to Model 2.2 .2 , which would be closer to the actual financial cost of moving. However, in this case the model does not fit the data as well as the Benchmark. ${ }^{18}$ Elimination of idiosyncratic shocks reduces the moving cost since wage fluctuations are very small and do not allow for mobility in the presence of high costs. This is an indication that observables contribute little to

\footnotetext{
${ }^{18}$ Likelihood Ratio statistic is equal to 1348 .
} 
the explanation of labor mobility. Another labor mobility model with shocks to the utility is Sullivan (2005), which also reports high moving costs. Keane and Wolpin (1997) do not assume such shocks, hence report significantly lower moving costs. The high moving cost should be considered as a combination of all frictions and costs which can not be modelled or observed, assuming that the actual moving costs are not reasonable.

\subsection{Conclusion}

Workers' gains and losses from free trade depend on the mobility of workers, since workers who are more mobile can find new jobs faster and would be less affected from policy changes compared to the others. Labor literature suggests that older workers are less mobile compared to young.

In this paper we analyzed different components of mobility costs especially components that relate to age. We found that wage premium of sectoral experience is an important factor in explaining lower mobility of old workers. The other significant factor is non-pecuniary moving cost, which increases rapidly in the first 10 years of a worker's career. However, the estimate for non-pecuniary moving cost depends on assumptions on the structure of shocks in the model.

To study this relation between the moving cost and structure of the shocks further, I considered different versions of the model with alternative assumptions. We 
found that allowing for utility shocks increase the moving costs significantly, since fluctuations in the wage do not explain the mobility well. Wage fluctuations are relatively small and do not allow for large volumes of mobility without having small moving costs. Another interesting alternative is allowing time persistence in the utility shocks, either with an autoregressive process or with random effects, which in both cases reduces the non-pecuniary moving cost by approximately $50 \%$.

In the next chapter, I will study the effects of a hypothetical trade liberalization in the metal manufacturing sector on workers in a general equilibrium setting using estimates of the basic model. 


\section{Appendix}

\section{Solution Method for Model 2.2.1}

I assume that $z_{t}^{i}$ is distributed mean zero 'normal' with standard deviation $\sigma_{z}$, and $u_{t}^{i}$ is mean zero 'extreme value' with standard deviation $\sigma_{u}$, thus $z_{t}^{i} \sim N\left(0, \sigma_{z}\right)$ and $e_{t}^{i} \sim E V\left(0, \sigma_{e}\right)$. We observe wages and sectoral choices over 10 years and find the parameters that maximize the probability of observing such a sample. Let $m_{t}^{i j}=m_{t}^{i j}\left(s_{t}, w_{t+1}^{d_{t+1}}\right)$ be the probability of moving from $i$ to $j$ for a worker with characteristics $s_{t}$ given the parameter set $\theta$ and wage $w_{t+1}^{d_{t+1}}$ for the observed choice. Let $f($.$) be the probability density of the random variable z_{t}$ and define wage equation as

$$
w_{t}^{i}=W^{i}\left(s_{t}^{i}\right)+\frac{\bar{w}_{t}^{i}}{\bar{h}_{t}^{i}} z_{t}^{i}
$$

where $W^{i}\left(s_{t}\right)$ is the expected wage as defined in the model. Then the likelihood of observing the sample is

$$
L=\prod_{n=1}^{N}\left\{\prod_{\tau=1}^{10} m_{\tau}^{d_{\tau}^{n}, d_{\tau+1}^{n}}\left(s_{\tau}^{n}, w_{\tau+1}^{n d_{\tau+1}}\right) f\left(\left(w_{\tau+1}^{n d_{\tau+1}^{k}}-W\left(s_{\tau+1}^{i}\right)\right) \frac{\bar{h}_{\tau+1}^{i}}{\bar{w}_{\tau+1}^{i}}\right)\right\}
$$

In order to calculate the probability of sector change, $m^{i j}$, we need to define the value functions as in Bellman (1957).

Value Functions: 
For the last period the expected alternative specific value is simply

$$
V_{T}^{i}\left(s_{T}^{n}\right)=w^{i}\left(s_{T}^{n}, z_{T}^{n i}\right)+v^{i}+u_{T}^{n i}
$$

for other periods

$$
V_{t}^{i}\left(s_{t}^{n}, u_{t}^{n}, z_{t}^{n}\right)=w^{i}\left(s_{T}^{n}, z_{T}^{n i}\right)+v^{i}+u_{t}^{n i}+\beta E_{u, z} V_{t+1}\left(s_{t+1}^{n}, e_{t+1}^{n}\right)
$$

and the value function is defined as

$$
V_{t+1}\left(s_{t+1}^{n}, S_{t+1}\right)=\max _{j}\left\{V_{t+1}^{j}\left(s_{t}^{n}, u_{t+1}^{n}, z_{t+1}^{n}\right)-C^{i, j}\left(s_{t}^{n}\right)\right\}
$$

where $S_{t+1}$ is the vector of random variables $S_{t+1}=\left\{u_{t+1}^{n k}, z_{t+1}^{n k}\right\}_{k=1}^{6}$ the expected value can be defined as

$$
\begin{aligned}
E_{e} V_{t+1}\left(s_{t+1}^{n}, e_{t+1}^{n}\right) & =E_{z, u} \max _{j}\left\{V_{t+1}^{j}\left(s_{t+1}^{n}, e_{t+1}^{n}\right)-C^{i, j}\left(s_{t}^{n}\right)\right\} \\
& =E_{z, u} V_{t+1}^{j}\left(s_{t+1}^{n}, e_{t+1}^{n}\right)+\Omega\left(s_{t+1}^{n}, z_{t+1}^{n}\right)
\end{aligned}
$$

where option value of moving, $\Omega$, is defined as

$$
\begin{aligned}
\Omega^{i}\left(s_{t}^{n}\right) & =E_{z, u}\left(\max _{j}\left\{V_{t+1}^{j}\left(s_{t+1}^{n}, e_{t+1}^{n}\right)-V_{t+1}^{i}\left(s_{t+1}^{n}, e_{t+1}^{n}\right)-C^{i, j}\left(s_{t}^{n}\right)\right\}\right) \\
& =-\nu_{u} E_{z} \log \left(m_{t+1}^{i i}\left(s_{t}, z_{t+1}^{n}\right)\right)
\end{aligned}
$$


where the probability of moving from sector $i$ to sector $k$ given $z$ can be defined as:

$$
m^{i k}\left(s_{t}, z_{t+1}\right)=\frac{\exp \left[E_{u} V_{t+1}^{i}-E_{u} V_{t+1}^{k}-C^{i, k}\left(s_{t}^{n}\right) / \nu_{u}\right]}{\sum_{j=1}^{6} \exp \left[\left(E_{u} V_{t+1}^{i}-E_{u} V_{t+1}^{j}-C^{i, j}\left(s_{t}^{n}\right)\right) / \nu_{u}\right]},
$$

where variance of $u_{t}$ is equal to $\sigma_{u}^{2}=\frac{1}{6} \nu_{u}^{2} \pi^{2}$. Finally the probability of moving is

$$
m^{i k}\left(s_{t}^{n}\right)=E_{z}\left(m^{i k}\left(s_{t}^{n}, z_{t+1}^{n}\right) \mid z_{t+1}^{n j}\right)
$$

Note that expectation on $u, E_{u}$, can be calculated analytically because it is additive to the utility. However expectation on $z, E_{z}$, has to be simulated or calculated using numerical integration since it is not additive to the utility. Also note that random shock to wage, $z$, will be known for exactly one sector in each period since we observe wage for the sector the worker is in.

\section{Solution Method for Model 2.2.2 and 2.2.5}

It is not possible to use a standard multinomial logit procedure since we observe wage offers only for one sector in each period for each worker. For example if the worker is in the manufacturing sector, the wage offer is known by the econometrician; however, for other sectors (i.e. agriculture) it is not known. Therefore, for the sector that is chosen by the worker the randomness comes only from 
the idiosyncratic component, $u_{t}^{i}$. For other sectors randomness comes from both wage and idiosyncratic utility, $z_{t}^{i}+u_{t}^{i}$ from the econometrician's perspective. A simple approximation method can be used to aggregate all choices those are not chosen and consider them as a single choice: So best alternative to $d_{t}$ is denoted as $E V_{t+1}^{j \neq d_{t}}=E\left\{\max _{j \neq d_{t}} V_{t+1}^{j}\left(s_{t+1}\right) \mid s_{t}\right\}=E\left\{V_{t+1}^{k}\left(s_{t+1}\right) \mid s_{t}\right\}-\nu_{e} \log \left(m_{t}^{i k}\left(s_{t}\right)\right)$ where $k \neq d_{t}$ and $\operatorname{Var}\left\{V_{t+1}^{j \neq d_{t}}\right\}=\operatorname{Var}\left\{e_{t+1}^{j}\right\}$. The observed choice $d_{t}$ has smaller variance since $w_{t+1}^{d_{t}}$ is observed by the econometrician, $\operatorname{Var}\left\{V_{t+1}^{d_{t}}\left(s_{t+1}, w_{t+1}^{d_{t}}\right)\right\}=\operatorname{Var}\left\{u_{t+1}^{d_{t}}\right\}$. With this notation we simplify worker's options to what he actually chose, $d_{t}$, versus the best alternative $j \neq d_{t}$. Note that $j \neq d_{t}$ does not refer to any actual option but expected value of the second best, in other words Emax of the options except $d_{t}$. Since those two options has different variances, exact analytical solution does not exist. However it is possible to find a simple approximate solution: Consider an "iid extreme value" random variable $\varepsilon_{t}^{i}$, where $\operatorname{Var}\left(\varepsilon_{t}^{i}\right)=\left\{\operatorname{Var}\left(u_{t}^{i}\right)+\operatorname{Var}\left(e_{t}^{i}\right)\right\} / 2$, and assume that $V_{t+1}^{j \neq d_{t}} \simeq E\left(V_{t+1}^{j \neq d_{t}} \mid s_{t+1}\right)+\varepsilon_{t+1}^{1}$ and $V_{t+1}^{d_{t}} \simeq E\left(V_{t+1}^{d_{t}} \mid s_{t+1}, w_{t+1}^{d_{t}}\right)+\varepsilon_{t+1}^{2}$. Then probability of observing decision $d_{t}$ given wage and state vector is

$$
m_{t}^{d_{t-1} d_{t}}=\frac{\exp \left[\left(E V_{t+1}^{d_{t}}-E V_{t+1}^{d_{t-1}}-C^{d_{t-1}, d_{t}}\right) / \nu_{\varepsilon}\right]}{\exp \left[\frac{E V_{t+1}^{j \neq d_{t}}-E V_{t+1}^{d_{t-1}}-C^{d_{t-1}, j}}{\nu_{\varepsilon}}\right]+\exp \left[\frac{E V_{t+1}^{d_{t}}-E V_{t+1}^{d_{t-1}}-C^{d_{t-1}, d_{t}}}{\nu_{\varepsilon}}\right]}
$$

variance of $\varepsilon_{t}$ is equal to $\frac{1}{6} \nu_{\varepsilon}^{2} \pi^{2}$. 


\section{Solution Method Model 2.2.3 and 2.2.4}

I will use Indirect Inference to estimate the extended models. Indirect Inference is very useful when it is easy to simulate data from a model but difficult to estimate the parameters. The main idea is to simulate data from a model and compare it to the actual data and try to make them as similar as possible. A misspecified model, which is called the auxiliary model, can be used to evaluate similarity between two data sets. The process is straightforward: 1. I estimate the parameters of the auxiliary model using actual data, 2. I guess parameters of the actual model and simulate data using actual model, 3. I estimate parameters of the auxiliary model using simulated data. 4. I compare the estimated parameters of auxiliary model and continue this procedure (step 2 to 4) until parameters of the actual data and simulated data are reasonably close to each other. Let $Q^{A}$ be the actual data set and $Q^{S}(\theta, x)$ be the data set simulated using the parameter vector $\theta$ and exogenous variable set $x$. Consider the auxiliary likelihood function $L(Q, \beta)$. Define $\hat{\beta}=\arg \max _{\beta} L\left(Q^{A}, \beta\right)$, and $\tilde{\beta}=\arg \max _{\beta} L\left(Q^{S}(\theta, x), \beta\right)$. Now I have to define a norm to evaluate the similarity between $\hat{\beta}$ and $\tilde{\beta}$, or $Q^{A}$ and $Q^{S}$ :

Norm proposed by Smith:

$$
\hat{\theta}=\arg \max _{\theta} L\left(Q^{A}, \tilde{\beta}(\theta)\right)
$$


Norm inspired from Wald:

$$
\hat{\theta}=\arg \min _{\theta}(\hat{\beta}-\tilde{\beta}(\theta))^{\prime} W(\hat{\beta}-\tilde{\beta}(\theta))
$$

Norm inspired from Gallant and Tauchen:

$$
\hat{\theta}=\arg \min _{\theta} \frac{\partial L\left(Q^{S}(\theta, x), \hat{\beta}\right)}{\partial \beta^{\prime}} W \frac{\partial L\left(Q^{S}(\theta, x), \hat{\beta}\right)}{\partial \beta},
$$

where $W$ is the weighting matrix. For more detailed discussion on other possible norms and indirect inference in general see Gourieroux, Monfort and Renault 1993 and Smith 1993.

\section{Auxiliary Model:}

The main idea is to use the basic model as the auxiliary model, however I prefer a slightly modified version of the basic model. I change the error terms in such a way that all choices have the same random error components, so that the model is a regular multinomial logit model. The basic model shows some similarities with a multinomial logit model. It can be considered as a two step logit model, because I first calculate the expected value of the second best alternative, then I calculate the probability of choosing the observed alternative. Converting the model into a regular logit model creates some bias in the estimated parameters, which is not a problem as long as we can define a one to one relationship between the auxiliary model parameters 
and the actual parameters. Using a regular logit model has an important advantage because it is possible to evaluate a logit likelihood function without using any loops like "for" or "while", by just using simple matrix operations after calculating the value function. The motive for using matrix operations instead of loops is to exploit the built-in matrix operation functions which are much faster than user written loops (i.e. Matlab 7.0). Note that if the matrix operations are manually written or if they are not efficiently programmed this effort would be futile (i.e. Fortran 90).

$$
\begin{gathered}
\text { Consider } \bar{V}_{t+1}^{i}=E V_{t+1}^{i}+w_{t+1}^{i}-\tilde{w}_{t+1}^{i} \text { if } d_{t}=i \text {, and } \bar{V}_{t+1}^{i}=E V_{t+1}^{i} \text { if } d_{t} \neq i . \\
\bar{m}_{t}^{i k}\left(s_{t}, \theta, \bar{\nu}\right)=\frac{\exp \left[\left(E \bar{V}_{t+1}^{i}-E \bar{V}_{t+1}^{k}-C^{i, k}\right) / \bar{\nu}\right]}{\sum_{j} \exp \left[\left(E \bar{V}_{t+1}^{i}-E \bar{V}_{t+1}^{j}-C^{i, j}\right) / \bar{\nu}\right]},
\end{gathered}
$$

Using the probability function above the parameters of the auxiliary model can be estimated as

$$
\tilde{\theta}^{r}=\arg \max \prod_{k=1}^{K}\left\{\prod_{\tau=1}^{10} \bar{m}_{\tau}^{d_{\tau}^{k}, d_{\tau+1}^{k}}\left(s_{\tau}, w_{\tau}^{n i}\right) f\left(\left(w_{\tau+1}^{n i}-W\left(s_{\tau+1}^{n}\right)\right) \frac{\bar{h}_{\tau+1}^{i}}{\bar{w}_{\tau+1}^{i}}\right)\right\}
$$

Assume that the parameter vector of the true structural model is $\theta$, and the auxiliary estimate for the $r^{t h}$ simulated data set is $\tilde{\beta}^{r}$ where the total number of simulated data sets is $R$. The goal is to simulate the data from parameter vector $\hat{\theta}$ such that $\tilde{\beta}=\frac{1}{R} \sum \tilde{\beta}^{r}$ will maximize the likelihood of observing the actual data set under the auxiliary model as described by Smith 1993. 
Comparison of Basic Model with Non-Linear Extrapolation of C and the Alternative with Linear Extrapolation of $\mathrm{C}$

Likelihood Ratio is 51.94 in favor of the non-linear extrapolation.

Table 2.A.1: Moving Costs

\begin{tabular}{|l|l|l|l|}
\hline & $C_{0}$ & $C_{1}$ & $C_{0} / \sigma_{e}$ \\
\hline Basic Model Estimate & 2.536 & 0.095 & 1.805 \\
\hline Basic Model Std Err & $(0.187)$ & $(0.016)$ & $(0.052)$ \\
\hline Alternative Estimate & 2.59 & 0.078 & 1.856 \\
\hline Alternative Std Err & $(0.1877)$ & $(0.014)$ & $(0.049)$ \\
\hline
\end{tabular}

Table 2.A.2: Wage Equation Estimates

\begin{tabular}{|l|l|l|l|l|l|l|}
\hline & $\sigma_{z}^{2}$ & $\phi_{1}$ & $\phi_{2}$ & $\phi_{3}$ & $\phi_{4}$ & $\phi_{5}$ \\
\hline & $\operatorname{Var}\left(\mathrm{z}_{t}\right)$ & Constant & HighSch & College & SecExp & MktExp \\
\hline Basic M. Estimate & 0.160 & 0.164 & 0.215 & 0.478 & 0.034 & 0.020 \\
\hline Basic M. Std Err & $(0.001)$ & $(0.015)$ & $(0.010)$ & $(0.011)$ & $(0.001)$ & $(0.001)$ \\
\hline Altern. Estimate & 0.160 & 0.165 & 0.214 & 0.476 & 0.034 & 0.019 \\
\hline Altern. Std Err & $(0.001)$ & $(0.015)$ & $(0.010)$ & $(0.011)$ & $(0.001)$ & $(0.001)$ \\
\hline
\end{tabular}

Table 2.A.3: Utility Estimates

\begin{tabular}{|l|l|l|l|l|l|l|}
\hline & $v^{1}$ & $v^{2}$ & $v^{3}$ & $v^{4}$ & $v^{5}$ & $v^{6}$ \\
\hline & Construc. & Manuf. & Metal. & Service & Trade & Home \\
\hline Basic Model Estimate & 0.508 & 0.434 & 0.262 & 0.471 & 0.574 & 0 \\
\hline Basic Model Std Err & $(0.090)$ & $(0.093)$ & $(0.080)$ & $(0.097)$ & $(0.091)$ & - \\
\hline Alternative Esimate & 0.0503 & 0.433 & 0.263 & 0.462 & 0.568 & 0 \\
\hline Alternative Std Err & $(0.089)$ & $(0.091)$ & $(0.079)$ & $(0.095)$ & $(0.090)$ & \\
\hline
\end{tabular}




\section{Chapter 3}

\section{Intergenerational Effects of Trade Liberalization: General Equilibrium Simulation of the Dynamic Model of Labor Mobility}

\subsection{Introduction}

After estimating mobility parameters of workers from different age and experience groups, we study how trade liberalization affects these groups differently. I simulate a hypothetical trade liberalization in the metal manufacturing industry using estimated parameters from the structural model. The metal sector is chosen because it has been especially vulnerable to trade shocks in the past, particularly affecting the steel industry. By the introduction of free trade, younger metal workers will be worse off but less worse off compared to older workers. The younger workers in other sectors will be better off, but again less so than many older workers; in addition some older workers will be worse off. This varying effect on older workers results in a broader division among older workers in viewing trade liberalization as good or bad.

I assume that the government decides to abandon tariffs in the metal sector, resulting in a $30 \%$ decrease in the price level of metals. The price level in the metal 
sector drops at time 1 right after the announcement in the end of period 0; so the trade liberalization is a shock therapy in this case. Note that tariffs in the steel industry, which is the largest industry in the metal sector, have been as high as $40 \%$. I will show how older and younger workers will be affected differently from free trade. Different from most of the previous research, I will consider a general equilibrium method for the policy simulation. ${ }^{19}$ Endogenous wage equations are derived from production functions which requires solution of wage equations, prices and optimization problem of workers simultaneously. I use Multiple Shooting with the estimates of Model 2.2.1 and calibrated production function parameters. The solution method is explained in the appendix.

We aggregate the sectors as we did in the previous chapter. The sectors are 1. Construction (which includes construction, mining and agriculture sectors), 2. Manufacturing (excluding metal), 3. Metal manufacturing, 4. Services (excluding trade), 5. Trade (wholesale and retail), 6. Staying at home. The products of these sectors are consumed by the consumers and used as inputs for production as well. Before the trade liberalization, the manufacturing sector is already open to free trade, so we actually mean "trade liberalization and free trade in the metal sector" when we refer to free trade. Other sectors are closed to world trade before and after the trade liberalization, therefore prices adjust endogenously in response to changes in

\footnotetext{
${ }^{19}$ Lee and Wolpin (2004) provide interesting discussions on a General Equilibrium model of labor markets, which is similar to this project from many aspects.
} 
supply and demand (of both producers and consumers). Simultaneous equations related to the supply and demand of products are derived from simple Cobb-Douglas functional forms. The equation for labor demand, which is basically an endogenous wage equation in this case since workers choose which sector to be in, also have a CobbDouglas form. However, labor supply is directly derived form the previous chapter Model 2.2.1 and does not have a closed functional form, it is rather an optimization problem of the different types of workers given aggregate parameters. Note that the aggregate parameters are also affected simultaneously from the decisions of the workers.

The adjustment of the economy is quite complicated: it is plausible to assume that wages will decrease $30 \%$ initially in the metal sector along with the price. However workers will move out of the metal sector to other sectors until wages adjust so that labor supply equals labor demand. Manufacturing sector is also directly affected from free trade because the metal sector product is an important input for manufacturing. With lower input prices manufacturing sector's output increase significantly, pushing wages up. Note that metal is an intermediate good, which is not consumed and has no direct effect on the Consumer Price Index. With the increased output of the second largest sector in the economy (manufacturing), total output increases noticeably, raising demand for non-traded goods such as services. Therefore, the prices in the economy in general increase with the increased demand, causing Consumer Price Index (henceforth CPI) to increase, making metal workers even more worse off. This 
intriguing adjustment process causes broad division among workers of different age and experience groups. More details will be provided in the following sections.

\subsection{Model}

After free trade the average wages in sectors will change, making some workers better off and some worse off. In general, wages in the metal sector will decrease and wages in other sectors will increase. The main goal of the policy simulation is twofold: first, to calculate average wages, prices and outputs over the transition; and second, to calculate value functions of workers using the average wages. If wages, prices and outputs were known then calculating value functions would be straightforward similar to the estimation. Note that I used average wages from CPS for the estimation, which is exogenous to the workers' individual optimization problem. For the policy simulation, however, wages, prices and outputs need to be endogenous to trade policy and labor flows. The value functions of workers are functions of average wages and the average wages are functions of value functions. Similar stories apply to price levels and outputs. Calculating wages, outputs, prices and value functions simultaneously is much more burdensome than calculating value functions alone. To ease the computational burden, I will assume a simplified version of Model 2.2.1 (with smaller state space) for calculating average wages. Once average wages are known I will use Model 2.2.1 to calculate the value functions of workers. First, I will introduce 
basic supply and demand relations for the general equilibrium model with structural labor supply.

\subsubsection{Consumers and Demand}

Consumers are identical and have a Cobb-Douglas utility functions,

$$
U_{t}^{j}=\prod_{i=1}^{I-1}\left(x_{t}^{i}\right)^{a_{i}}+\zeta^{j}
$$

which leads to the money-metric utility function described in Model 2.2.1 (which is $\left.U_{t}^{j} \propto w_{t}^{j}+v^{j}+u_{t}^{j}\right)$; where $x_{t}^{i}$ is the sector $i$ product,${ }^{20}$ consumed at time $t, \sum_{i=1}^{N} a_{i}=1$, $\zeta^{j}$ is the random idiosyncratic utility derived from working in sector $j$. Therefore the consumer price index can be calculated as:

$$
C P I_{t}=\prod_{i=1}^{I-1}\left(p_{t}^{i}\right)^{a_{i}}
$$

For traded goods the price level is exogenous: $p_{t}^{i}=p_{i}^{W}+\tau_{i}$, where $p_{i}^{W}$ is the world price and $\tau_{i}$ is the tariff rate. For non-traded goods price level is endogenous:

$$
p_{t}^{i}=\frac{M_{i}}{q_{t}^{i}}
$$

where $q_{t}^{i}$ is the total amount of product produced and $M_{i}$ is the share of income in the economy spent on the product both by consumers and producers which can be

\footnotetext{
${ }^{20}$ Some sectors' proucts are not consumed but only used as inputs, such as Metal sector's product.
} 
calculated simply by exploiting the the Cobb-Douglas nature of the economy:

$$
M_{i}=a_{i} \sum_{j=1}^{I-1}\left(b_{6}^{j}+b_{7}^{j}\right) q_{t}^{j} p_{t}^{j}+\sum_{j=1}^{I-1} b_{i}^{j} q_{t}^{j} p_{t}^{j}
$$

where $b_{i}^{j}$ 's are parameters taken from Cobb-Douglas production functions which will be explained in the next section. Note that savings are not allowed in this simple economy. The details of the calibration method are described in the appendix.

\subsubsection{Production and Labor Demand}

Production functions are Cobb-Douglas and the real wage, $w_{t}^{i}$, is assumed to be the real marginal product of effective human capital possessed by workers. The production function is defined as:

$$
\begin{aligned}
q_{t}^{i} & =A^{i}\left(L_{t}^{i} \bar{h}_{t}^{i}\right)^{b_{6}^{i}}\left(K^{i}\right)^{b_{7}^{i}} \prod_{j=1}^{I-1}\left(x_{t}^{j, i}\right)^{b_{j}^{i}}, \\
& =B^{i}\left(L_{t}^{i} \bar{h}_{t}^{i}\right)^{b_{6}^{i}} \prod_{j=1}^{I-1}\left(x_{t}^{j, i}\right)^{b_{j}^{i}},
\end{aligned}
$$

where $A^{i}$ is a coefficient of productivity, $L_{t}^{i}$ is the total number of workers in sector $i, \bar{h}_{t}^{i}$ is the average human capital level of individuals working in that sector, similar to the general convention $K^{i}$ is the capital level which is assumed to be fixed, $x^{j, i}$ is the $j$ sector product used in $i$ 's production. Since capital is fixed we can define another coefficient for convenience, $B^{i}=A^{i}\left(K^{i}\right)^{b_{7}^{i}}$. Shares of labor in the production functions are adjusted to match the shares of labor in gross domestic product in each 
Table 3.1: Input Matrix $\left(b_{j}^{i}\right)$

\begin{tabular}{|l|l|l|l|l|l|}
\hline & Const & Manuf & Metal & Service & Trade \\
\hline Const & 0.08 & 0.07 & 0.05 & 0.02 & 0.00 \\
\hline Manuf & 0.23 & 0.35 & 0.07 & 0.06 & 0.04 \\
\hline Metal & 0.05 & 0.05 & 0.29 & 0.00 & 0.00 \\
\hline Service & 0.18 & 0.17 & 0.14 & 0.24 & 0.29 \\
\hline Trade & 0.06 & 0.06 & 0.07 & 0.01 & 0.02 \\
\hline Labor & 0.26 & 0.16 & 0.25 & 0.37 & 0.37 \\
\hline Capital & 0.14 & 0.15 & 0.12 & 0.31 & 0.27 \\
\hline
\end{tabular}

sector. Initially, all prices are normalized to be unity and the fixed coefficient, $B^{i}$, is adjusted such that productions in each sector roughly match sectoral gross domestic products. Thus the wage equation can be derived as:

$$
\begin{aligned}
w_{t}^{i} & =\frac{p_{t}^{i}}{C P I_{t}} A^{i} b_{6}^{i}\left(L_{t}^{i} \bar{h}_{t}^{i}\right)^{b_{6}-1} h_{t}^{i}\left(K^{i}\right)^{b_{7}^{i}} \prod_{j=1}^{I-1}\left(x_{t}^{i, j}\right)^{b_{j}^{i}} \\
& =\frac{p_{t}^{i}}{C P I_{t}} B^{i} b_{6}^{i}\left(L_{t}^{i} \bar{h}_{t}^{i}\right)^{b_{6}^{i}-1} h_{t}^{i} \prod_{j=1}^{I-1}\left(x_{t}^{i, j}\right)^{b_{j}^{i}} .
\end{aligned}
$$

where $p_{t}^{i}$ is the price level and $L_{t}^{i}$ is the number of workers in the sector. Parameters for labor demand equations, $B^{i}$ and $b_{j}^{i}$ are calibrated using data from the Bureau of Economic Analysis. The details of the calibration method are described in the appendix. The shares of inputs are summarized in Table 3.1.

\subsubsection{Labor supply}

I assume that workers stay in the market for 40 years. Therefore a worker can get a maximum of 40 years of sectoral and market experience. I discretize the state space so that market and sectoral experience can only take $q$ values. Note that a worker's 
Table 3.2: Worker types

\begin{tabular}{|l|l|l|l|l|l|l|l|l|l|l|}
\hline Type & $I$ & $I I$ & $I I I$ & $I V$ & $V$ & $V I$ & $V I I$ & $V I I I$ & $I X$ & $X$ \\
\hline MktExp & 5 & 15 & 15 & 25 & 25 & 25 & 35 & 35 & 35 & 35 \\
\hline SecExp & 5 & 5 & 15 & 5 & 15 & 25 & 5 & 15 & 25 & 35 \\
\hline Age & 25 & 35 & 35 & 45 & 45 & 45 & 55 & 55 & 55 & 55 \\
\hline
\end{tabular}

market experience is at least as large as her sectoral experience. Hence, the size of the state space is $T I\left(q^{2}+q\right) / 2$, where $I$ is the total number of sectors, and $T$ number of years required for the transition from autarky steady state to free trade steady state. A worker ages with probability $\gamma=q / 40$ in each period. If we consider all possible combinations of sectoral and market experience and a thirty year transition, then the size of the state space would be $30 \times 6\left(40^{2}+40\right) / 2=147600$ and a worker would age in each period with probability $\gamma=1$, as in reality.

Each worker chooses her sector similar to the Basic Model 2.1, with the decision set as in (5), so it includes five sectors and a non-market sector (staying at home). The state-space, however, is simplified to ease the computational burden

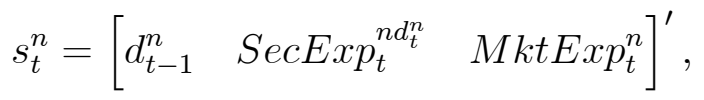

where market experience $M k t E x p_{t}^{n} \in\{5,15,25,35\}$ and sectoral experience $\operatorname{SecE} \operatorname{Exp}_{t}^{n d_{t}^{n}} \in$ $\{5,15,25,35\}$. Note that sectoral experience is less than or equal to market experience by definition $M k t E x p_{t}^{n} \geq \operatorname{SecExp} p_{t}^{n d_{t}^{n}}$, therefore the size of the state space is 1800 (assuming $T=30$ ), and there are ten types of workers in the economy differentiated by their age and experience. 
Table 3.3: Transition Probabilities, $\operatorname{Pr}\left(s_{t+1}^{r} \mid s_{t}^{n}\right)$

\begin{tabular}{|l|l|l|l|l|l|l|l|l|l|l|}
\hline & $I$ & $I I$ & $I I I$ & $I V$ & $V$ & $V I$ & $V I I$ & $V I I I$ & $I X$ & $X$ \\
\hline$d_{t+1}=d_{t}, \operatorname{Pr}=0.9$ & $I$ & $I I$ & $I I I$ & $I V$ & $V$ & $V I$ & $V I I$ & $V I I I$ & $I X$ & $X$ \\
\hline$d_{t+1}=d_{t}, \operatorname{Pr}=0.1$ & $I I I$ & $V$ & $V I$ & $V I I I$ & $I X$ & $X$ & - & - & - & - \\
\hline$d_{t+1} \neq d_{t}, \operatorname{Pr}=0.9$ & $I$ & $I I$ & $I I$ & $I V$ & $I V$ & $I V$ & $V I I$ & $V I I$ & $V I I$ & $V I I$ \\
\hline$d_{t+1} \neq d_{t}, \operatorname{Pr}=0.1$ & $I I$ & $I V$ & $I V$ & $V I I$ & $V I I$ & $V I I$ & - & - & - & - \\
\hline
\end{tabular}

In each period, the probability of aging (gaining experience) is $\gamma=0.1$. For example, a type III worker becomes type VI with probability $\gamma$ in each period (if she stays in her sector). In addition, if a worker changes her sector, her sectoral experience drops to the minimum level, which is 5 years. For example, if a type III worker changes her sector, she becomes type II. If a worker with 35 years of market experience ages, she receives a lump sum payment ${ }^{21}$ and exits the market, and a worker with 5 years of experience enters the system.

The wage equation is also simplified and defined as

$$
w_{t}^{n i}=\frac{\bar{w}_{t}^{i}}{\bar{h}_{t}^{i}}\left(\phi_{6}^{i}+\phi_{4} \operatorname{Sec} \operatorname{Exp} p_{t}^{n i}+\phi_{5} M k t E x p_{t}^{n}+z_{t}^{n i}\right)
$$

where the constant ${ }^{22} \phi_{6}$ is a weighted average of $\phi_{1}, \phi_{2}$ and $\phi_{3}$. The equations (5), (10), (13), (9), (12) and (13) from Model 2.1 are still relevant for this model. Note that the parameters, $C_{0}, C_{1}, C_{0} / \sigma_{e}, \phi_{4}, \phi_{5}, \phi_{6}^{i}, v^{1}, v^{2}, \ldots, v^{6}$ are taken from the estimates of Model 2.1.

\footnotetext{
${ }^{21}$ The lump-sum payment is equal to 10 years' discounted average wage, which is equal to 8.0.

${ }^{22}$ I assume that all workers have the same level of education. Education only effects workers' decison to stay at home or work, it does not effect workers' decison on which sector to work. Because education increases wages offers from all sectors by the same amount.
} 


\section{Labor Allocation in Sectors:}

The number of workers in sector $i$ is equal to the sum of all types of workers, $L_{t}^{i}=\sum_{n=1}^{10} L_{t}^{n i}$. I consider a continuum of workers where $\sum_{i=1}^{6} L_{t}^{i}=1$. I assume that probability of a type $n$ worker choosing sector $j$ if she is in sector $i$ is defined as

$$
m_{t}^{n i j}=E_{z} \frac{\exp \left[\left(E_{u} V_{t+1}^{j}-E_{u} V_{t+1}^{i}-C^{i, j}\right) / \nu_{e}\right]}{\sum_{k} \exp \left[\left(E_{u} V_{t+1}^{k}-E_{u} V_{t+1}^{i}-C^{i, k}\right) / \nu_{e}\right]}
$$

where $\nu_{e}=\sqrt{6} \sigma_{e} / \pi$ and the alternative specific value functions are

$$
V_{t}^{i}=U_{t}^{i}\left(s_{t}^{n}, u_{t}^{n}, z_{t}^{n}\right)+\beta \sum_{r=1}^{10} \operatorname{Pr}\left(s_{t+1}^{r} \mid s_{t}^{n}\right)\left[\Omega_{t}^{i}\left(s_{t+1}^{r}\right)+E_{u, z} V_{t+1}^{i}\left(s_{t+1}^{r}, u_{t+1}^{r}, z_{t+1}^{r}\right)\right]
$$

The labor allocation equation is

$$
L_{t+1}^{n j}=\sum_{r=1}^{10} \tilde{P}\left(s_{t+1}^{n} \mid s_{t}^{r}\right) \sum_{i=1}^{6} L_{t}^{r} m_{t}^{r i j}
$$

where $\tilde{P}\left(s_{t+1}^{n} \mid s_{t}^{r}\right)$ is the transition probability for labor allocation. Note that the transition probability for labor allocation, $\tilde{P}\left(s_{t+1}^{n} \mid s_{t}^{r}\right)$ needs to be defined differently from the actual transition probability, $\operatorname{Pr}\left(s_{t+1}^{n} \mid s_{t}^{r}\right)$, so that the number of workers in the system does not change. For example, a young worker enters the market when another worker retires, therefore $\tilde{P}(I \mid V I I)=0.1, \tilde{P}(I \mid V I I I)=0.1, \tilde{P}(I \mid I X)=0.1$ and $\tilde{P}(I \mid X)=0.1$ and for all other types $\tilde{P}\left(s_{t+1}^{n} \mid s_{t}^{r}\right)=\operatorname{Pr}\left(s_{t+1}^{n} \mid s_{t}^{r}\right)$. However, the probability of an old worker becoming young is still zero, $\operatorname{Pr}(I \mid V I I)=0, \operatorname{Pr}(I \mid V I I I)=0$, 
Table 3.4: Steady State Percentage of Workers

\begin{tabular}{|l|l|l|l|l|l|l|l|l|l|l|}
\hline Type & $I$ & $I I$ & $I I I$ & $I V$ & $V$ & $V I$ & $V I I$ & $V I I I$ & $I X$ & $X$ \\
\hline MktExp & 5 & 15 & 15 & 25 & 25 & 25 & 35 & 35 & 35 & 35 \\
\hline SecExp & 5 & 5 & 15 & 5 & 15 & 25 & 5 & 15 & 25 & 35 \\
\hline Autarky & $25 \%$ & $10 \%$ & $15 \%$ & $5 \%$ & $7 \%$ & $13 \%$ & $5 \%$ & $2 \%$ & $6 \%$ & $12 \%$ \\
\hline Free Trade & $25 \%$ & $10 \%$ & $15 \%$ & $4 \%$ & $7 \%$ & $14 \%$ & $4 \%$ & $2 \%$ & $6 \%$ & $13 \%$ \\
\hline
\end{tabular}

$\operatorname{Pr}(I \mid I X)=0$ and $\operatorname{Pr}(I \mid X)=0$.

\subsection{Simulation Results}

One year's average real wage is approximately 1 in the economy, so all numbers presented here could be considered relative to this wage level. Also note that, the label "Young" is used for workers with 5 years of sectoral and market experience; "Old 1" for workers with 5 years of sectoral experience and 35 years of market experience; and "Old 2" for workers with 35 years of sectoral and 35 years of market experience.

The economy consists of six sectors, 1. Construction, agriculture and mining, 2. Manufacturing except metal 3.Metal manufacturing, 4. Service except Trade 5. Wholesale and retail trade, 6. Staying at home. The sectors will be labeled as Construction, Manufacturing, Metal, Service, Trade and Home respectively, using the largest industry's name in each sector.

Initially we assume that all prices are equal to 1 , and we calibrate the parameter $B^{i}$ so that average wages in sectors under autarky are equal to average wages observed in CPS. Note that we mean autarky in metal sector when we use the term "autarky"; 
and similarly "free trade" means free trade of metal sector product. For other sectors, the trade openness is not changing through the policy simulation: we assume that Manufacturing product is traded so the world price, 1, is taken exogenously, but Construction, Service and Trade sector prices are calculated endogenously given the change in demand and production, using equations (25) and (26).

In autarky, metal is not traded and the equilibrium price is 1 . Then at the end of time zero we assume that the government announces free trade for the metal sector (a shock therapy) which will be in effect by the beginning of time 1, where the time unit can be considered as one year. We assume that world price is 0.7 for this product. Then, we analyze how wages, labor allocation, output and prices adjust after this free trade announcement (given the set of simultaneous equations of workers' and producers' decisions as described in section 3.2).

\section{Gross Flows}

Figures 3.1.1-6 illustrate the ratio of workers who leave their sector over years. After the announcement of free trade metal workers anticipate the wage decrease (which would be $30 \%$ if they do not react), therefore the number of all types of workers moving from the metal sector to other sectors increase at time zero. Of course, the opposite of this story is observed in all other sectors except Home.

There are two particularly interesting sectors other than metal. The first one is manufacturing, because we see a much larger decrease in out-flows in this sector compared to others, which means that manufacturing workers are much better off 
after the announcement. We will discuss the reasons for this difference later on, but it is obvious that the real wages increase relatively more in this sector. Also note that the workers have perfect foresight in our model (since it is a rational expectations model with no aggregate uncertainty except the trade liberalization in the metal sector), which means that workers see that they will be better off if they stay in the manufacturing sector and they act upon it. However, because of the individual shocks some workers still decide to move, thus net flows are not equal to gross flows.

The other interesting sector is Home; because we see that the out-flows of young workers increase while the out-flows of old workers decrease at the same time. This means that working provides more utility after free trade for young workers and less utility for older workers: a hint indicating that unexperienced old workers will be worse off in general after free trade. Finally, note that older workers' flows out of the Home sector are smaller compared to younger workers, indicating that they will take longer to find new jobs in the other sectors if they lose their job because of free trade.

\section{Labor Adjustment}

See Figures 3.2.1-6 for the illustrations of labor adjustments. These are directly derived from gross flows explained in the previous paragraph. We see major changes in only two sectors: Metal and Manufacturing. The metal sector shrinks about $60 \%$, consistent with the trade liberalization and decrease in the product price. Most of the labor adjustment in the metal sector takes place in the first five years: we observe that the labor allocation completes $94 \%$ of the distance between autarky allocation and 
free trade allocation. For the Service sector this number is $83 \%$, for the manufacturing sector it is $89 \%$, and it is $60 \%$ for the Home sector. Note that most of the sectors' steady state labor allocations are almost unchanged after free trade (except Metal and Manufacturing). It is obvious that the Metal sector would be significantly affected, however this is not obvious for the Manufacturing sector, which we turn to in the next subsection.

Another intriguing point is the presence of ridges in the labor allocation graphs of Construction, Trade and Staying home sectors (Figures 3.2.1, 3.2.5 and 3.2.6). In these sectors we see that the number of workers continue to increase until time 5 , then it slowly decreases, however in the steady state this number is still larger than in the autarky steady state (it does not decrease further). First of all, we have to note that these changes are relatively small: at any given time, the number of workers is not more than $1 \%$ different from any other point in time. For the Staying home sector, the explanation is quite straightforward: Metal workers choose to stay at home since moving to Home sector is costless and they have less incentive to work in their original sector. Hence, we see a large flow from Metal sector to the Home sector, and workers who stay home slowly move out as they receive attractive shocks from other sectors. So the first 5 time periods are mainly characterized by large out-flows from the metal sector. The utility of being in the Metal sector decreases so much that, most of the Metal workers just move out as they receive any acceptable offer from any sector. Although moving to market sectors (Construction, Manufacturing, 
Metal, Service and Trade) is costly, the same story applies, most of the metal workers move out as soon as they receive a reasonable shock from any sector. Being in the metal sector is undesirable for most of the workers, so they move out right away to any sector that sends good shocks. However, being in the Manufacturing sector seems to be the most desirable; so those workers who move to Trade and Staying at home sectors from the Metal sector move again, but this time to the Manufacturing sector if they receive a good offer.

\section{Output}

Output levels relative to autarky output levels, $q_{t}^{i} / q_{0}^{i}$, are illustrated in Figures 3.3.1-6. First of all, the metal sector output decreases $60 \%$ after free trade, as a result of a decrease in the price level and out-flow of workers. There are two sectors primarily affected from this price decrease: Manufacturing and Construction. Note that Metal is used primarily in producing itself, it has $30 \%$ share among all inputs. Other than that, it is used in Manufacturing and Construction, $5 \%$ and $4 \%$ shares in inputs respectively. Therefore the decrease in the input price increases the production of Manufacturing about $10 \%$ and Construction about 3.5\%. Other sectors are not significantly affected, we see a $1 \%$ increase in the Service output and 0.5 increase in the Trade output. As a result the total output increases by about $2.5 \%$. There are two interesting points that will be explained in the next paragraph: 1. Why Construction output does not increase as much as the Manufacturing output? 2. Why the Trade output continuously increases although the number of workers decrease after time 
period $5 ?$

\section{Prices}

Illustrations of price adjustments are presented in Figures 3.4.1-6. The price level in the Metal sector decreases from 1 to the world price level (which is 0.7 ) as the government abandons the tariffs for that sector. The Manufacturing sector takes the world price, which is 1 for that sector even in autarky, because free trade is allowed for the Manufacturing product at all times and the term autarky is actually used for the Metal sector. Other sectors' products are not traded so demand and supply jointly determine the price levels. Note that all non-traded products are demanded by both producers and consumers. We keep track of outputs and price levels in our simulations, as they are determined simultaneously along with the values of workers, (see the appendix for details on the solution method).

Here is a simplified explanation of supply and demand relations after the trade liberalization: First, the price of metal decreases. Metal is used as input in the Manufacturing and Construction sectors, therefore the supply of these products increases along with the reduced input price. In the Manufacturing sector, the supply increases significantly since the price level is exogenous and inelastic. However, the Construction sector price is endogenous: an increase in supply reduces the price and limits further increase in supply. With the increased output in these two sectors (especially with the large increase in the Manufacturing sector which is very large), the total output increases. Thus, the demand for all products increases, causing the prices of 
non-traded products to increase, which in turn increases the output in the non-traded sectors. Note that even if the number of workers decreases slightly after the initial jump in the Trade sector, the output continues to increase further because the relative price of Manufacturing input is much lower. All these price increases raise the CPI. Note that the decrease in the Metal sector product has no direct effect on CPI since metal is only used as an intermediate good, and not consumed by agents.

\section{Wages}

Real wages are determined jointly by the effective number of workers and the price levels. The evolution of wages is described in Figures 3.5.1-5. The real wages decrease in the Metal sector, and increase in all other sectors as one might expect. Because of large out-flows from the Metal sector, we observe ridges in the first five years after the trade liberalization. In the metal sector real wages increase slightly since the number of workers continues to decrease, increasing marginal product of labor. In all other sectors wages decrease slightly in the first five years (the periods with large out-flows from the Metal sector) but afterwards they continue to increase in the non-traded sectors (Construction, Service and Trade) due to continuously increasing prices, parallel to the output increases in the Manufacturing sector, which is not matched by the other sectors. This increase in output increases the demand for nontraded output and the increase in output is small causing an increase in prices, thus increasing the wages.

Welfare of Workers 
Welfare of workers is shown in Figures 3.6.1-6. Note that a Young worker is a worker with 5 years of sectoral and market experience (Type I), Old 1 is a worker with 5 years of sectoral and 35 years of market experience (Type VII), while Old 2 is a worker with both 35 years of sectoral and market experience (Type X). The figures show the changes in the present discounted utility after the trade liberalization. Note that one year's average wage is about 1.0 , therefore a change of -0.5 is equivalent to losing 6 months salary right away with no further decrease in future salaries. So the numbers do not refer to equivalent percentage wage losses as used in the displaced workers literature; they should be considered as one time losses.

Let us start the analysis with the Metal sector (Figure 3.6.3): as one might expect, all workers are worse off by the trade liberalization. The workers who are most affected are the Old 2 type workers since they were enjoying higher wages compared to others because of their high sectoral experience. If we compare them with the Young workers, we see that they differ from 3 aspects: first, they have more sectoral experience which causes them to lose more; second, they have higher non-pecuniary mobility costs which makes it more difficult for them to find new jobs; third, their time horizon is shorter which might make them less worse off since they would be subject to negative effects of free trade for a shorter period of time. Shorter time period also means that they are closer to retirement, increasing CPI decreases the purchasing power of their retirement savings. Hence the effect of shorter time period is ambiguous: it might increase or decrease the negative effects of trade liberalization. Figure 3.6.3 indicates 
that Old 1 is slightly more worse off (-0.8) compared to Young (-0.5), while Old 2 is a lot more worse off (-2.0). These values cannot directly be compared with the results of the literature on displaced workers, since they only consider wage decreases. For example, Jacobson LaLonde and Sullivan (1993) report that tenured workers might lose $25 \%$ of their wage continuously due to displacement. That would be equivalent to $210 \%$ percent one time loss of one year's wage which is very close to my findings. Note that I use present discounted welfare derived from utility functions, therefore my analysis also includes non-wage components of the utility as well.

Different from the displaced workers literature, I can use the welfare effects of trade liberalization in the metal sector on the other sectors as well. For example Figure 3.6.2 shows that the welfare of manufacturing workers increases proportionally to their sectoral and market experience. Old 1 workers with 35 years of sector and market experience gain about 0.25 , while Old 2 workers gain only 0.1 and Young workers gain about 0.02 . This graph is almost like a mirror image of the graph of Metal worker's welfare change (Figure 3.6.3).

Young workers in the metal sector do not experience high costs since they are very mobile and can easily find new jobs in the other sectors. Likewise, young workers in the Manufacturing sector do not experience high benefits (compared to older workers) since they are very mobile and their option value of moving and working in the metal sector decreases significantly. We call this a "mirror effect". Note that wages are almost unchanged in other sectors. 
On the other hand, the welfare effects in the non-traded market sectors are more variant (see Figures 3.6.1, 3.6.4 and 3.6.5). Young workers are unanimously better off, but by a small amount ranging between 0.01 and 0.03 . Note that their option value does not decrease as much as the Manufacturing workers' option value, because the increase in wages in the Manufacturing sector compensates the decrease in wages in the Metal sector (for their option values). Old 1 workers are unanimously worse off ranging between -0.04 and -0.06 . The reason for their being worse off is the increase in the CPI, which decreases the purchasing power of their retirement benefits, while the increase in the real wages partially compensates this decrease, although it is not sufficient to completely take it away. Old 2 workers are slightly better off in the Construction and Service sectors (0.02 and 0.03) and slightly worse off in the Trade sector $(-0.02)$. This difference is caused by the differences in the initial increases in wages: note that the wage increase in the Trade sector is gradual. Old 2 workers in the Service and Construction sectors enjoy an increased wage sufficient to compensate for the increase in the CPI (which reduces the purchasing power of their future retirement benefits).

We see that older workers gain (or lose) an amount ranging between -2.0 to +0.25 . Young workers gain (or lose) an amount ranging between -0.5 to +0.1 . Hence welfare effects of tariff reduction in the metal sector shows a wider range on older workers, creating larger losses and benefits among them, consistent with the findings of the 
Pew Global Attitudes Survey. ${ }^{23}$

\section{Experience and Welfare}

After we calculate the wage flows we can use the model from Chapter 2 (Model 2.2.1), to calculate how each worker is affected by trade liberalization. Note that the reason we assumed only 10 types of workers in this chapter was to restrict the state space, since endogeneity of wages increase the state space tremendously. If the wages were known, we could have used directly Model 2.2.1, as we did for the estimation. Therefore after calculating the wage flows, we can calculate values of the workers the same way we did for the estimation without worrying about the size of the state space. The change in workers' values are illustrated in Figures 3.7.1-5 and Figures

\subsection{1-5.}

There are three main factors affecting workers' attitudes towards free trade: first, moving costs and value of outside options; second, number of years to work; and third, changes in CPI. Workers in the metal sector are hurt more if they are less mobile because it is more difficult for workers with limited mobility to find new jobs in other sectors. Note that the value of the outside option increases significantly for the metal workers.

Workers in the Manufacturing sector are helped more if they are less mobile because their probability of working in the metal sector is smaller compared to the

\footnotetext{
${ }^{23}$ Note that the question in the survey is on free trade general not on a particular sector as I studied in this research. Young metal workers can easily be made better off by a multi-sector trade liberalization since they are not significantly worse off. On the other hand, older metal worker will unlikely be better off even if there were other sectors opening up for free trade.
} 
workers with high mobility. Note that since the wages in other sectors do not change much, the more mobile a worker is the more her outside option decreases after free trade because of the decrease in the Metal sector. Therefore in the Manufacturing sector a worker's being better off is negatively correlated with her mobility. Hence, high moving cost increases the positive effects of free trade if the outside option decreases because of the decrease in the Metal sector wages. Similarly, high moving cost increases the negative effects of free trade in a sector if the wages in that sector decrease because of free trade.

On the other hand, this explanation does not apply to sectors other than Manufacturing since their outside option does not decrease at all, because of the significant increase in the Manufacturing wages. In those sectors, positive effects of trade liberalization decrease with age as workers get closer to their retirement, since the purchasing power of their retirement compensation decreases. On the other hand positive effects of trade liberalization increase with sectoral experience since workers enjoy higher increase in their wages. Note that especially in Service and Trade sectors the sectoral experience has little effect as the wage changes are very small in these sectors.

\section{Change in Present Discounted Value of Wage Flows}

Note that some papers in the literature consider firing cost rather than mobility costs, as in Utar (2005) and Kambourov and Manovskii (2003). The mobility costs mentioned in this paper may include firing cost as well as any other unmodelled frictions. Therefore one might argue that the changes in workers' utility might be 
different with a different set of assumptions. Fortunately, this model imitates the labor flows well no matter where these frictions come from. Note that we studied different assumptions on these frictions in Chapter 2.

We consider changes in the present discounted value of expected wages as a proxy of the changes in utility. Unlike the utility, changes in the wages are not affected by the assumptions on the source of frictions. Therefore, by showing that there are similarities between the qualitative effects of trade liberalization on present discounted utility and present discounted wages, we show that the qualitative implications of the model are robust for any given assumption on frictions.

Consider the present discounted value of expected wage flows, $\tilde{V}_{t}^{i}$, given as

$$
\tilde{V}_{t}^{i}=w_{t}^{i}+\sum_{j=1}^{I} m_{t}^{i j} \tilde{V}_{t+1}^{j}
$$

The change in $\tilde{V}_{t}^{i}$ values after the trade liberalization are illustrated in Figure 3.9.1-5. Note that these figures look very similar to Figures 3.7.1-5, which explain the changes in the utility, $V_{t}^{i}$. Naturally, the numbers differ especially for the Metal sector. So we conclude that the quantitative implications of the model may be affected by the assumptions on the sources of friction

Finally, Figures 3.11.1-5 show the percentage changes in the expected wages. Note that our results are comparable with the previous "displaced workers literature", our finding for workers around 55 years old who lose $25 \%$ of their wage, is similar to what 
Jacobson LaLonde and Sullivan (1993) reports for experienced workers.

\subsection{Conclusion}

In Chapter 2, I estimated a dynamic structural discrete choice model of sectoral mobility and human capital accumulation in an open economy subject to trade shocks using the National Longitudinal Survey of Youth. I estimated different variations of the model to demonstrate the robustness of the model and the validity of the assumptions. In Chapter 3, I used the estimates of the model to analyze the effects of a hypothetical trade liberalization in the metal manufacturing sector, particularly on younger and older workers.

The results show that estimated moving costs are large and increase further by age. Preference shocks are important in explaining labor mobility.therefore psychological and unobserved factors play a role in mobility decisions. However, incorporating serially correlated preference shocks into the model decreases moving costs. In the case of free trade in the metal manufacturing sector, younger metal workers will be hurt but less so than older workers. The younger workers in other sectors will be helped more than most of the older workers. However, older workers with large sectoral experience in the manufacturing sector will be better off than all young workers in the economy, while most of the old workers in the economy without sectoral experience will be worse off. This varying effect on older workers results in a broader division among older workers in viewing trade liberalization as good or bad than among younger workers, 
consistent with the findings of the Pew Global Attitudes Survey. The results also show that displaced younger metal workers can find new jobs in other sectors faster than older workers if they lose their jobs because of free trade. Increasing mobility costs by age suggests that non-monotonic age-correlated benefits in the Trade Adjustment Assistance program may yield a more efficient compensation scheme.

The main finding of the paper is: old workers are more split and young workers are more unanimous in seeing free trade as good or bad. The results might be different for different simulation exercises. In this exercise we liberalized a sector which produces an intermediate good, which has no direct effect on CPI. If we were studying a liberalization of the manufacturing sector the results would be different: we could see more workers being better off parallel with the decrease in CPI. The main finding, which is the unanimity of younger workers in general, would be unchanged.

Incorporating capital mobility in the model in addition to worker mobility would allow us to study the welfare effects of free trade more precisely, especially over the long run, a task which is left for future research. The simulations predict that displaced metal workers' attempts to find new jobs in other sectors will be slow, leading to a temporary rise in unemployment. Pissarides (1985) type searching agents could be used to study how free trade changes the unemployment rate in the long run, a task which is also left for future work. 


\section{Appendix}

\section{Calibration Parameters}

\section{Utility Function}

We calibrate the utility function parameters from the "Relative importance of components in the Consumer Price Indexes: U.S. city average, December 2004" table. Since the utility function is Cobb-Douglas, share of sector $i$ products can be considered as the parameter $a_{i}$. Note that products of whole/retail trade and metal manufacturing do not appear in this table. Processed foods enter in the manufacturing sector and fresh fruits; vegetables enter in the construction sector which also includes agriculture and mining. Consumers who rent, pay a different price for shelter compared to home owners: we consider the price paid by home owners because renting a house might include other services which should not be included as a part of construction sector but as a part of service sector (we add the difference to the service sector). Another important point is related to the main input of the construction sector which is land: since we do not consider land as an input we deduct the approximate cost of land from the cost of shelter. We assume that cost of land is approximately $60 \%$, of course this number is a guess and it would be different for each city. The share of construction sector is approximately $10 \%$, the share of manufacturing is approximately $40 \%$, and the share of service sector is about $50 \%$ in our 
model.

\section{Production Functions}

The share of inputs for each product can be considered as parameters of the Cobb-Douglas production function, $b_{j}^{i}$. We mainly use the set of tables labeled as "The Use of Commodities by Industries after Redefinitions, 1997" from the Bureau of Economic Analysis' internet site. We consider the output levels before tax. We use a one digit industry table for all sectors except Manufacturing and Metal. For sectors which are consist of more than one sector, such as service, we take a weighted average of shares. For manufacturing and metal sectors we use a four digit table, we combine sub-divisions of metal industry and subtract them from the manufacturing shares from the one digit table and take the relative size of metal sector into account. The results are summarized in table 3.1 .

Before calibrating the coefficient $B^{i}$, we normalize all inputs $x_{t}^{i, j}=1$, for every $i, j, t$ and we normalize total labor $\sum_{n} \sum_{j} L^{n j}=1$ where $n$ stands for the worker type. The average sectoral experience of workers is endogenous in the model; we use probabilities of sector change to calculate average sectoral experience. Using the average sectoral experience and education levels for each sector we calculate average human capital level for each sector, which then, is used to calculate effective total labor in each sector, $L_{t}^{i} \bar{h}_{t}^{i}$. Then we pick $B^{i}$ such that, average real wage in each 
sector is equal to implied average real wage over the years:

$$
\sum_{t=1}^{17} w_{t}^{i}=B^{i} b_{6}^{i}\left(L_{t}^{i} \bar{h}_{t}^{i}\right)^{b_{6}^{i}-1}
$$

note that we do not need to worry about the inputs since they are normalized to one. After this calibration, we need to consider quantities of inputs relative to the autarky quantities, $x_{t}^{i, j} / x_{\text {Autarky }}^{i, j}$ to use them in the production function.

\section{Labor Supply}

The parameters, $C_{0}, C_{1}, C_{0} / \sigma_{e}, \phi_{4}, \phi_{5}, \phi_{6}^{i}, v^{1}, v^{2}, \ldots, v^{6}$ are taken from the estimates of Model 2.1. The parameter, $\phi_{6}^{i}$, is a weighted average of $\phi_{1}, \phi_{2}, \phi_{3}$ given the percentage of high school and college graduates for each sector.

\section{Solution Method for Simulations}

We use a method similar to multiple shooting, described in Lipton et al. 1982, to solve for the transition and steady states. The solution described here is for one type of worker, it can be generalized for more than one type simply by increasing the state space.

\section{Autarky Steady State:}

In autarky prices are given as 1 for all sectors and the inputs $x^{i, j}$ are also normalized to unity. Therefore we solve the system without worrying about the prices ad inputs since all parameters are calibrated under the assumption of all prices being unity. 
We will exploit the lack of aggregate uncertainty, the only uncertainty is the one time shock to price because of trade liberalization. So the system we are solving is deterministic since we only have a one time shock and nothing else stochastic. The random idiosyncratic shocks in the model do not make the aggregate system stochastic because we have a continuum of workers, hence all agents have a perfect foresight of the aggregate parameters (except the trade shock). If we know the steady state labor allocation, $L^{i}$, we can calculate wages, $w^{i}$. If we know the steady state values of workers, $V^{i}$, we can calculate their probabilities of sector change, $m^{i j}$. Moreover knowing $m^{i j}$ and $w^{i}$ it is possible to calculate values of workers $V^{i}$. Hence all parameters can be considered functions of other parameters:

$$
w_{t}^{i}=\frac{p_{t}^{i}}{C P I_{t}} \frac{\partial q^{i}\left(L_{t}^{i}\right)}{\partial L_{t}^{i}}
$$

where $q^{i}$ is the production function and $C P I_{t}$ is the consumer price index. Probability of sector change

$$
m_{t}^{n i k}=E_{z} \frac{\exp \left[\left(E_{u} V_{t+1}^{n k}-E_{u} V_{t+1}^{n i}-C^{n, i, k}\right) / \nu\right]}{\sum_{j} \exp \left[\left(E_{u} V_{t+1}^{n j}-E_{u} V_{t+1}^{n i}-C^{n, i, j}\right) / \nu\right]}
$$

Value of workers

$$
E_{u} V_{t}^{i}=w_{t}^{i}+v^{i}+\nu \log \left(1+\exp \left(m_{t}^{i i} / \nu\right)\right)+\beta E V_{t+1}^{i}
$$


Labor allocation

$$
L_{t+1}^{n j}=\sum_{r=1}^{10} \tilde{P}\left(s_{t+1}^{n} \mid s_{t}^{r}\right) \sum_{i=1}^{6} L_{t}^{r i} m_{t}^{r i j}
$$

Let

$$
X_{t}=\left[L_{t}^{1}, L_{t}^{2} \ldots, L_{t}^{60}, V_{t}^{1}, V_{t}^{2}, \ldots, V_{t}^{60}\right]^{\prime}
$$

and consider the system above as a mapping $F: \Re^{120} \rightarrow \Re^{120}$, such that $X_{t}=$ $F\left(X_{t+1}\right)$. In the steady state $X_{t}=X_{t+1}$, therefore there is a fixed point of function $F$. The steady state is the solution of the nonlinear equation

$$
F\left(X^{S S}\right)-X^{S S}=0
$$

which can be solved by any nonlinear equation solver.

Free Trade Steady State:

For the free trade steady state we have to worry about the prices because prices are actually endogenous for some sectors and a drop in the metal sector price will effect prices endogenously, deviating from the autarky price levels in many sectors.

Assume that the autarky output levels are given as $q_{A}^{i}$, for $i=1 . . I$. For the traded goods the prices will still be exogenous and equal to world price, $p_{F T}^{i}=p_{W}^{i}$, however the free trade outputs for all sectors and the prices for non-traded sectors will be endogenous to the model, $p_{F T}^{i}$ and $q_{F T}^{i}$. The price levels will be determined by the 
equation

$$
p_{t}^{i}=\frac{q_{A}^{i}}{q_{t}^{i}} \frac{a_{i} \sum_{j=1}^{I-1}\left(b_{6}^{j}+b_{7}^{j}\right) q_{t}^{j} p_{t}^{j}+\sum_{j=1}^{I-1} b_{i}^{j} q_{t}^{j} p_{t}^{j}}{a_{i} \sum_{j=1}^{I-1}\left(b_{6}^{j}+b_{7}^{j}\right) q_{A}^{j}+\sum_{j=1}^{I-1} b_{i}^{j} q_{A}^{j}},
$$

and the quantities will be determined by

$$
q_{t}^{i}=B^{i}\left(L_{t}^{i} \bar{h}_{t}^{i}\right)^{b_{6}^{i}} \prod_{j=1}^{I-1}\left(\frac{1}{p_{t}^{j}} \frac{q_{t}^{i} p_{t}^{i}}{q_{A}^{i}}\right)^{b_{j}^{i}}
$$

where $t=F T$. Therefore $q_{F T}^{i}$ 's and $p_{F T}^{i}$ 's are included as control variables in the system, but the solution method is almost identical to the autarky solution except whys time we have two more equations. Let

$$
X_{t}=\left[L_{t}^{1}, L_{t}^{2} \ldots, L_{t}^{60}, V_{t}^{1}, V_{t}^{2}, \ldots, V_{t}^{60}, q_{t}^{1}, q_{t}^{2}, \ldots, q_{t}^{5}, p_{t}^{1}, p_{t}^{2}, \ldots, p_{t}^{5}\right]^{\prime}
$$

and consider the system above as a mapping $F: \Re^{130} \rightarrow \Re^{130}$, such that $X_{t}=$ $F\left(X_{t+1}\right)$. In the steady state $X_{t}=X_{t+1}$, therefore there is a fixed point of function $F$. The steady state is the solution of the nonlinear equation

$$
F\left(X^{S S}\right)-X^{S S}=0
$$

which can be solved by any nonlinear equation solver.

Transition: 
Solving for transition is relatively more difficult than the steady state but the problem can be attacked by a similar approach. The economy is at autarchy steady state equilibrium initially, at time 0 and then the economy switches to free trade as shock therapy. Consider the system above, assume starting from $t=0$ the economy will become sufficiently close to its free trade steady state $X^{F T}$ at $t=T$, such that $\left(X_{T}-X^{F T}\right)^{\prime}\left(X_{T}-X^{F T}\right)<\delta$, where $\delta$ is a very small number for the tolerance level. We will conveniently assume that $X_{T+k}=X_{T}$ for every $k \geq 0$, since there will not be any aggregate shocks in the economy. Let $X=\left[X_{0}, X_{1}, X_{2}, \ldots, X_{T}\right]^{\prime}$, be the transition of all state and control variables starting from $t=0$, (autarchy) until $t=T$, (free trade steady state). Then we can define a mapping from $H: \Re^{70(T+1)} \times[0,1]^{60} \rightarrow \Re^{70(T+1)}$, such that $X=H\left(X, L_{0}\right)$. Therefore this problem is just a larger version of the steady state problem. We solve the nonlinear equation

$$
H\left(X, L_{0}\right)-X=0
$$

to find the fixed point. Note that this time we can consider

$$
X_{t}=\left[V_{t}^{1}, V_{t}^{2}, \ldots, V_{t}^{60}, q_{t}^{1}, q_{t}^{2}, \ldots, q_{t}^{5}, p_{t}^{1}, p_{t}^{2}, \ldots, p_{t}^{5}\right]^{\prime}
$$

since the initial labor allocation, $L_{0}$, is now known and it can be calculated forward.

In practice we first find the steady state of autarchy and of free trade. Then 
we guess a value for $T$, such as 40 . Starting from the steady state autarchy labor allocation we solve the nonlinear equation (35). Finally we check if $X_{T}$ is equal to the free trade steady state, if so we are done and if not we increase $T$, and repeat the procedure.

\section{Notes on Wage Equation}

Consider the production function:

$$
y=b\left(\sum_{n} L^{n} h^{n}\right)^{\alpha}
$$

where $b$ is a constant which accounts for the production function coefficient and all non-labor inputs and $L^{n}$ is the number of workers with effective human capital level $h^{n}$. Assume that workers receive their real marginal product:

$$
w^{n}=\frac{p}{\phi} \frac{\partial y}{\partial L^{n}}
$$

where $p$ is the price of the product and $\phi$ is the price index. Then

$$
w^{n}=\frac{p}{\phi} b \alpha\left(\sum_{n} L^{n} h^{n}\right)^{\alpha-1} h^{n}
$$

where $L$ is the total number of workers. Assume that $\bar{h}$. is the average human capital 
in sector. Now consider the human capital accumulation process: $h^{n}=H\left(s^{n}\right)+z$, then the average effective human capital in the sector is $\bar{h}=\frac{1}{L}\left(\sum_{n} L^{n} h^{n}\right)$, where $H$ is a linear function of state variables $s^{n}$ and $z$ is a mean random shock to each worker's effective human capital. Note that $z$ is different for all workers and it is mean zero. Therefore we can write wages using average human capital such as

$$
w^{n}=\frac{p}{\phi} b \alpha(L \bar{h})^{\alpha-1} h^{n}
$$

Now consider the average wage in sector:

$$
\bar{w}=\frac{p}{\phi} b \alpha(L \bar{h})^{\alpha-1} \bar{h}
$$

Hence we can write wages as a function of average effective human capital and average wages in sectors

$$
\begin{aligned}
w^{n} & =\frac{p}{\phi} b \alpha(L \bar{h})^{\alpha-1} h^{n} \\
& =\bar{w} \frac{h^{n}}{\bar{h}} .
\end{aligned}
$$




\section{References}

[1] Bellman, R. (1957). "Dynamic Programming." Princeton NJ, Princeton University Press.

[2] Boldrin, M., and M. Horvath (1995). "Labor Contracts and Business Cycles," The Journal of Political Economy.

[3] Bond, E. W. and J. H. Park (2002)."Gradualism in Trade Agreements with Asymmetric Countries." Review of Economic Studies, 69:2 (April).

[4] Borjas, G., V. Ramey (1995). "Foreign Competition, Market Power and Wage Inequality," The Quarterly Journal of Economics.

[5] Cameron, S., S. Chaudhuri and J. McLaren (2003). "Mobility Costs and Dynamics of Labor Market Adjustments to External Shocks: Theory," Mimeo: University of Virginia.

[6] Chaudhuri, S. and J. McLaren (2003a). "The Simple Analytics of Trade and Labor Mobility I : Homogeneous Workers." Mimeo:University of Virginia

[7] Chaudhuri, S. and J. McLaren (2003b). "The Simple Analytics of Trade and Labor Mobility II: Two Types of Worker." Mimeo:University of Virginia.

[8] Davidson, C., L. Martin and S. J. Matusz (1999). "Trade and Search Generated Unemployment." Journal of International Economics 48:2 (August), pp. 27199. 
[9] Davidson, C. and S. J. Matusz (2001). "On Adjustment Costs." Michigan State University Working Paper.

[10] Davidson, C., and S. Matusz (2002). "Trade Liberalization and Compensation," Mimeo: Michigan State University.

[11] Davis, S., J. Haltiwanger and S. Schuh (1996). Job Creation and Destruction. Cambridge: MIT Press.

[12] Dehejia, V. (2003). "Will Gradualism work when Shock Therapy Doesn't?" Economics and Politics 15:1 (March), pp. 33-59.

[13] Dixit, Avinash (1993). "Prices of Goods and Factors in a Dynamic Stochastic Economy." In Jones Festschrift.

[14] Dixit, A., and V. Norman (1986). "Gains from Trade without Lump-Sum Compensation," Journal of International Economics, 36.

[15] Dixit, A., and V. Norman (1980). Theory of International Trade. Cambridge, U.K.: Cambridge University Press. Ch. 2-4.

[16] Dixit, A., and R. Rob (1994). "Switching Costs and Sectoral Adjustments in General Equilibrium with Uninsured Risk.” Journal of Economic Theory 62, pp. 48-69. 
[17] Feenstra, R., and T. Lewis (1994). "Trade Adjustment Assistance and Pareto Gains from Trade," Journal of International Economics, 36.

[18] Groot, W., M. Verberne (1997). "Aging, Job Mobility, and Compensation," Oxford Economics Papers, 49.

[19] Gourieroux, C., A. Monfort and E. Renault (1993). "Indirect Inference," Journal of Applied Econometrics, 8.

[20] Ichida, T. (2003). "Occupational Choice and Compensation for Losers from Free Trade," Mimeo: Columbia University.

[21] Jacobson, L., R. LaLonde and D. Sullivan (1993). "Earning Losses of Displaced Workers," AmericanEconomic Review, 83.

[22] Jovanovic, B., and R. Moffitt (1990). "An Estimate of a Sectoral Model of Labor Mobility," The Journal of Political Economy 98.

[23] Kambourov, G., and I. Manovskii (2003). "Labor Market Restrictions and the Sectoral Reallocation of Workers: The Case of Trade Liberalizations," University of Western Ontario working paper.

[24] Kambourov, G., and I. Manovskii (2004). "A Cautionary Note on Using (March) CPS Data to Study Worker Mobility," Mimeo: University of Toronto. 
[25] Keane, M., and A. Smith (2003). "Generalized Indirect Inference." Mimeo: Yale University

[26] Keane, M., and K. Wolpin (1994). "The Solution and Estimation of Discrete Choice Dynamic Programming Models by Simulation and Interplotation." The Review of Economics and Statistics, 76.

[27] Keane, M., and K. Wolpin (1997). "The Career Decisions of Young Men.” Journal of Political Economy 105.

[28] Kletzer, L. (1989). "Returns to Seniority After Permanent Job Loss," American Economic Review, 79.

[29] Lazear, E. (1979). "Why is there Mandatory Retirement?," The Journal of Political Economy, 87.

[30] Lee, D. and K. Wolpin (2004). "Intersectoral Labor Mobility and the Growth of the Service Sector" Econometrica - forthcoming.

[31] Karp, L. and T. Paul (1994). "Phasing In and Phasing Out Protectionism with Costly Adjustment of Labour," Economic Journal 104:427 (November), pp. 137992.

[32] Klein, M. W., S. Schuh, and R. K. Tries (2003). "Job creation, job destruction, and the real exchange rate." Journal of International Economics 59(March), pp. $239-265$. 
[33] Keane, M., and K. Wolpin (1997). "The Career Decisions of Young Men.” Journal of Political Economy 105.

[34] Lipton, D., J. Poterba, J. Sachs and L. Summers (1982). "Multiple shooting in Rational Expectation Models," Econometrica 50.

[35] Magee, S. (1980). "Three Simple tests of the Stolper-Samuelson Theorem" In Issues in International Economics: Essays in Honor of Harry Johnson, edited by P. Oppenheimer, London, Oriel.

[36] Mincer, J. (1958). "Investment in Human Capital and Personal Income Distribution," The Journal of Political Economy, 66.

[37] De Melo, J. and D. Tarr (1990). "Welfare Costs of U.S. Quotas in Textiles, Steel and Autos." The Review of Economics and Statistics, 72.

[38] Mortensen, Dale and George Neumann (1989). "Interfirm Mobility and Earnings," In Search Models and Applied Labor Economics, edited by Nicholas Kiefer and George Neumann. New York, Cambridge University Press.

[39] Mussa, M. (1978). "Dynamic Adjustment in the Hecksher-ohlin-Samuelson Model," Journal of Political Economy, 85.

[40] Mussa, M. (1974). "Tariffs and the Distribution of Income: The Importance of Factor Specificity, Substitutability, and Intensity in the Short and Long Run." Journal of Political Economy 82, pp. 1191-1204. 
[41] Osborne, M., and A. Rubinstein (1990). Bargaining and Markets. San Diego, Academic Press.

[42] Neal, D. (1995). "Industry Specific Human Capital: Evidence from Displaced Workers," Journal of Labor Economics, 13.

[43] Patel, J., C. H. Kapadia, and D. B. Owen (1976). Handbook of Statistical Distributions. New York: Marcel Dekker, Inc.

[44] Pissarides, C. A. (1985). "Short Run Equilibrium Dynamics of Unemployment, Vacancies and Real Wages," The American Economic Review, 75.

[45] Podursky, M. and P. Swaim (1987). "Job Displacement and Earning Loss: Evidence from the Displaced Worker Survey," Industrial and Labor Relations Review, 41 .

[46] Smith, A., (1993). "Estimating Nonlinear Time Series Models Using Simulated Vector Autoregressions." Journal of Applied Econometrics, 8.

[47] Staiger, R. W. (1995). "A Theory of Gradual Trade Liberalization," in Jim Levinsohn, Alan V. Deardorff, and Robert M. Stern, New Directions in Trade Theory, Ann Arbor, The University of Michigan Press.

[48] Sullivan, P. (2005). "A Dynamic Analysis of Educational Attainment, Occupational Choices, and Job Search.” Mimeo: University of Michigan 
[49] Tauchen, G. and R. Hussey (1991). "Quadrature Based Methods for Obtaining Approximate Solutions to Nonlinear Asset Pricing Models," Econometrica, 59.

[50] Topel, R. (1991). "Specific Capital, Mobility, and Wages: Wages Rise with Job Seniority," The Journal of Political Economy, 99.

[51] Utar, H. (2005). "Employment Dynamics and Import Competition," Mimeo: Pennsylvania State University.

[52] Viner, J. (1937). Studies in the Theory of International Trade. New York: Harper. 


\section{LIST OF FIGURES}

\section{Chapter 1}

Adjustment of Labor: Figure 1.1

Adjustment of Wages: Figures 1.2-3

Adjustment of Labor for Alternative cases: Figure 1.4

Delay and Labor Unity: Figures 1.5-6

Chapter 2

Mobility of Workers by Age: Figure 2.1.1

Distribution of Workers by Various Characteristics: Figures 2.1.2-6

Alternative Extrapolations of Moving Cost Figures 2.2.1-4

\section{Chapter 3}

Labor Out-Flows: Figures 3.1.1-6

Adjustment of Labor Allocations: Figures 3.2.1-6

Adjustment of Output Levels: Figures 3.3.1-6

Adjustment of Prices: Figures 3.4.1-6

Adjustment of Wages: Figures 3.5.1-5

Changes in Utility (Old and Young Workers): Figure 3.6.1-6 
Changes in Utility (All Workers, 2D): Figures 3.7.1-5

Changes in Utility (All Workers, 3D): Figures 3.8.1-5

Changes in Expected Wage Flow (All Workers, 2D): Figures 3.9.1-5

Changes in Expected Wage Flow (All Workers, 3D): Figures 3.10.1-5

Percentage Change in Wages (All Workers, 2D): Figures 3.11.1-5

Percentage Change in Wages (All Workers, 3D): Figures 3.12.1-5 
Figure 1.1: Adjustment of Labor - Benchmark Cases

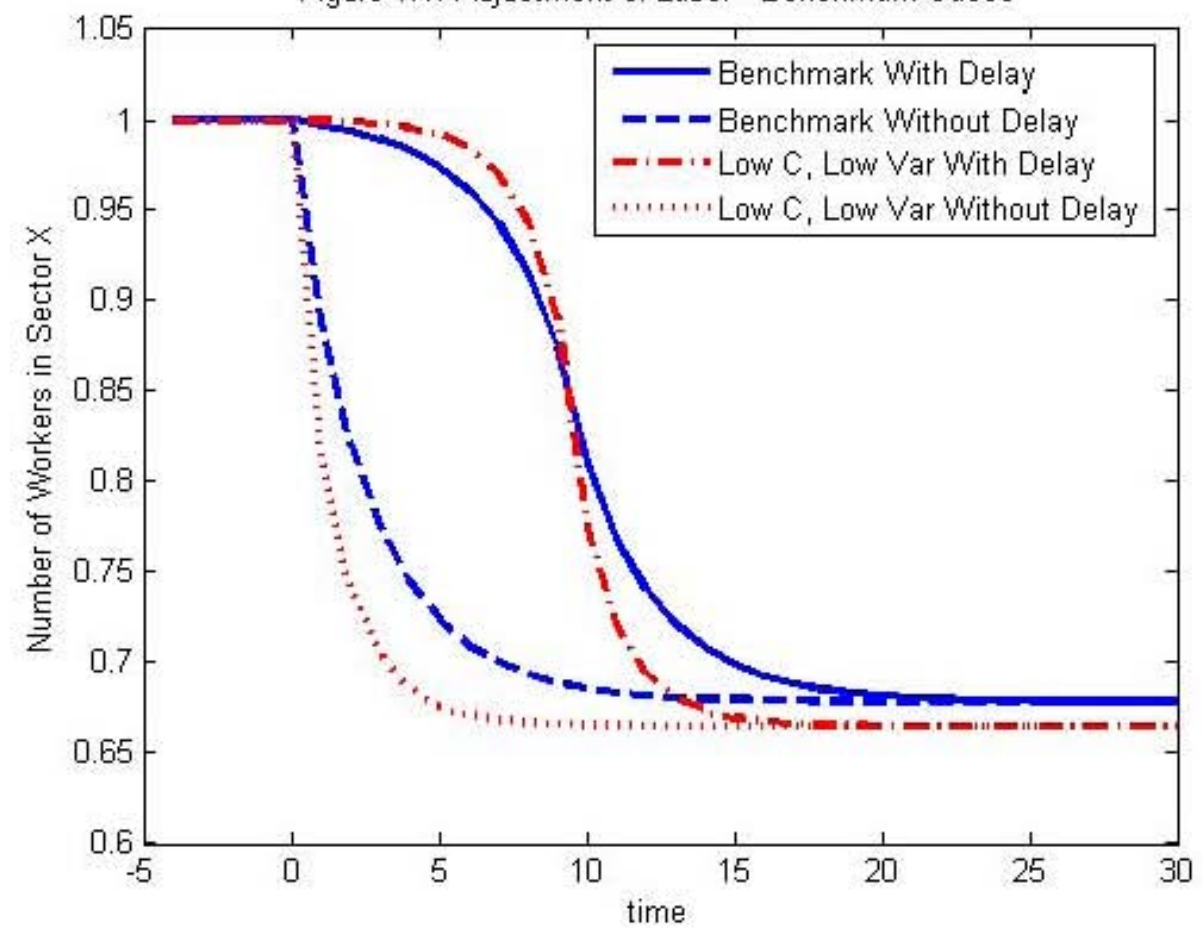

Figure 1.2: Wages of Import Competing Sector Workers - Benchmark Cases

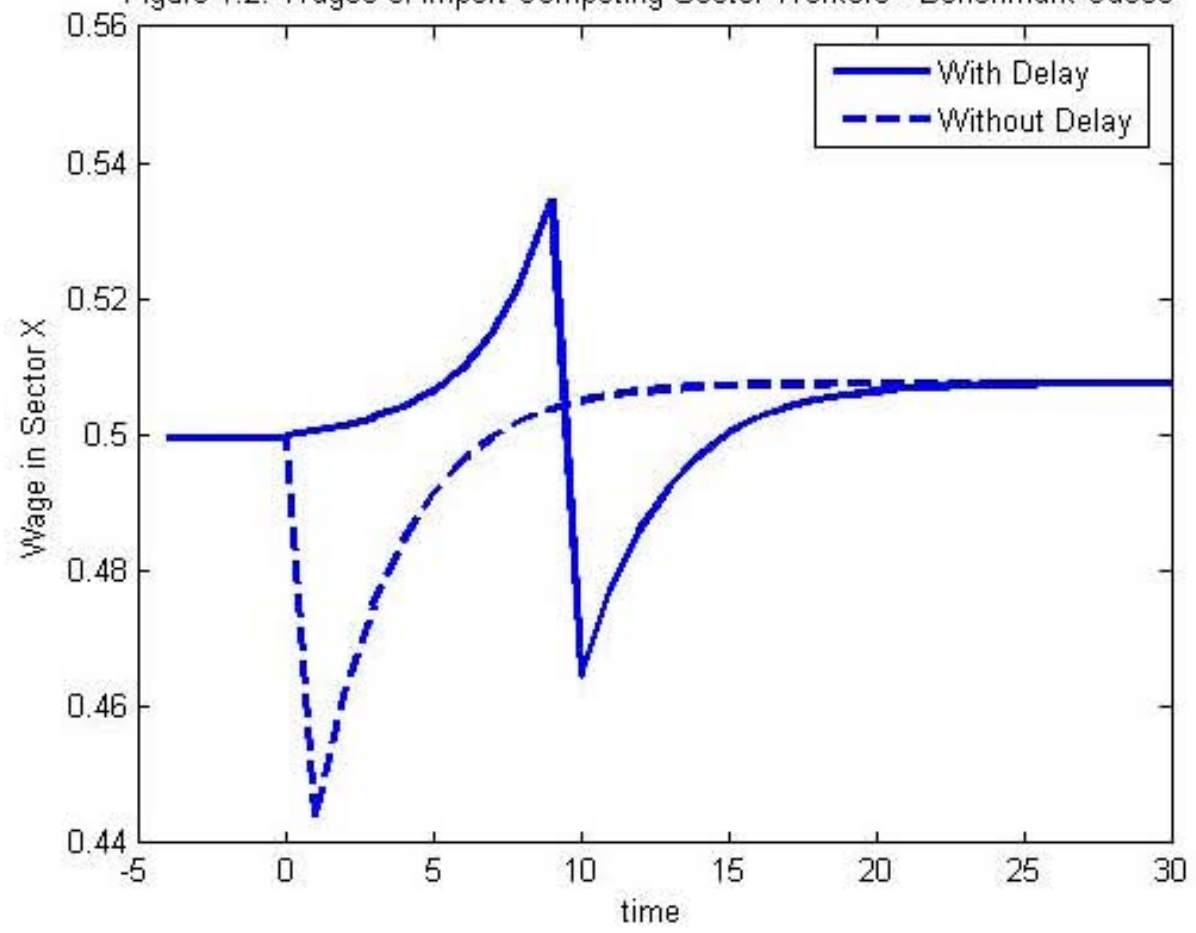


Figure 1.3: Wages of Export Sector Workers - Benchmark Cases

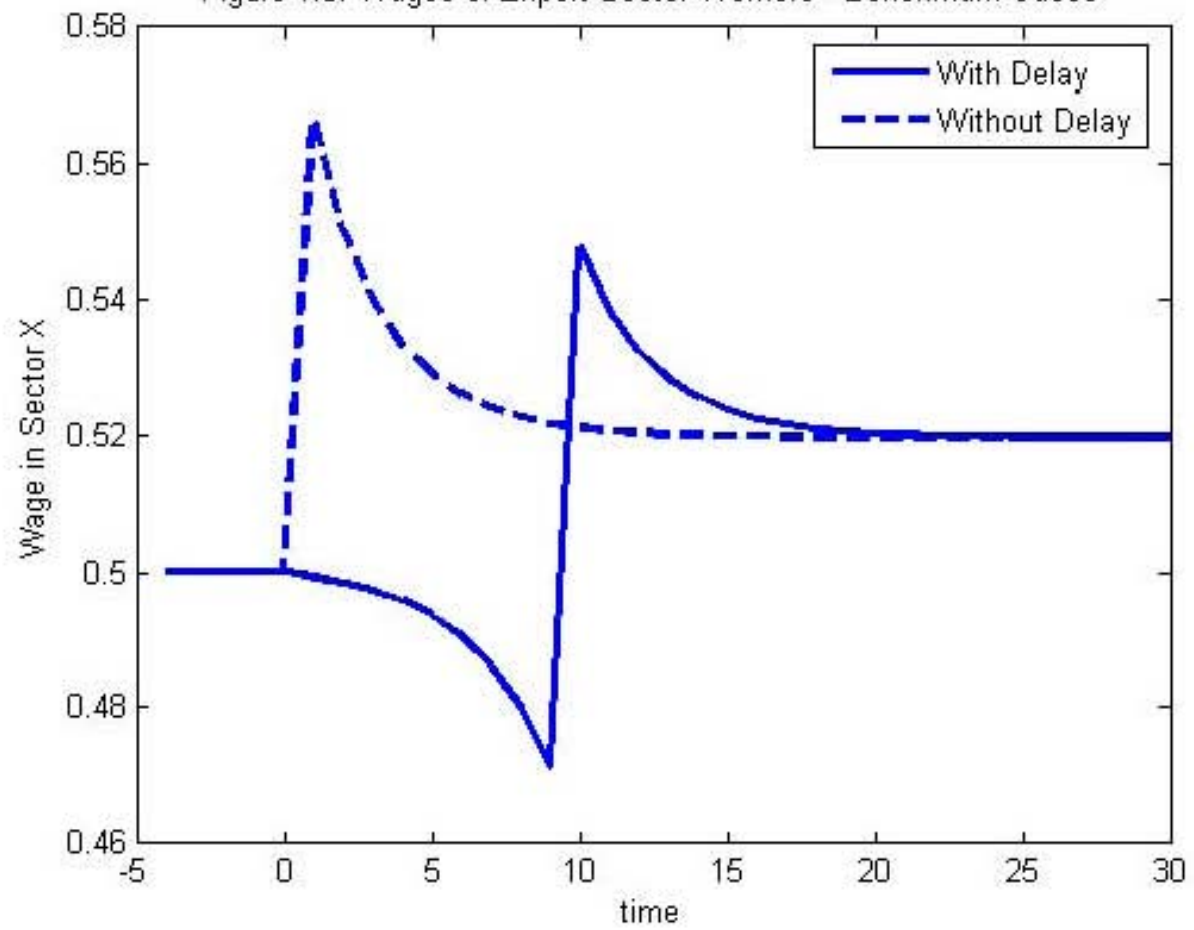

Figure 1.4: Adjustment of Labor - High and Low Variance Cases

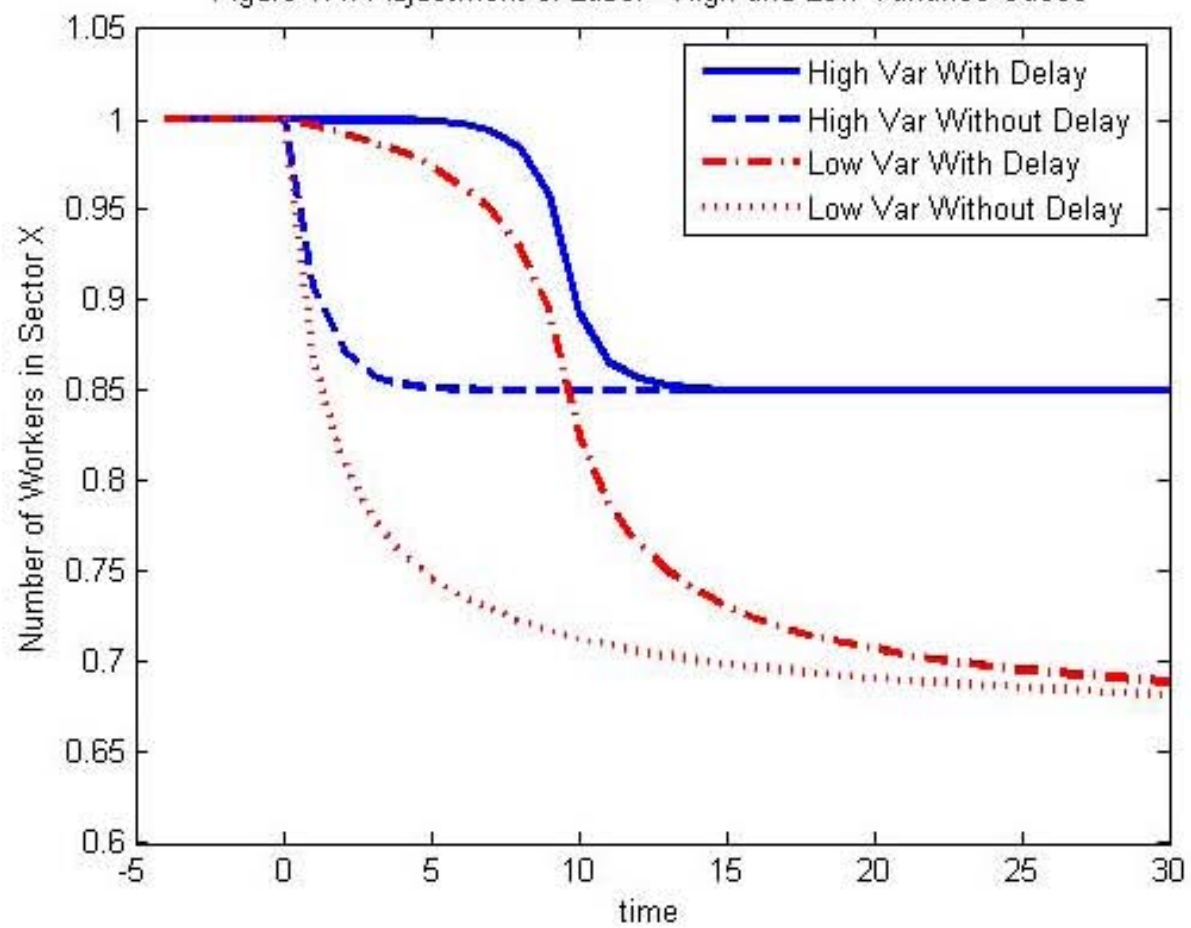


Figure 1.5: Delay and Worker Unity

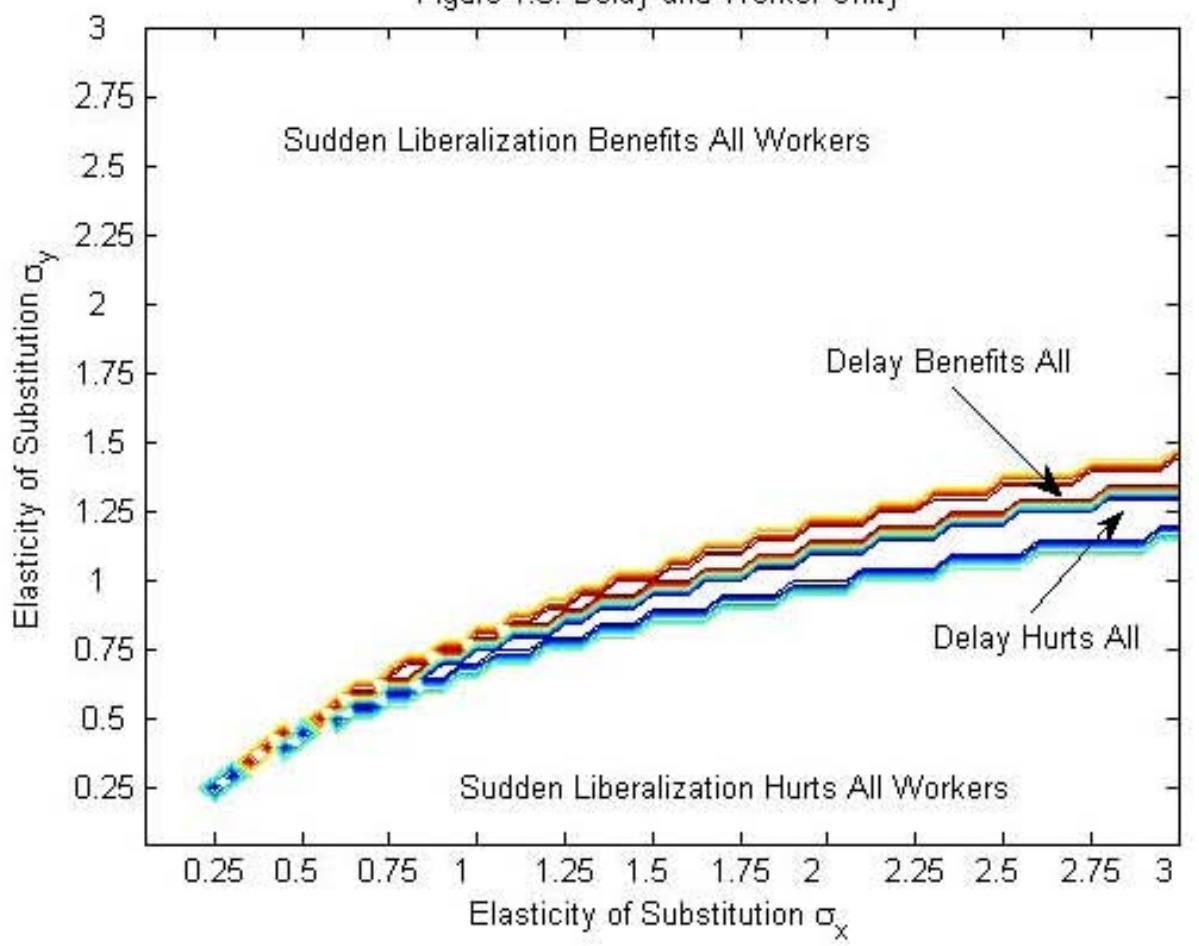

Figure 1.6: Length of Delay Required for Worker Unanimity

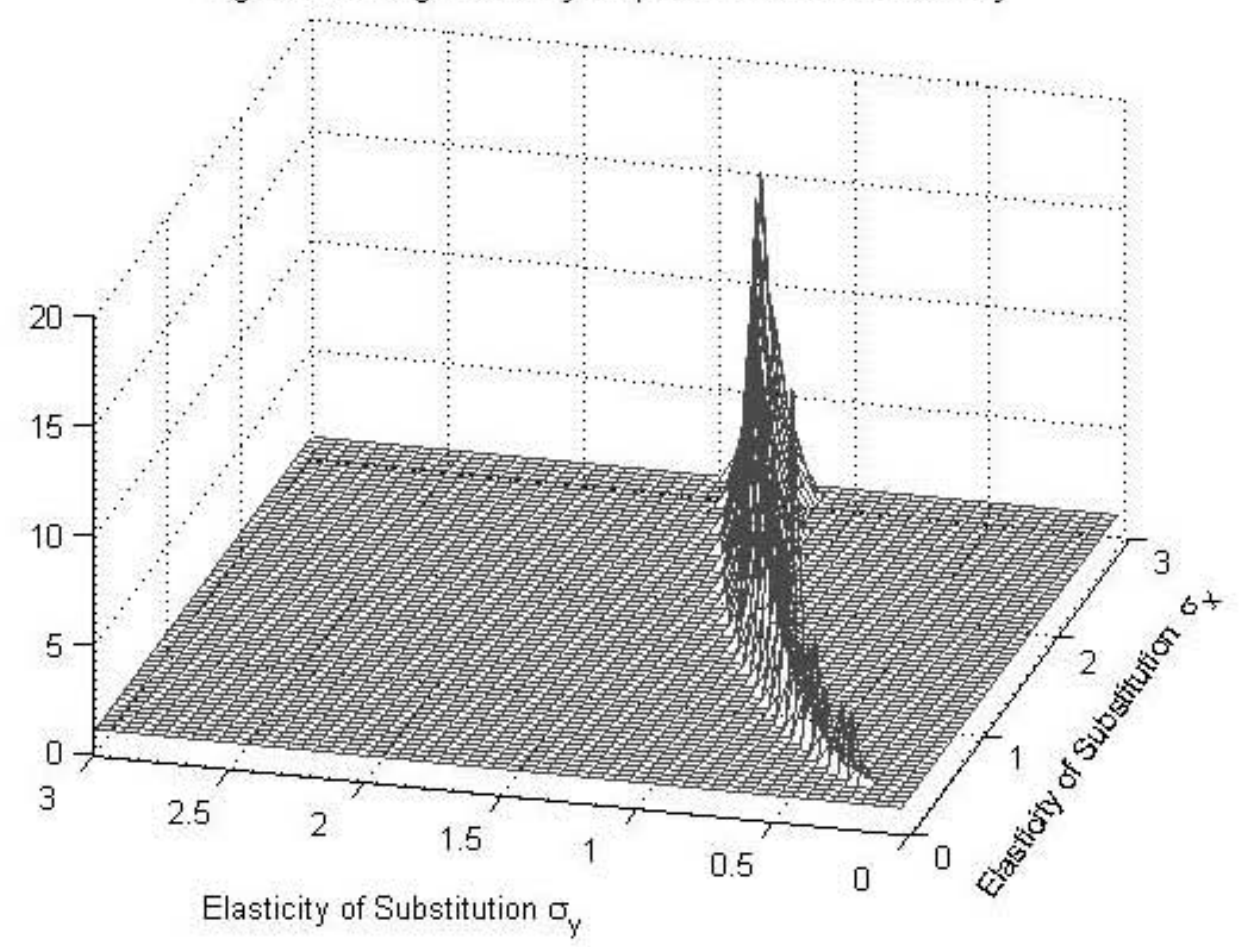


Figure 2.1.1: Mobility of Workers by Age

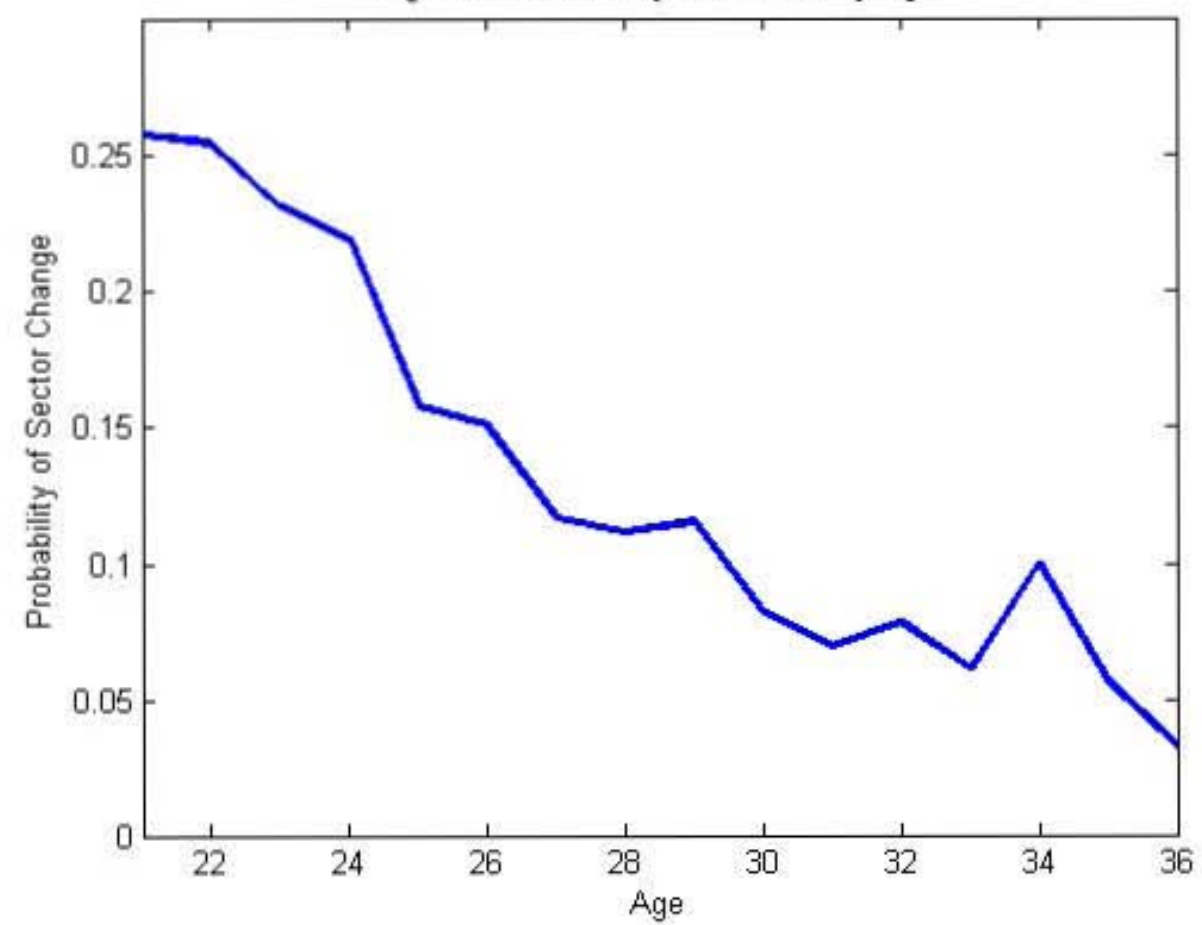

Figure 2.1.2: Distribution of Workers by Age

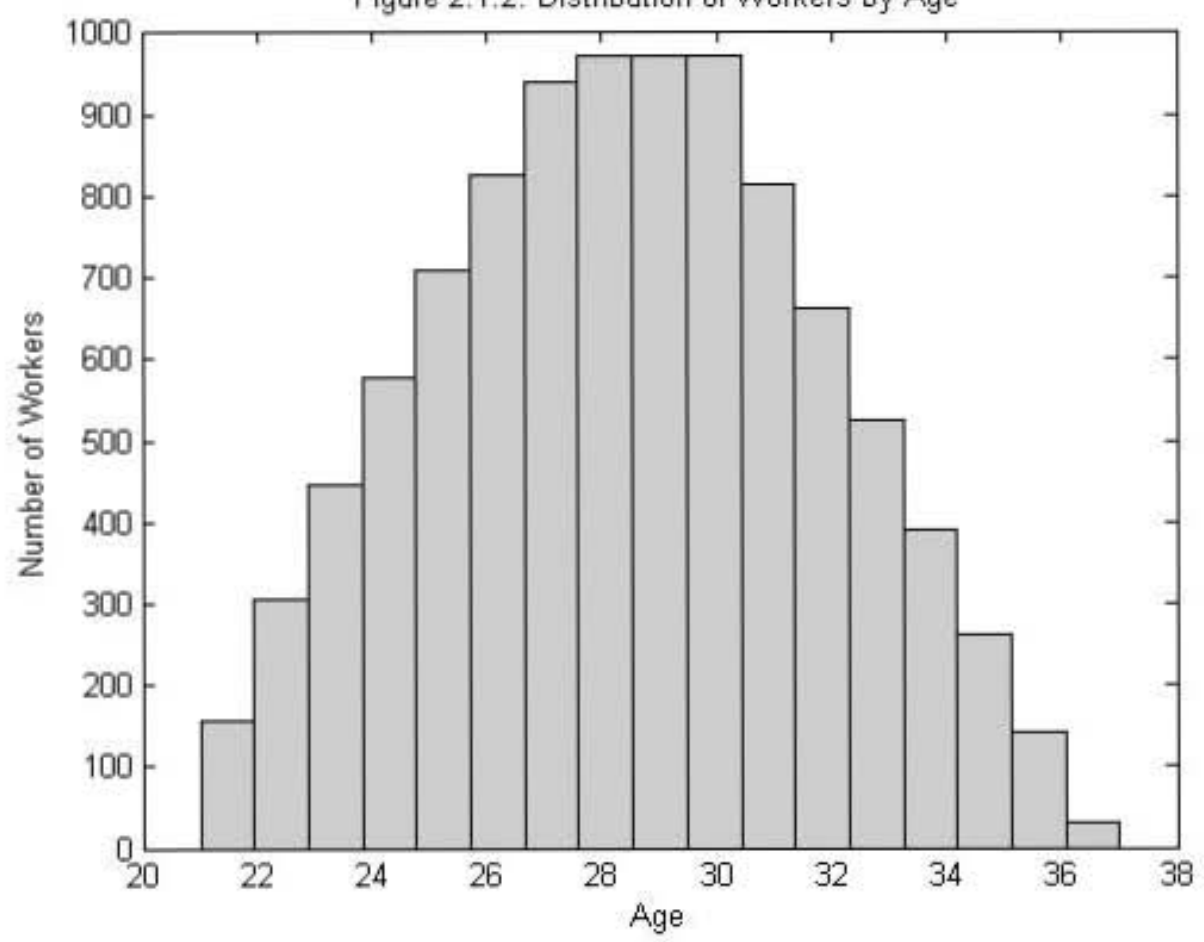




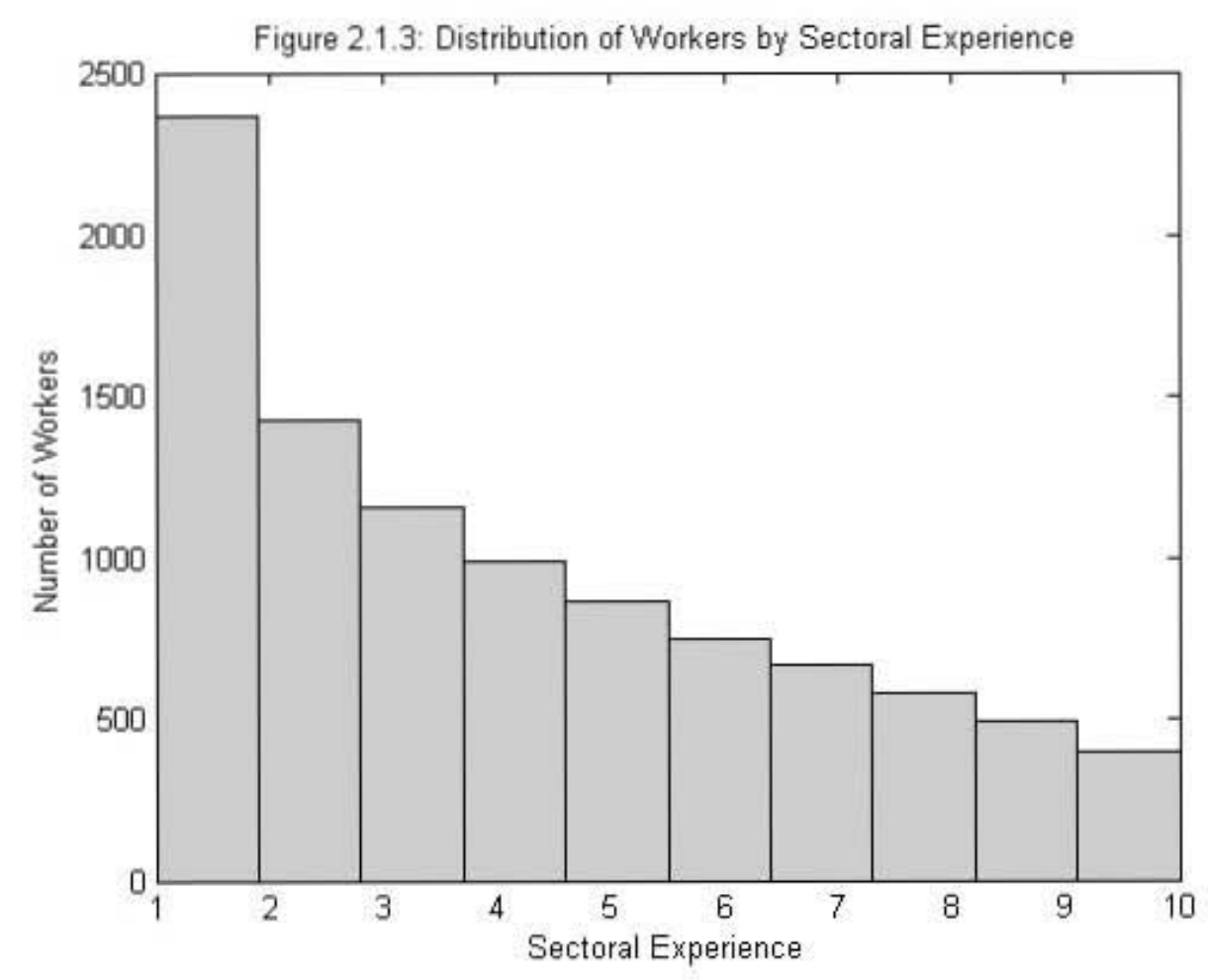

Figure 2.1.4: Distribution of Workers by Education

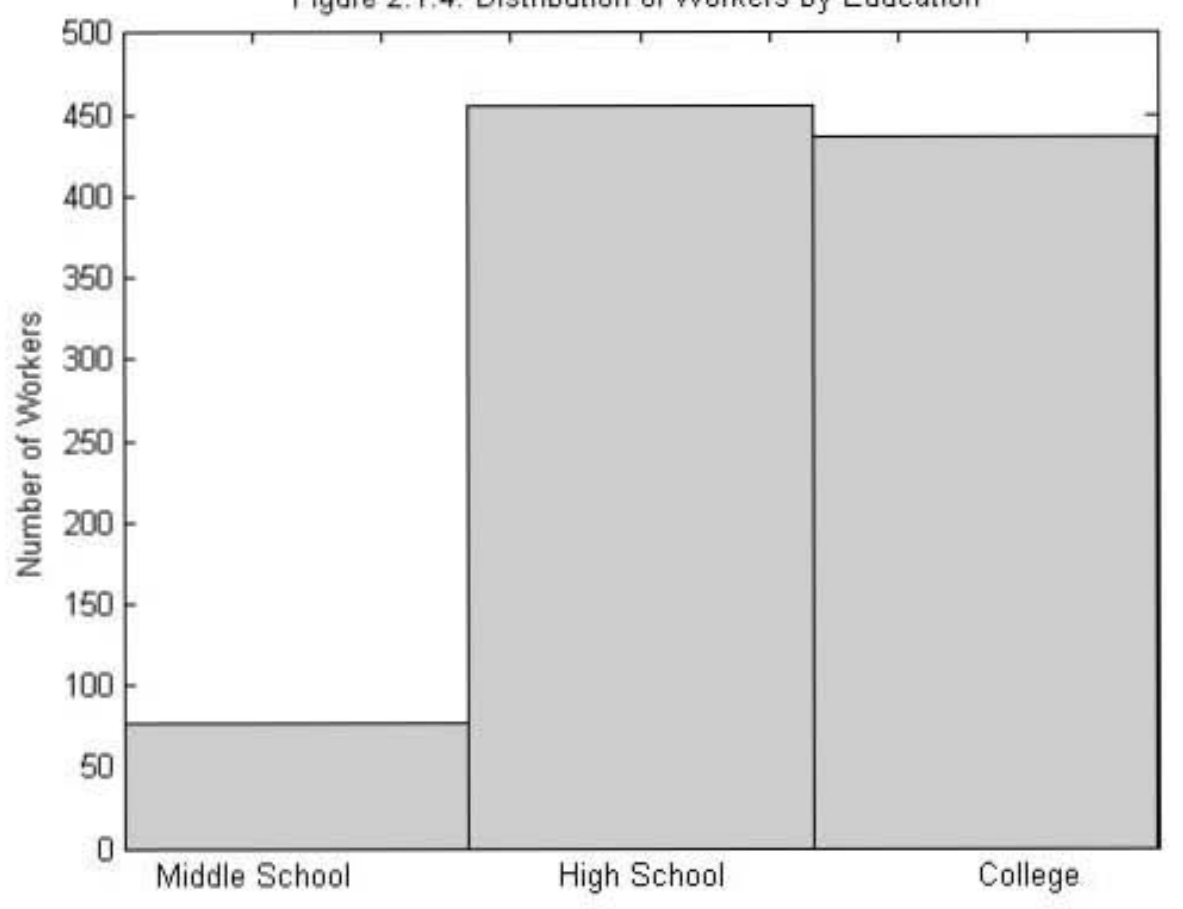


Figure 2.1.5: Distribution of Workers by Market Experience

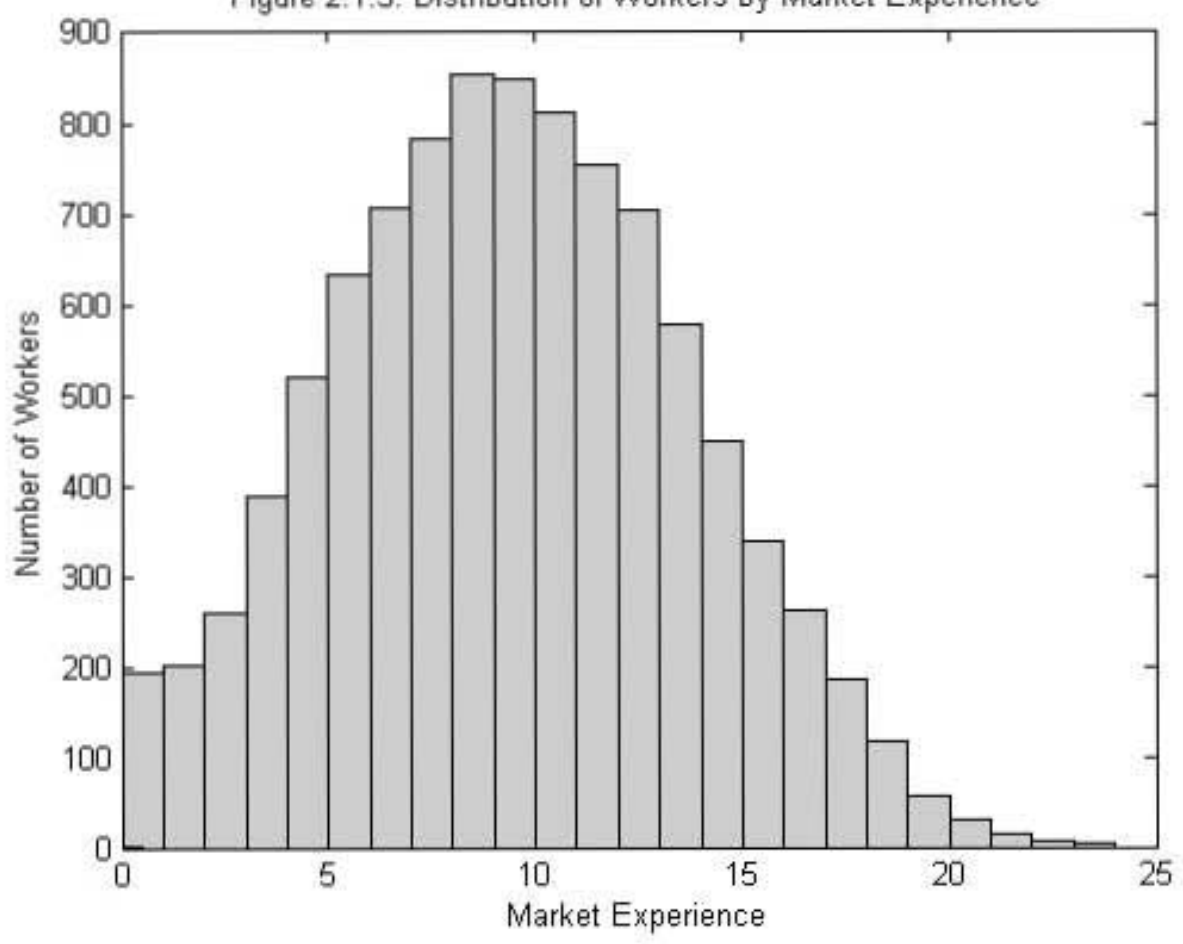

Figure 2.1.6: Distribution of Workers by Wage

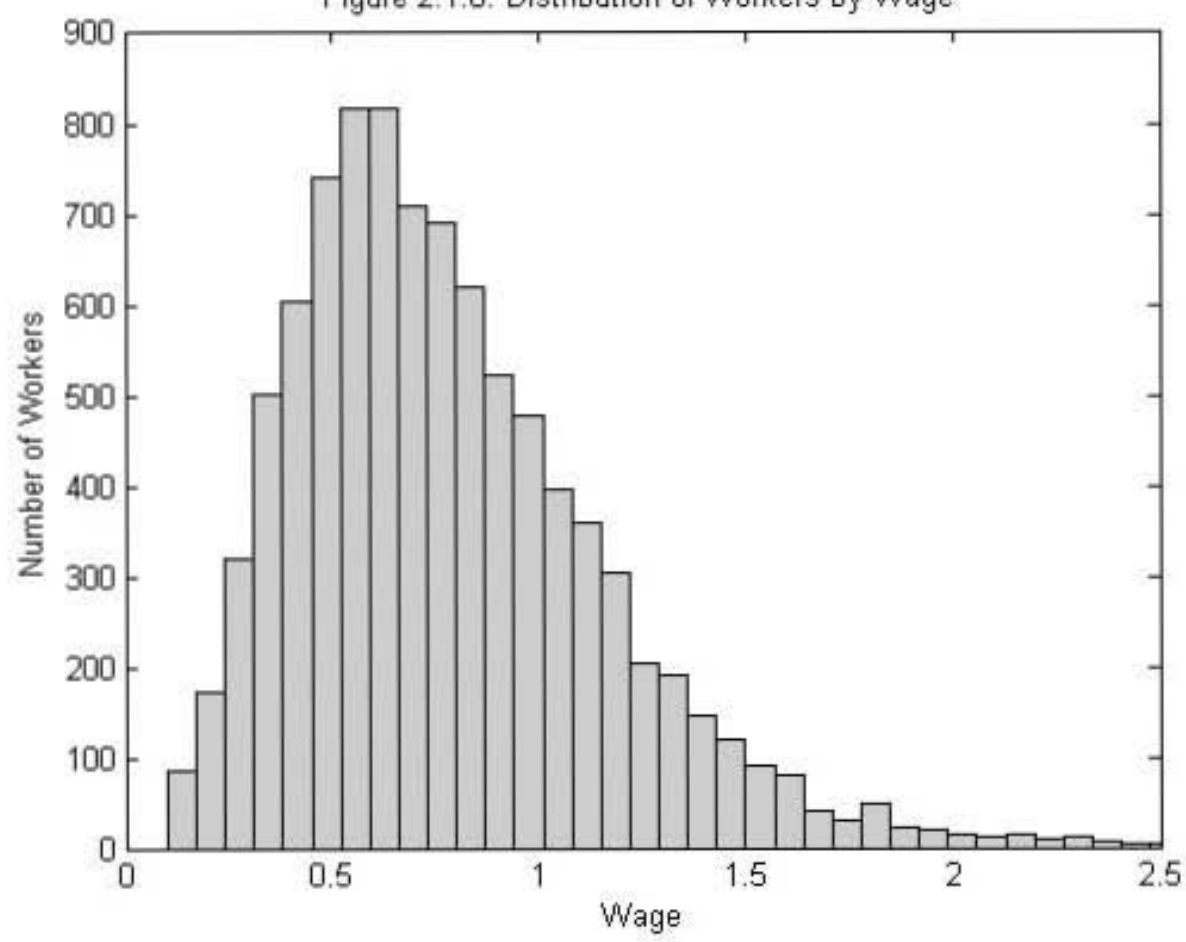


Figure 2.2.1: Non-linear Extrapolation of $\mathrm{C}$

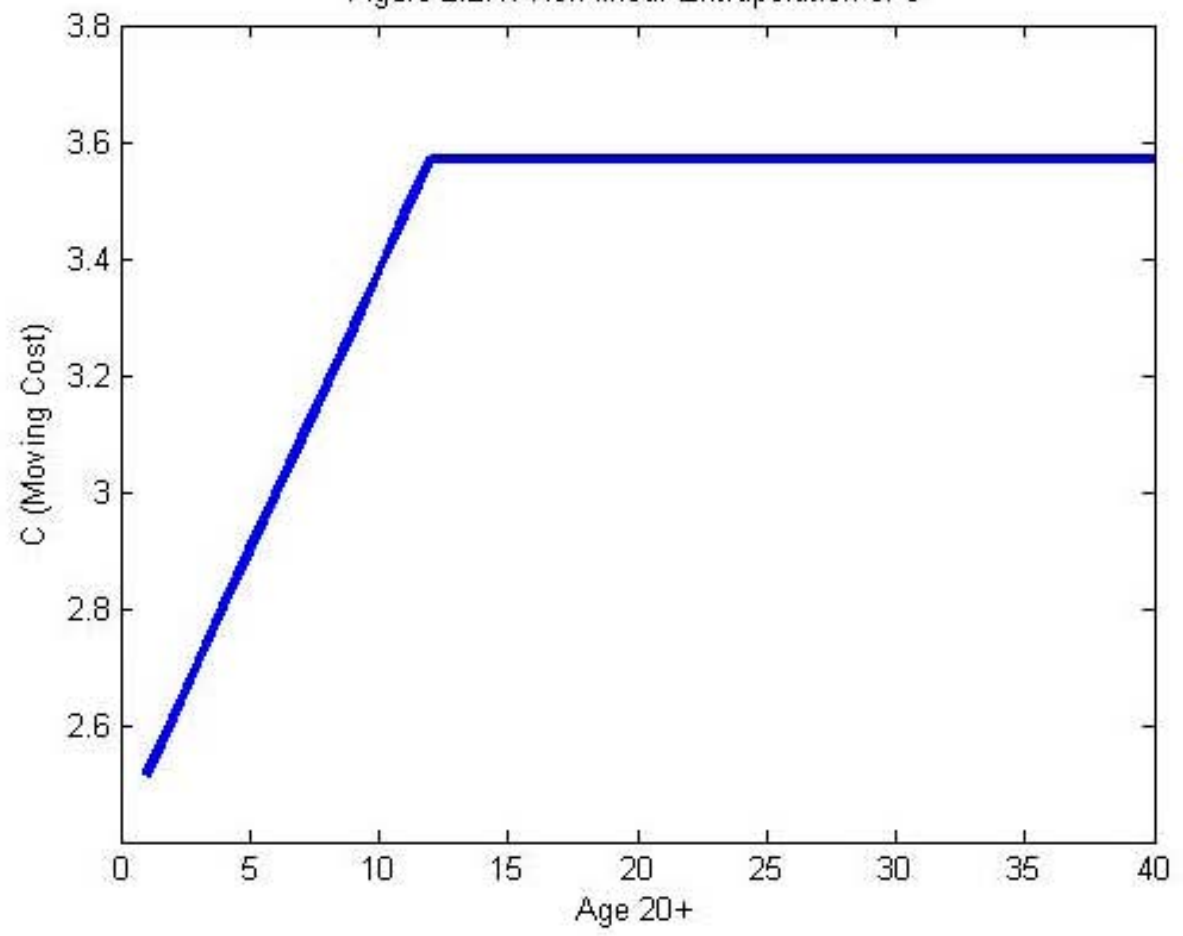

Figure 2.2.2: Goss Flows when $C$ is non-linear

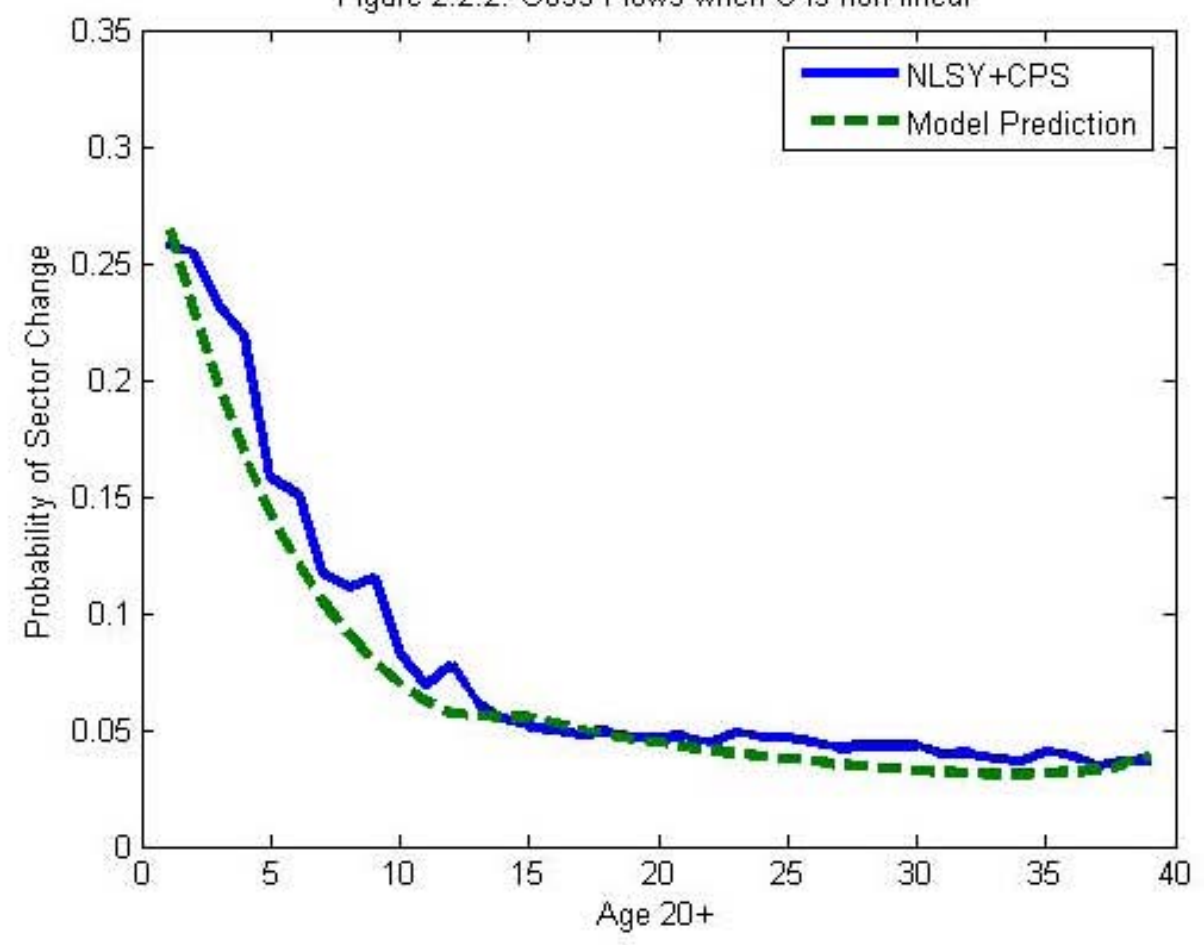


Figure 2.2.3: Linear Extrapolation of $\mathrm{C}$

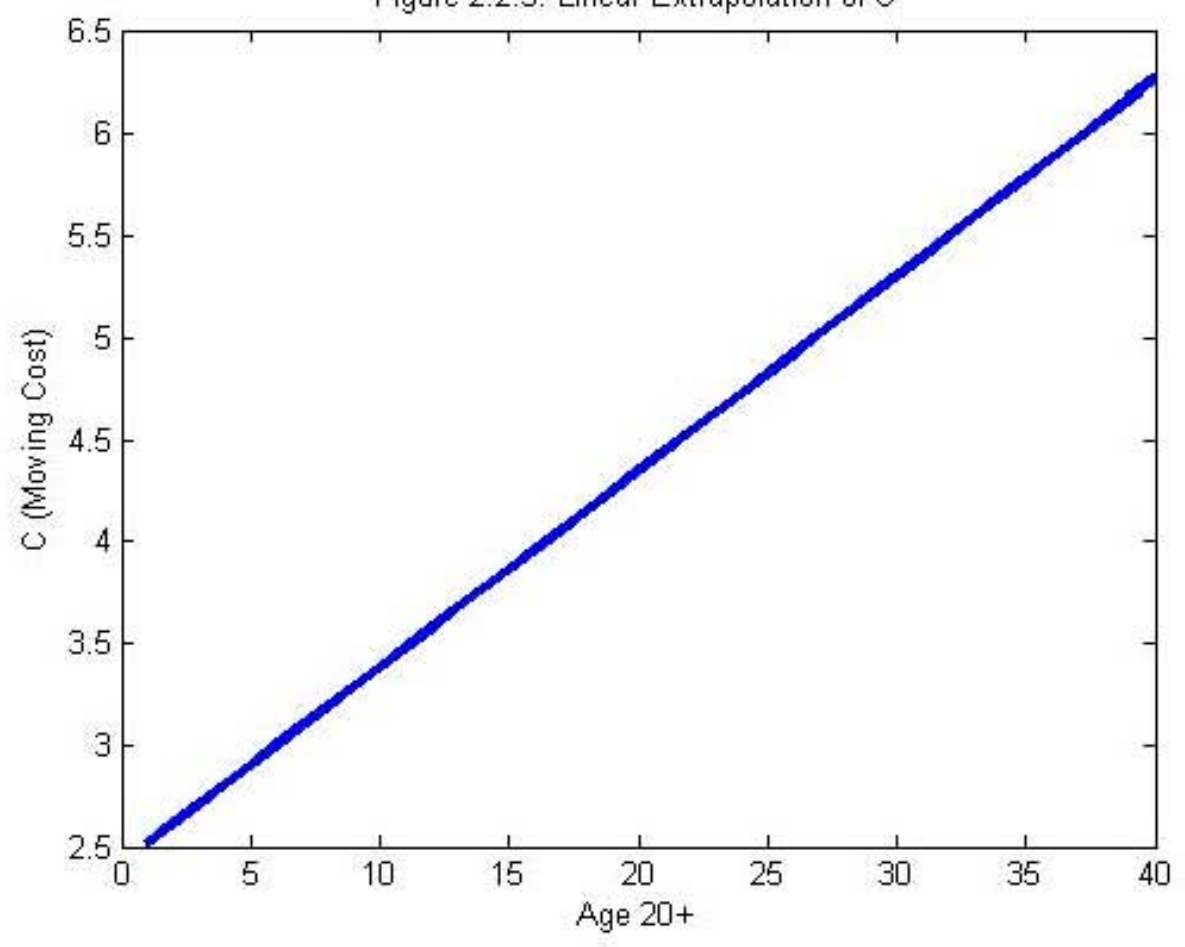

Figure 2.2.4: Gross Flows when $C$ is linear

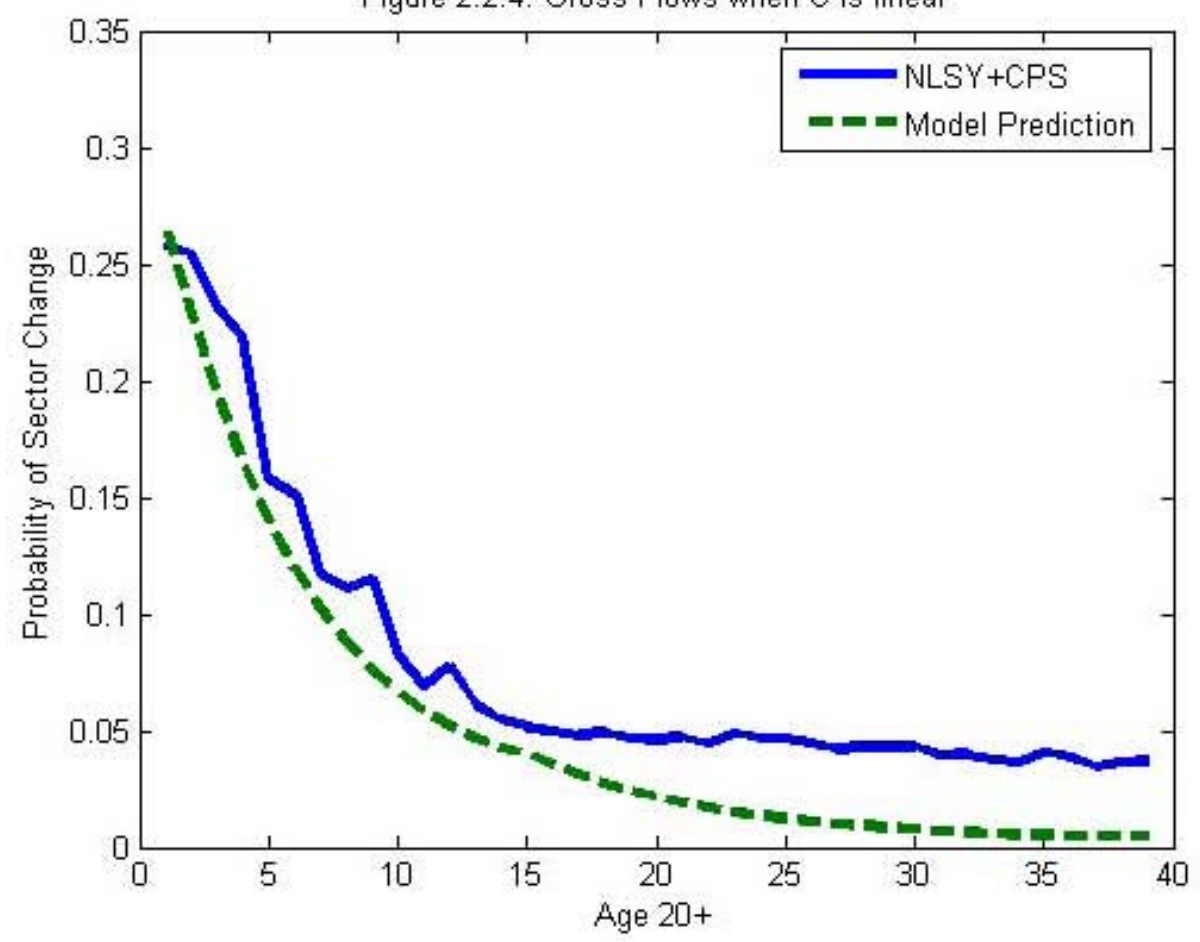



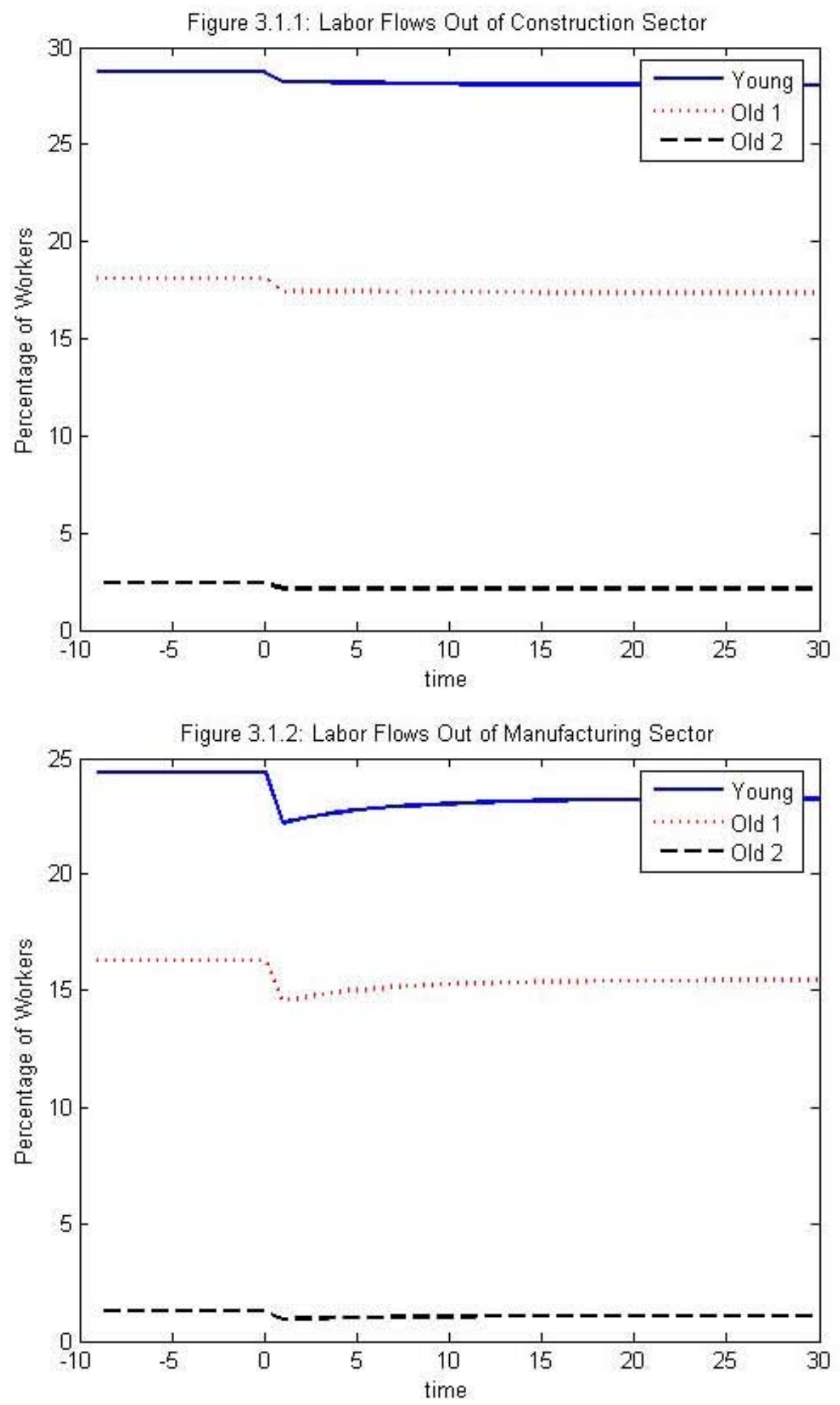


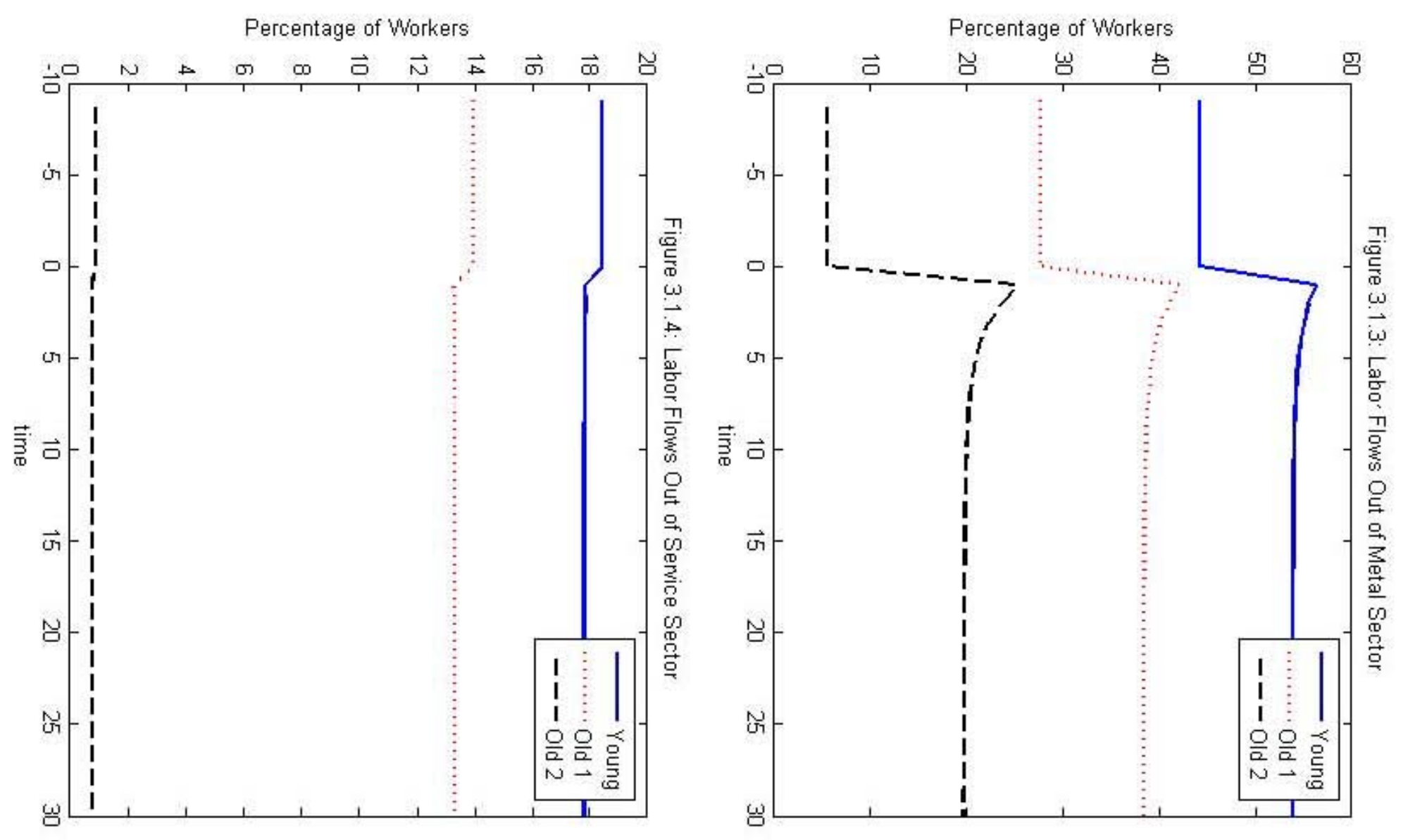


Figure 3.1.5: Labo Flows Out of Trade Sector

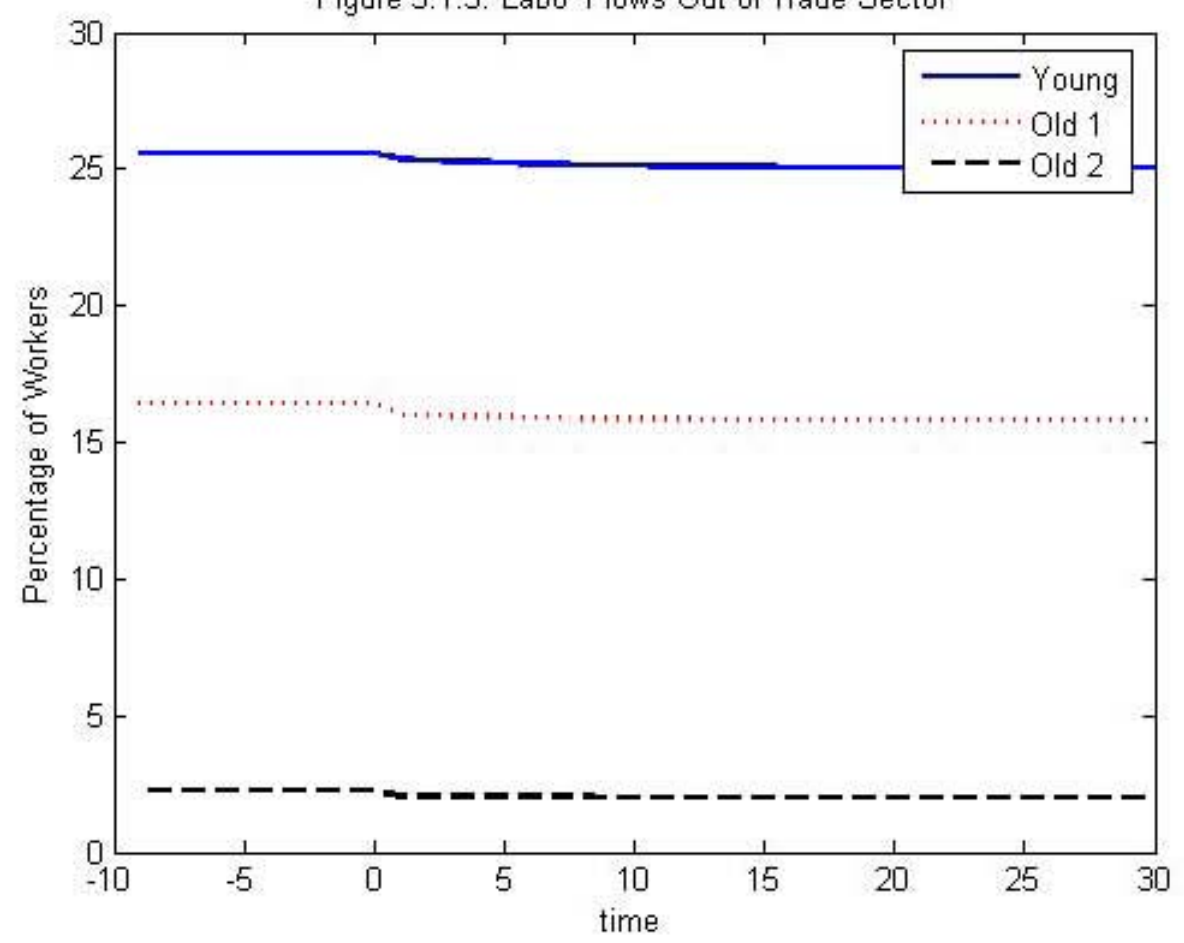

Figure 3.1.6: Labor Flows Out of Non-Market Sector

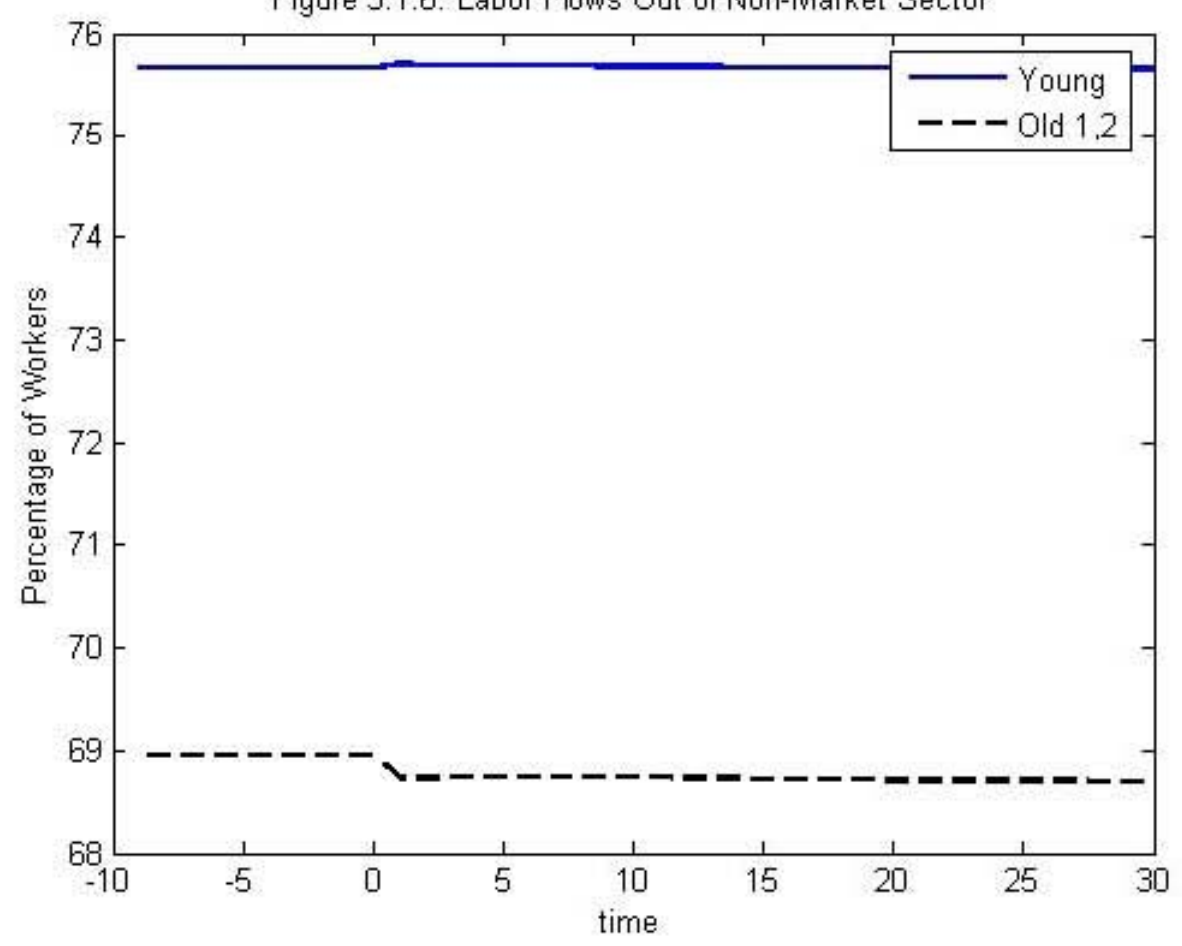



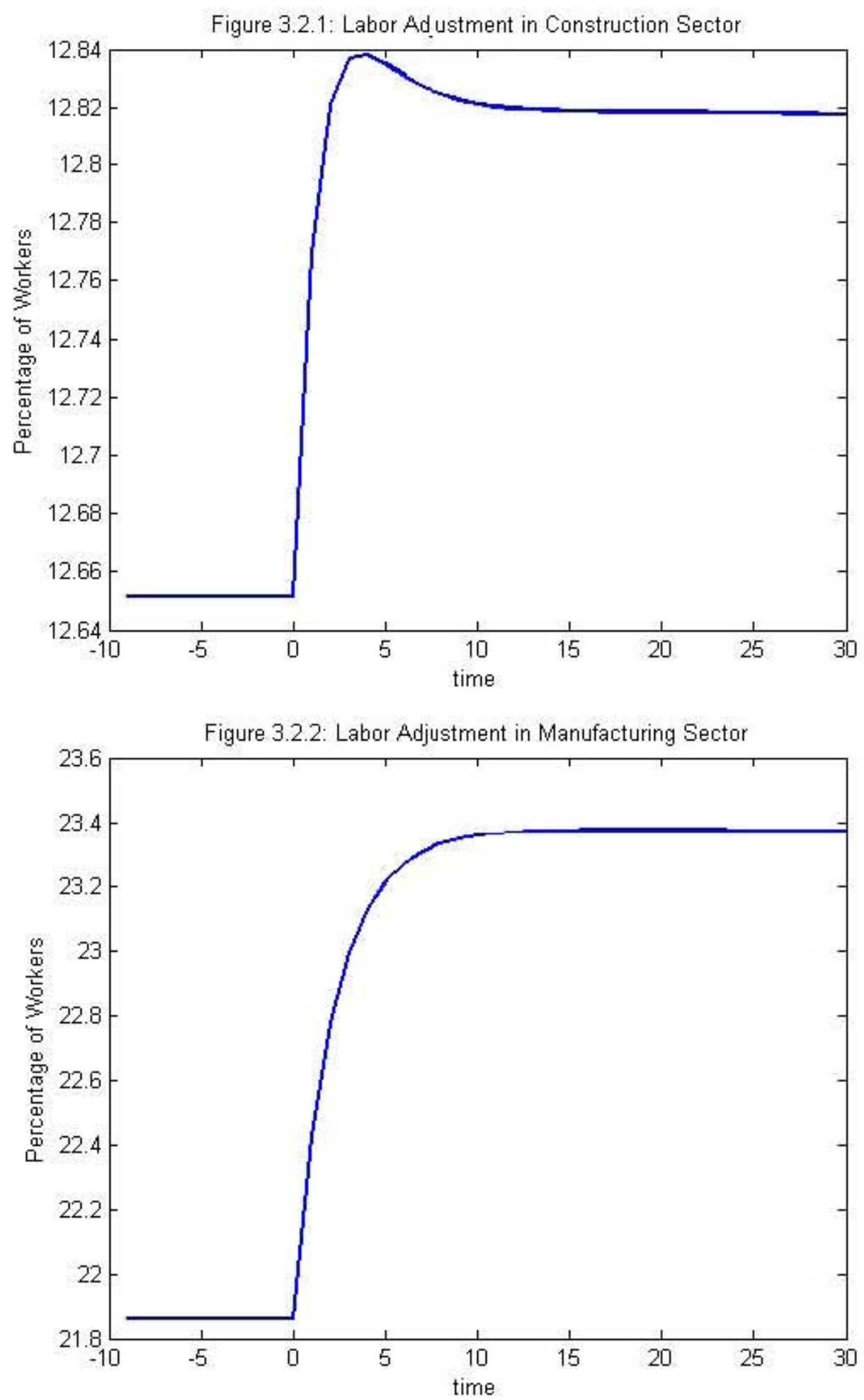


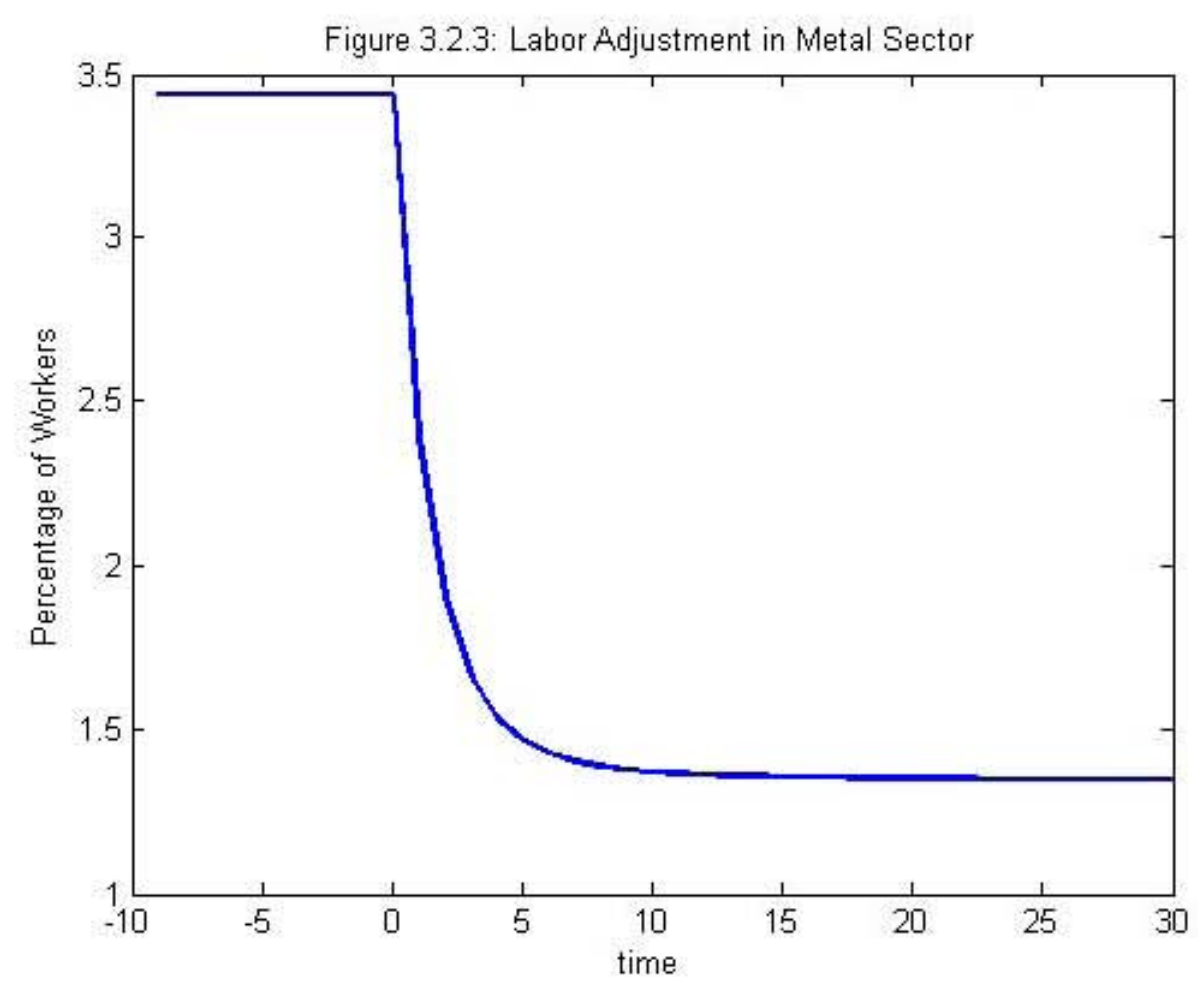

Figure 3.2.4: Labor Adjustment in Service Sector

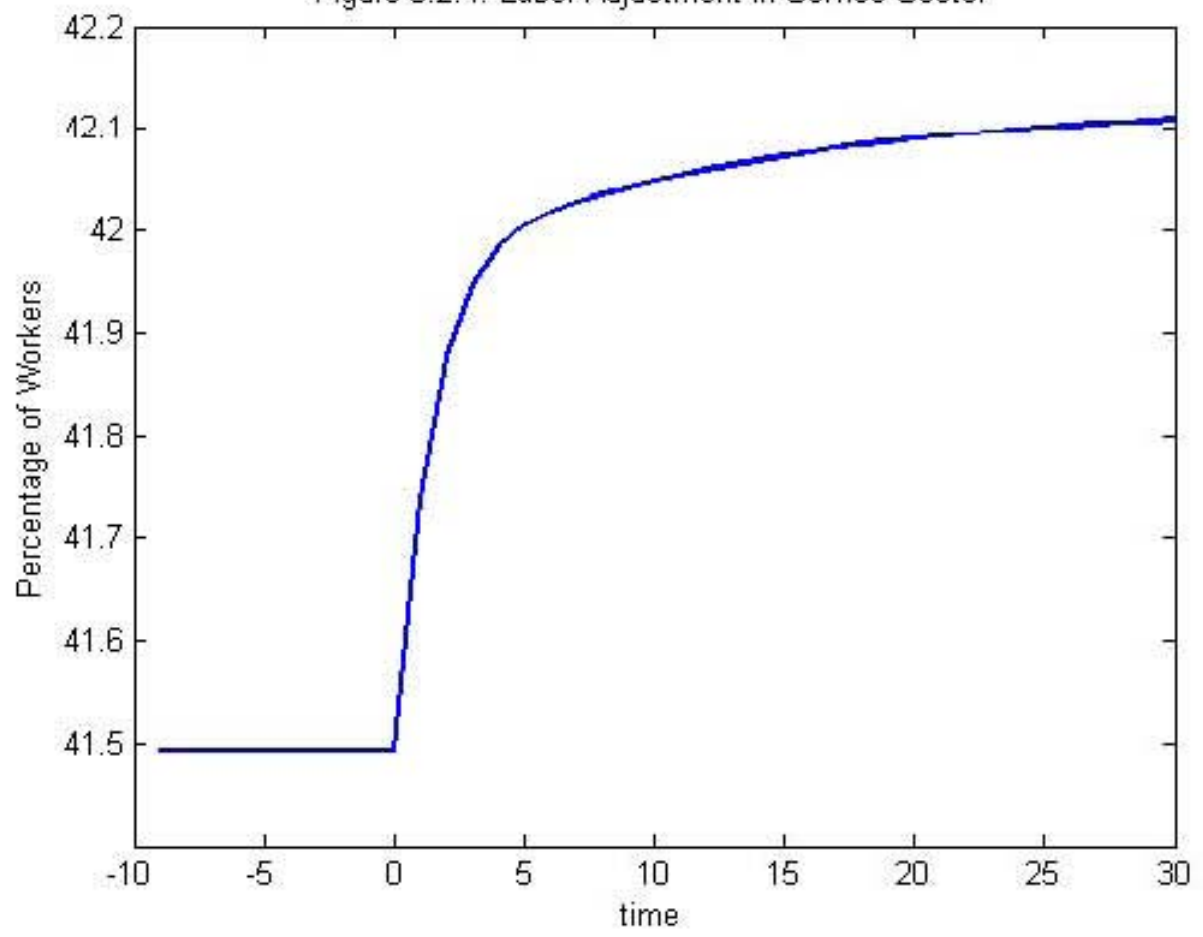




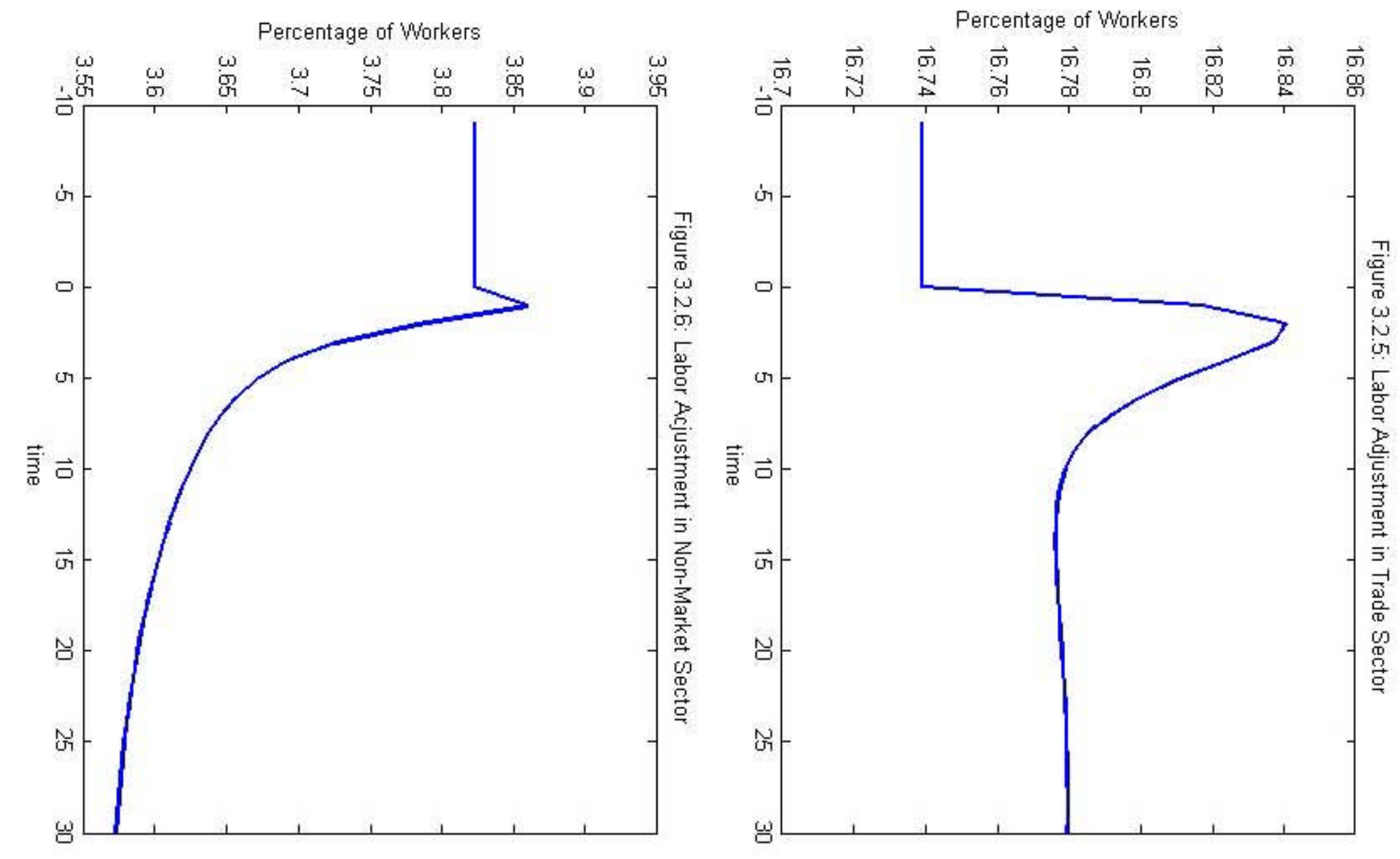



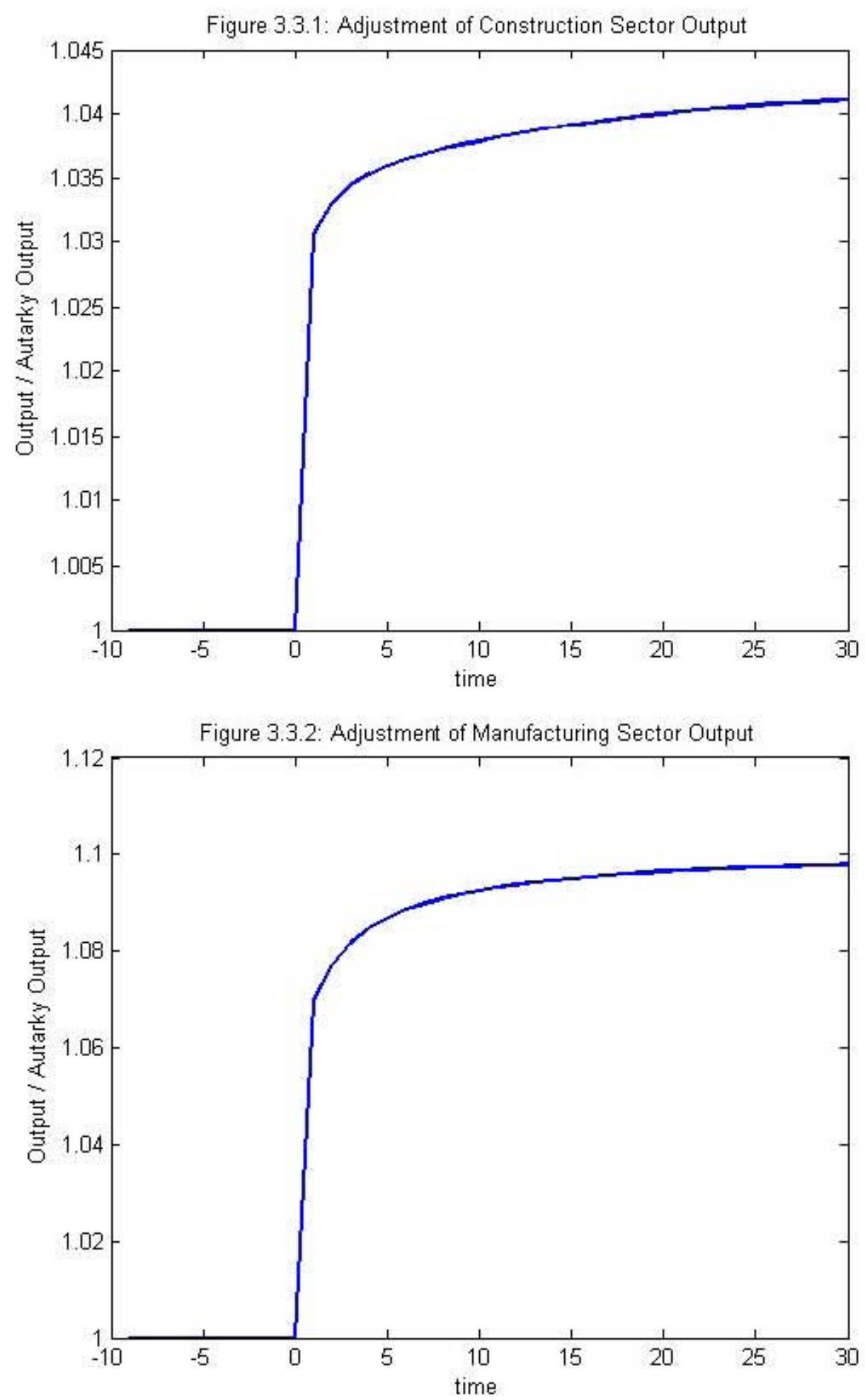
Figure 3.3.3: Adjustment of Metal Sector Output

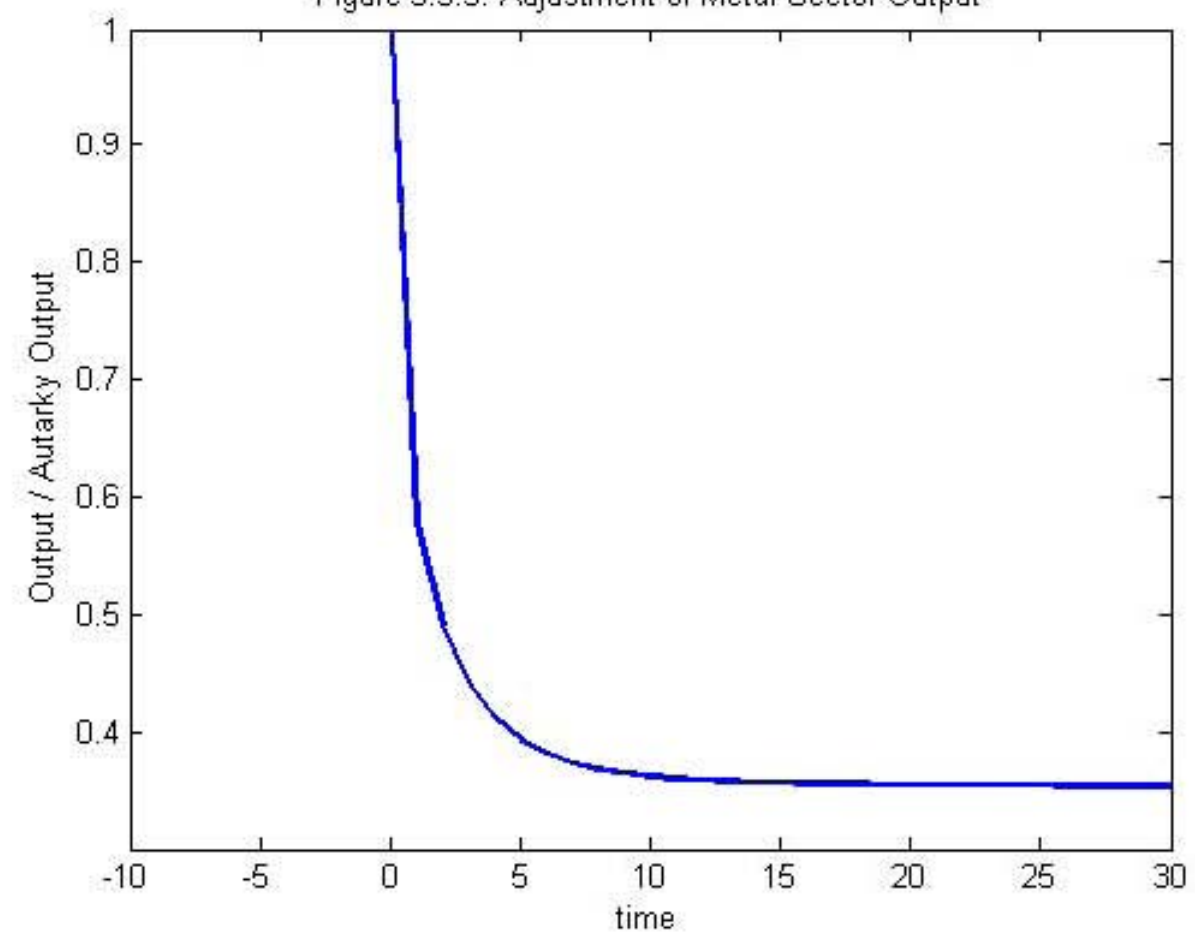

Figure 3.3.4: Adjustment of Service Sector Output

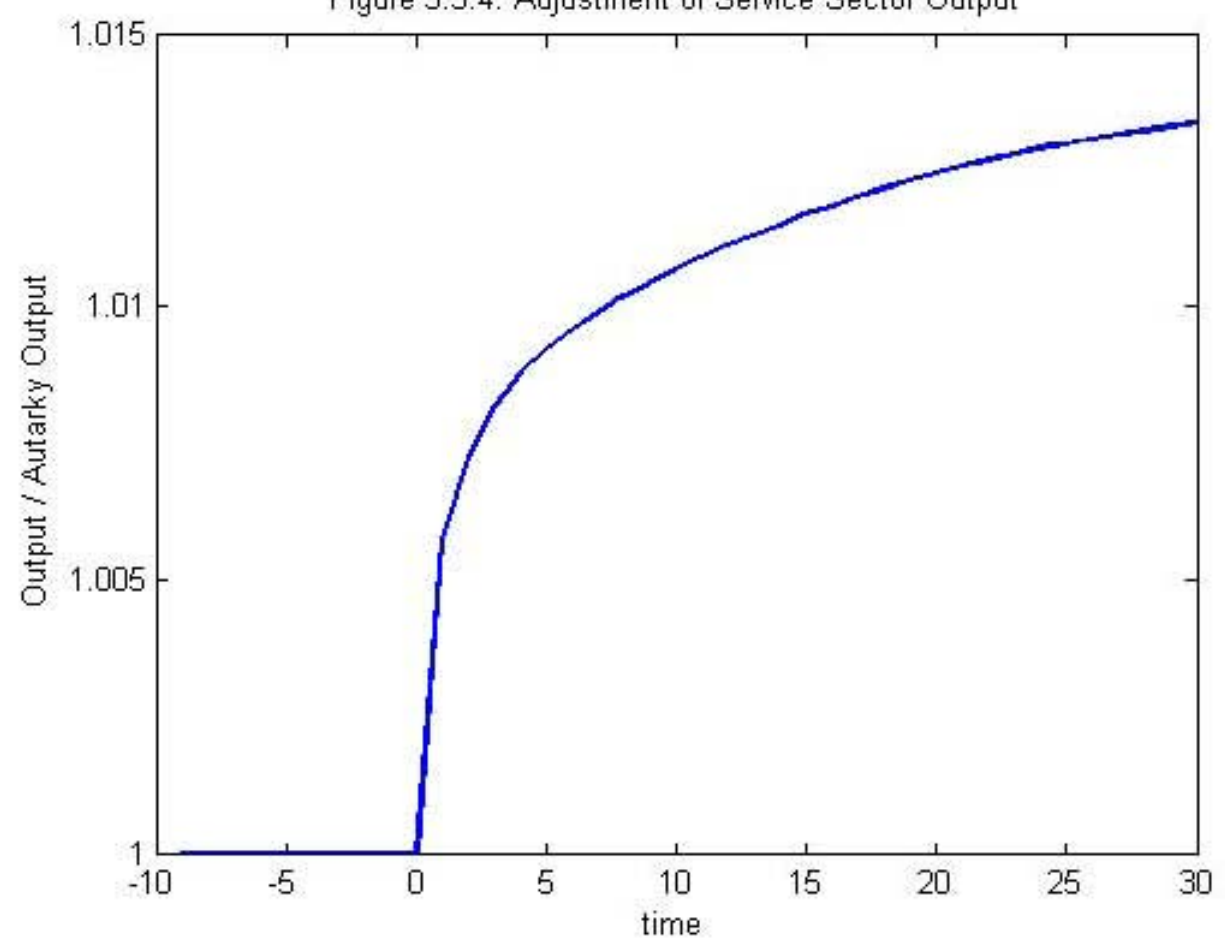



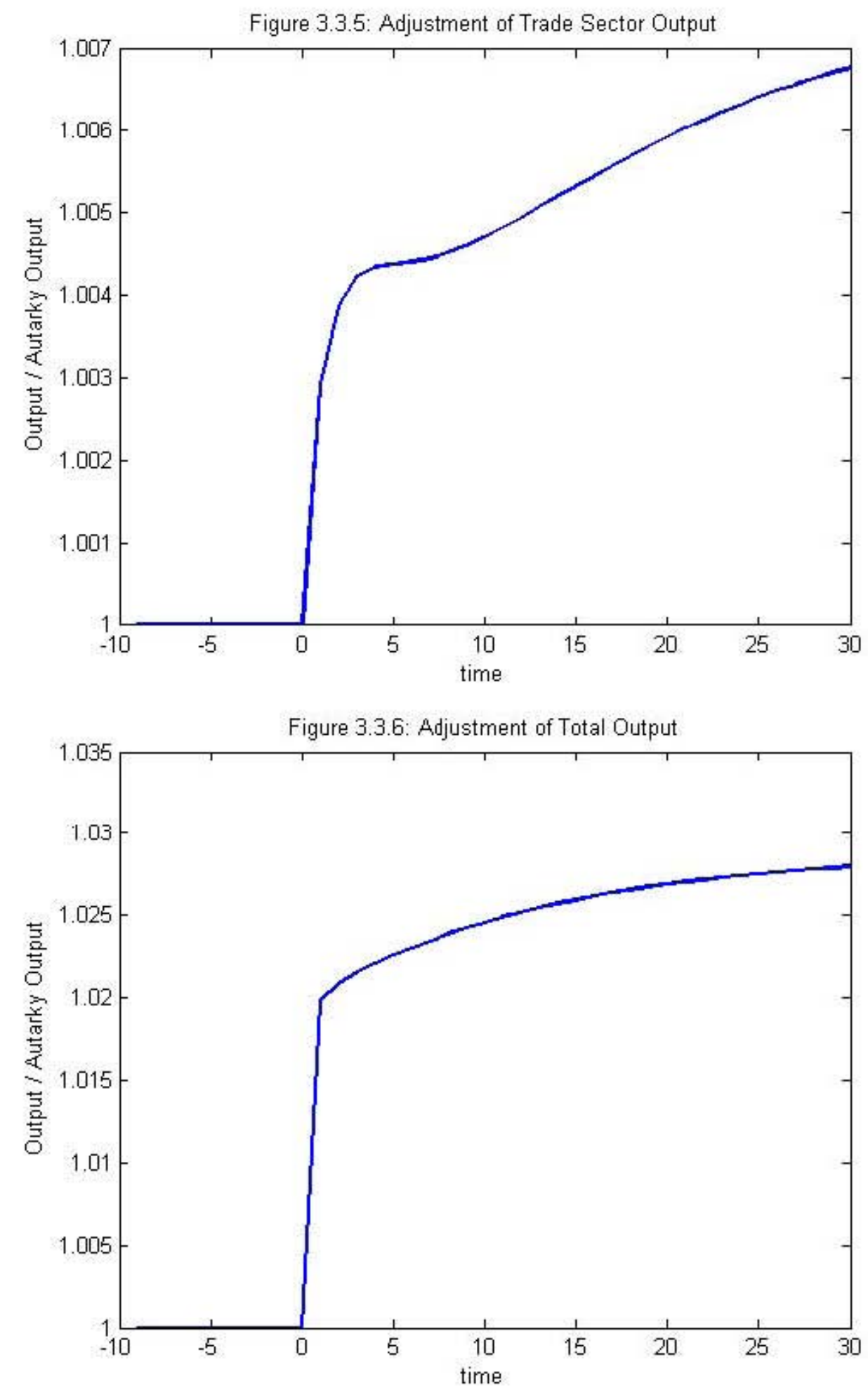


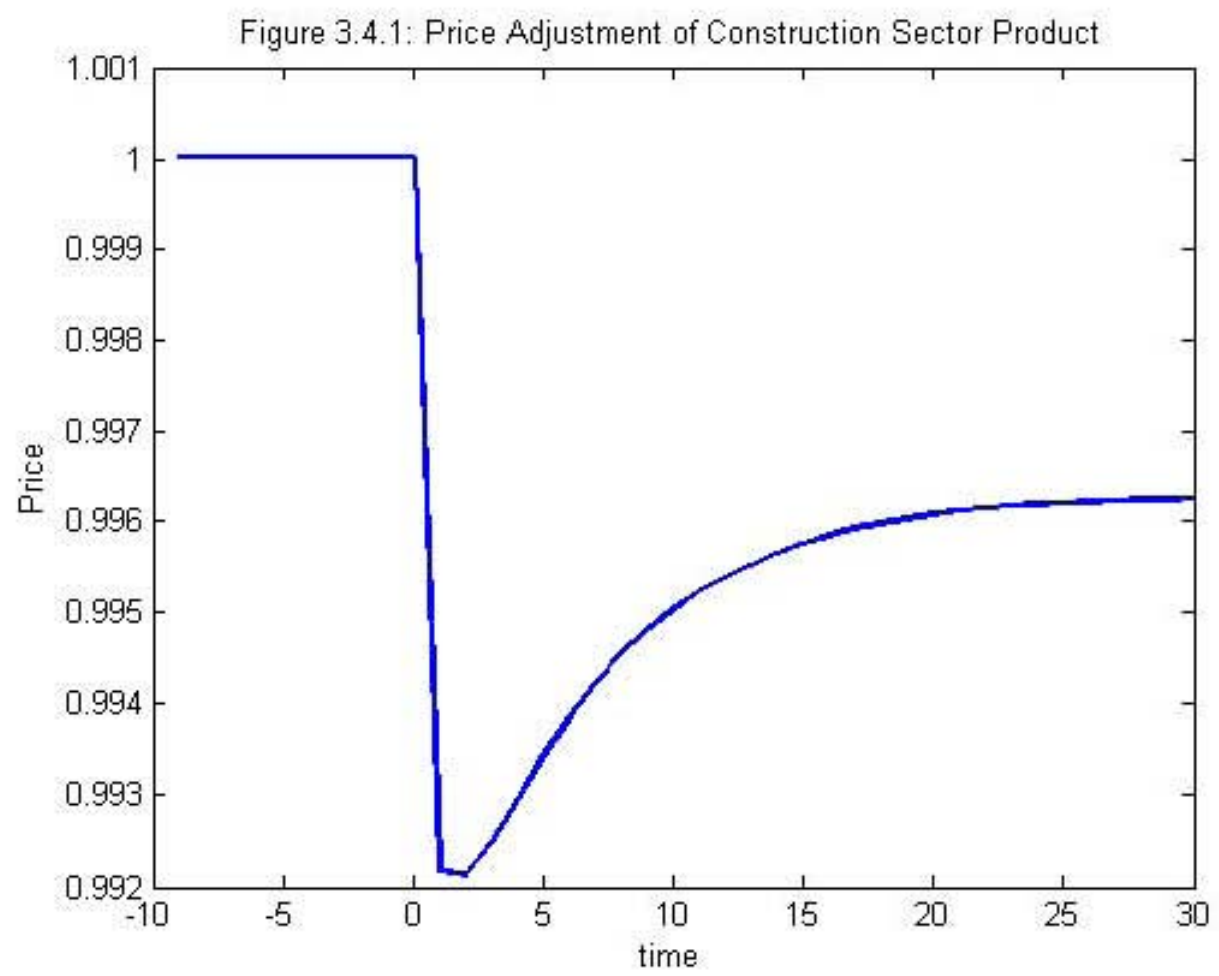

Figure 3.4.2: Price Adjustment of Manufacturing Sector Product

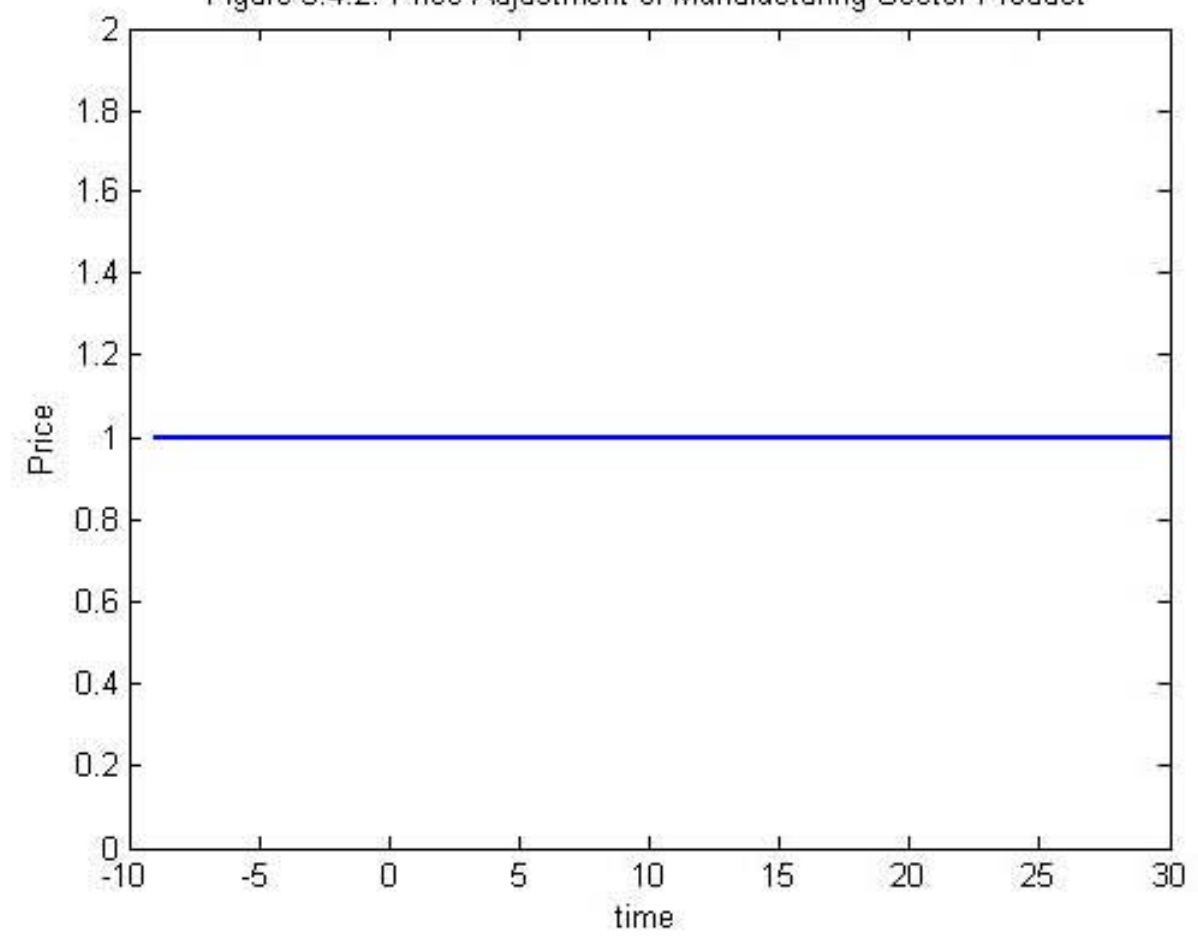



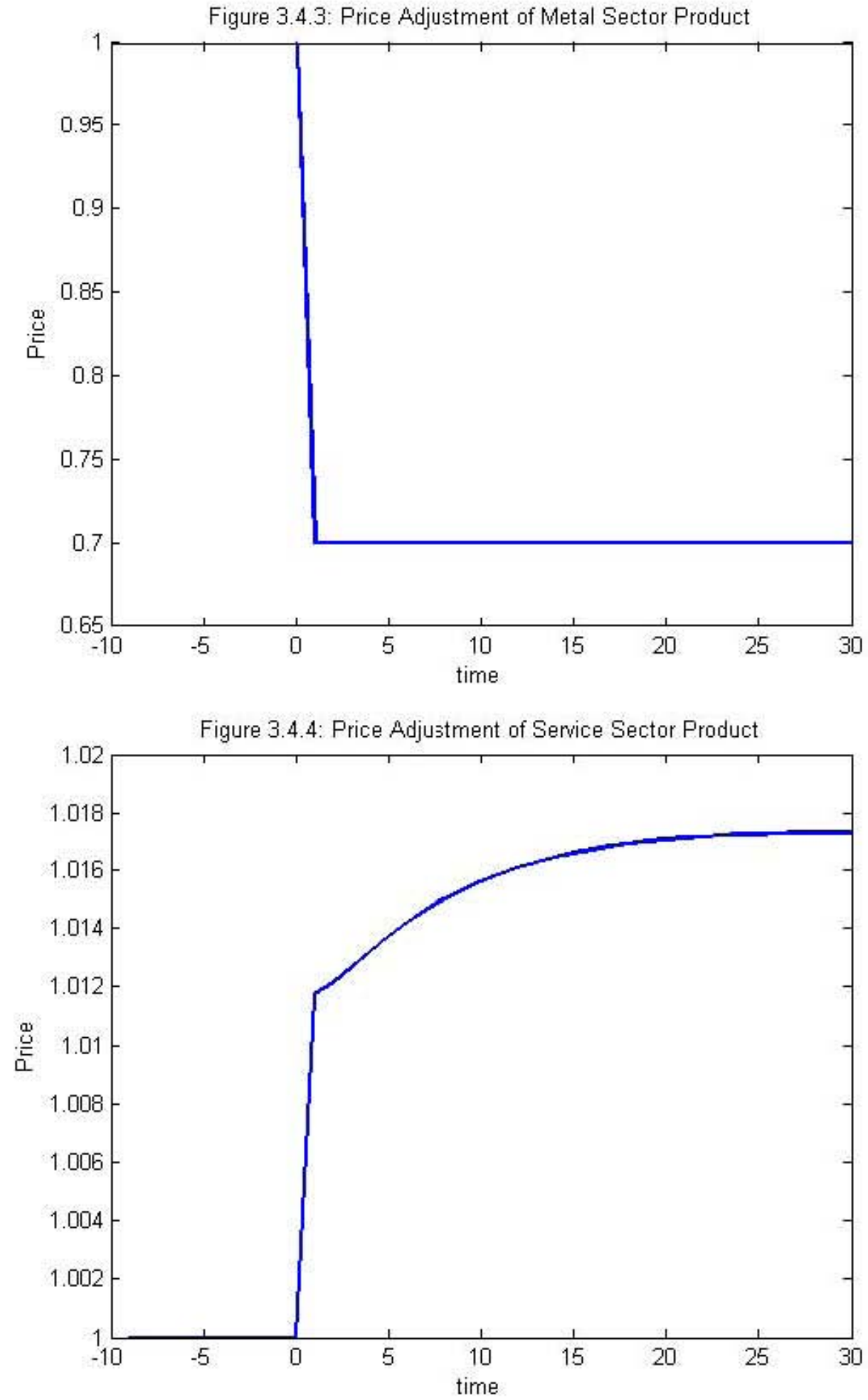

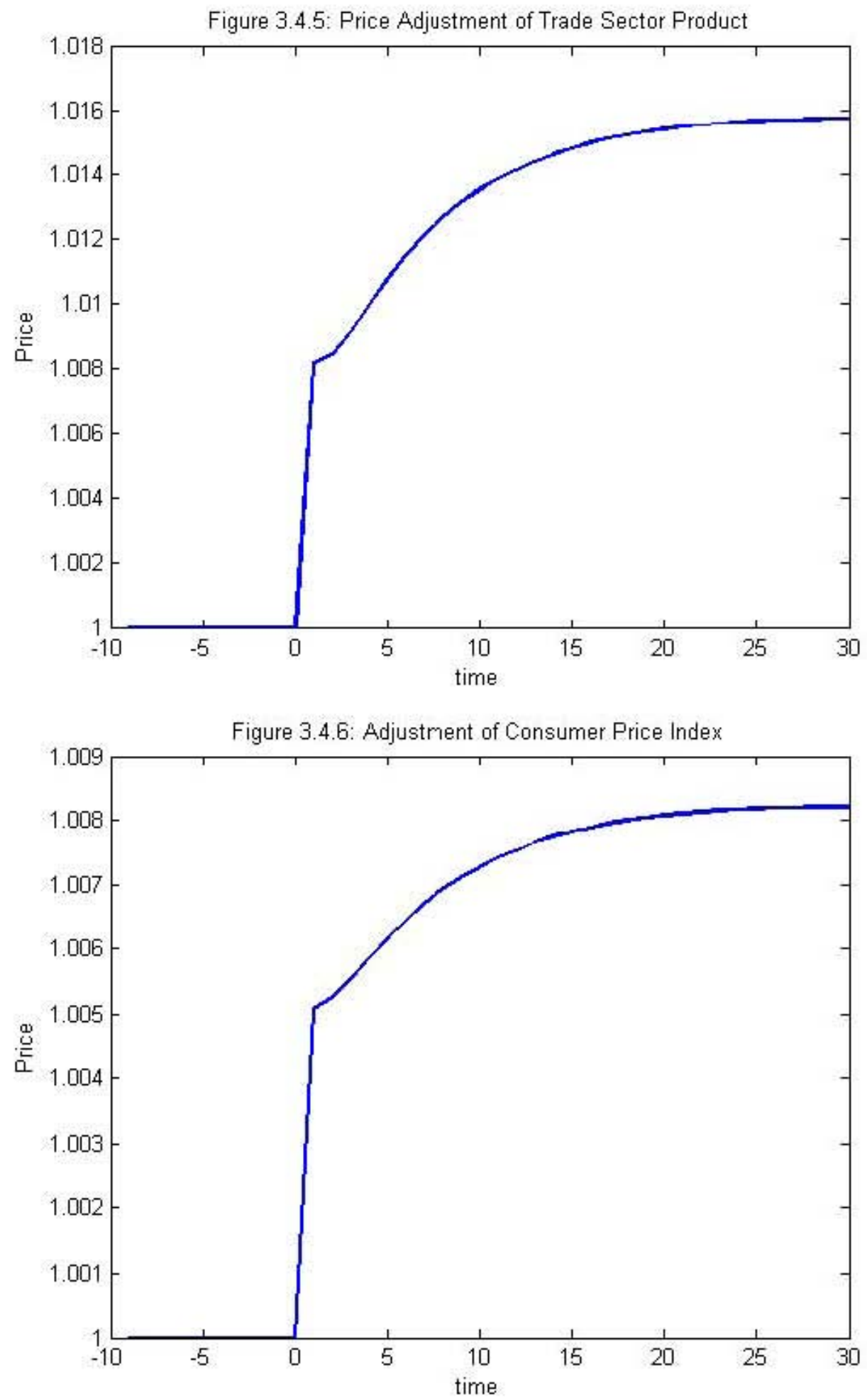

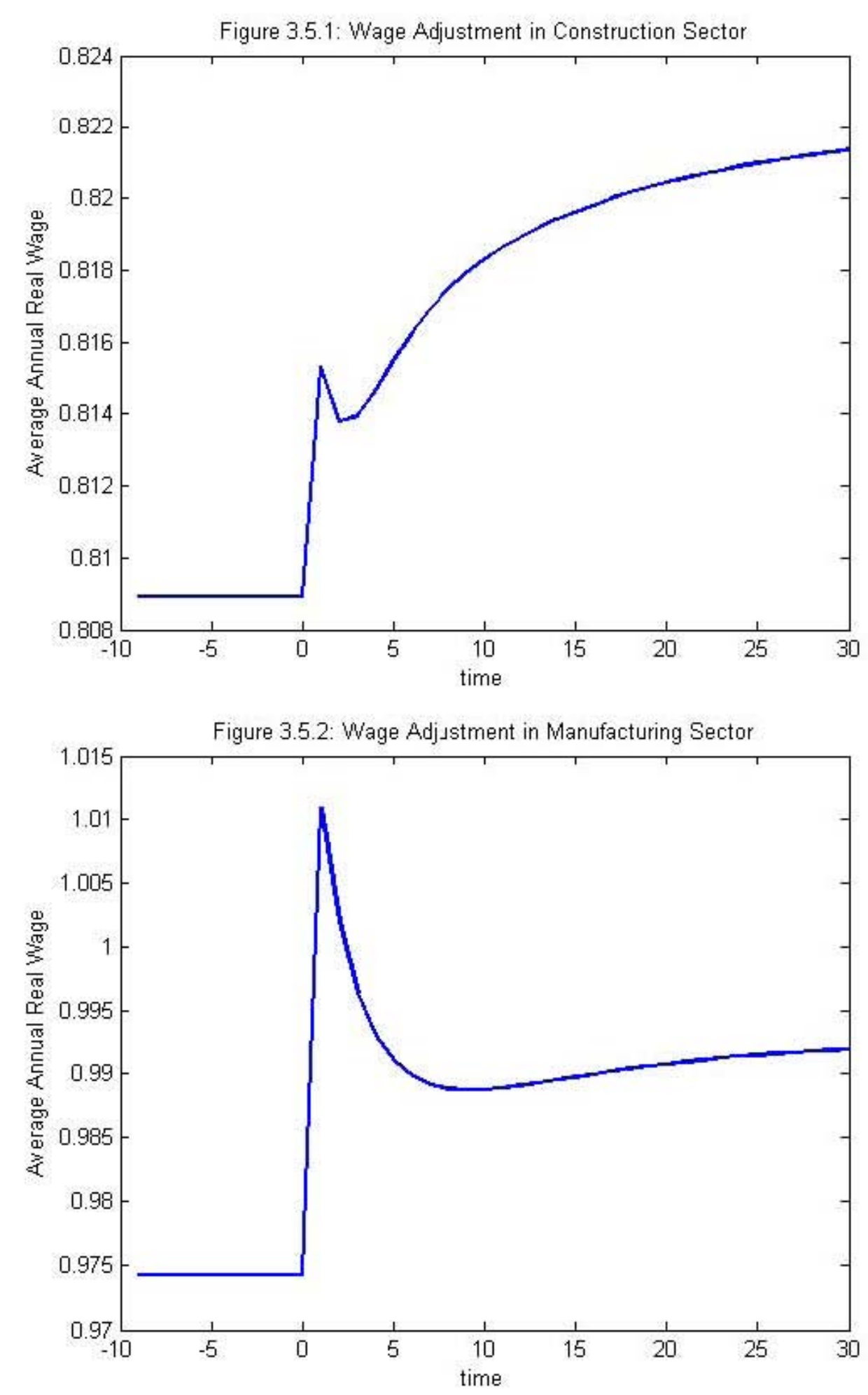


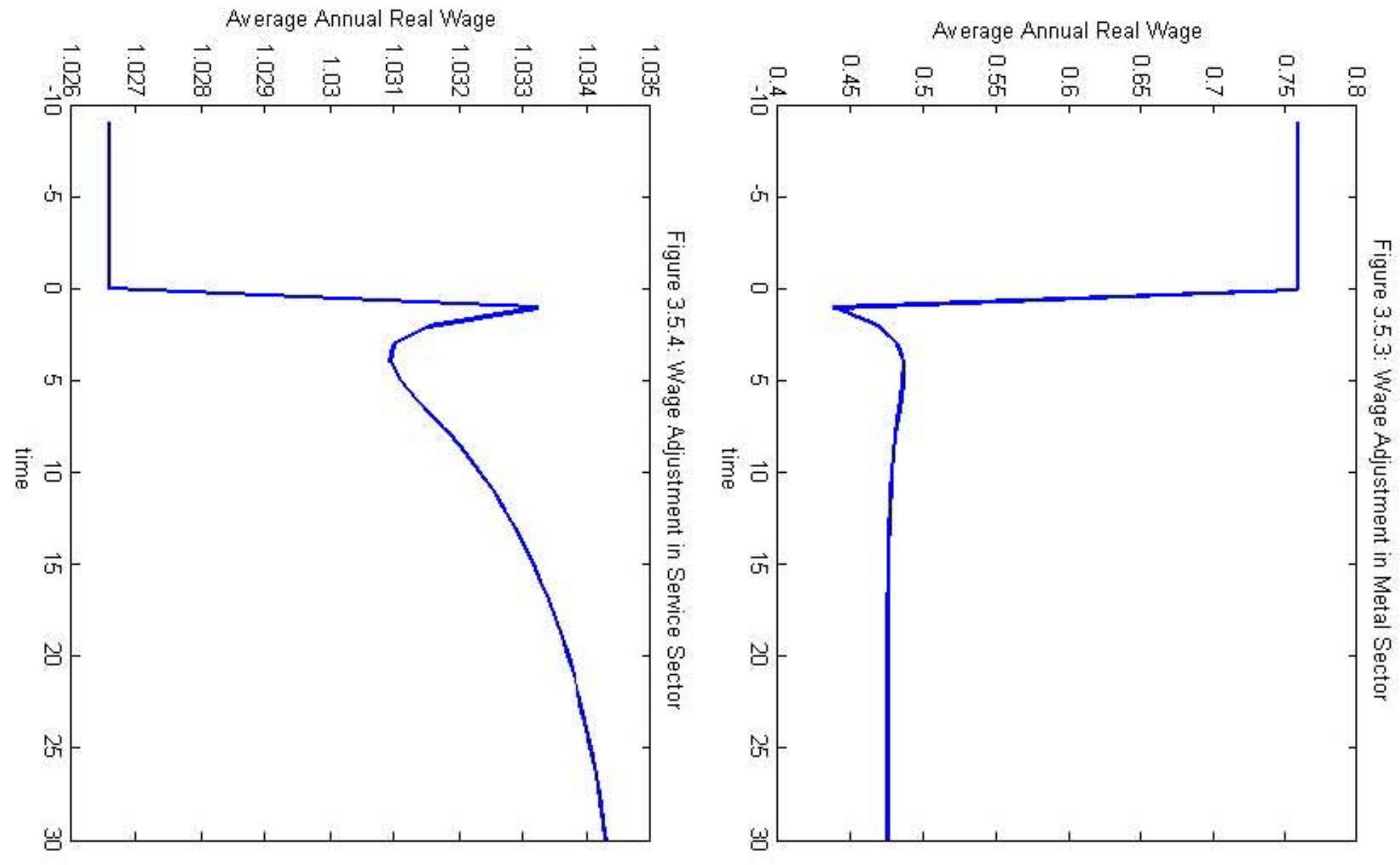




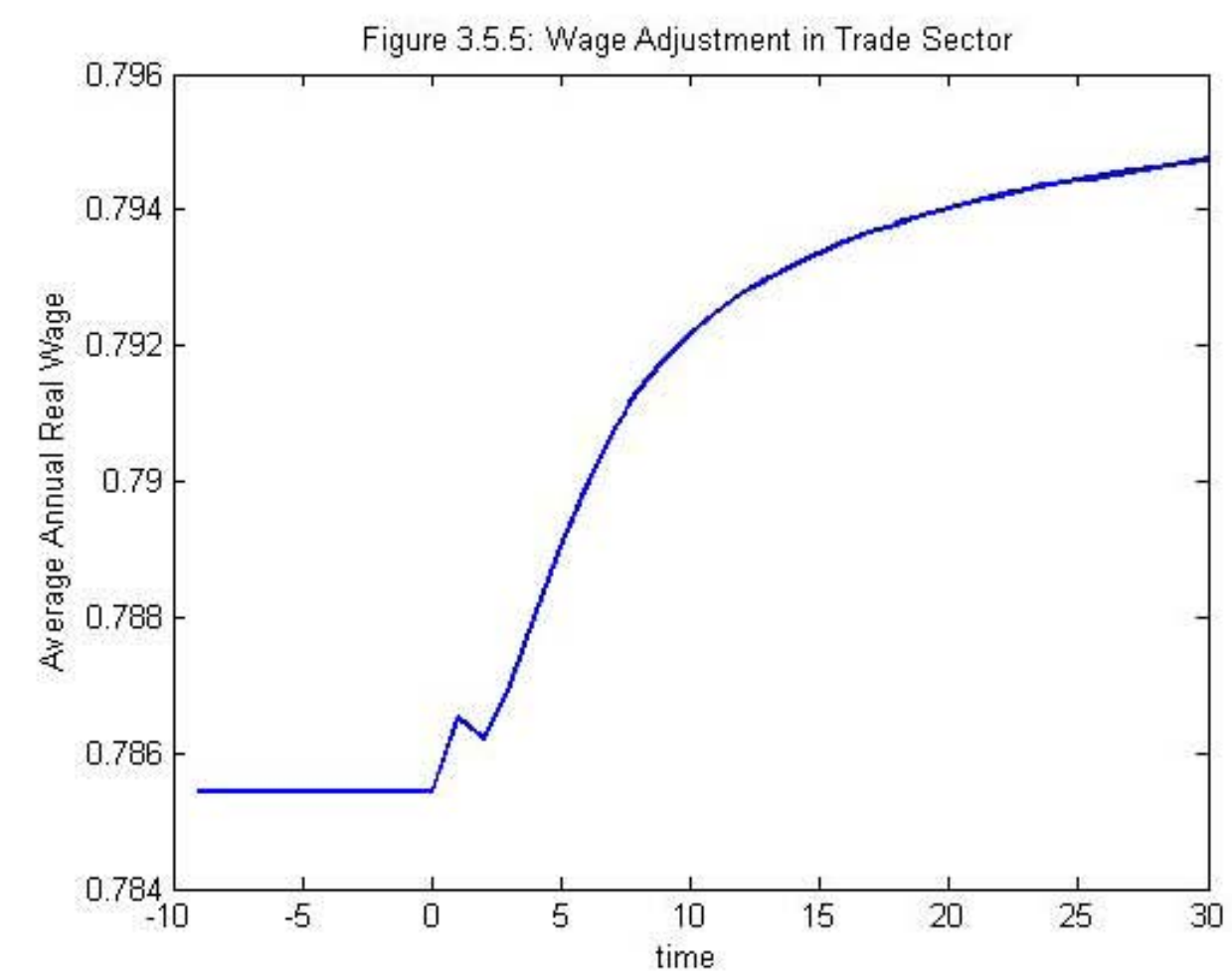

Figure 3.6.1: Change in Value of Construction Workers

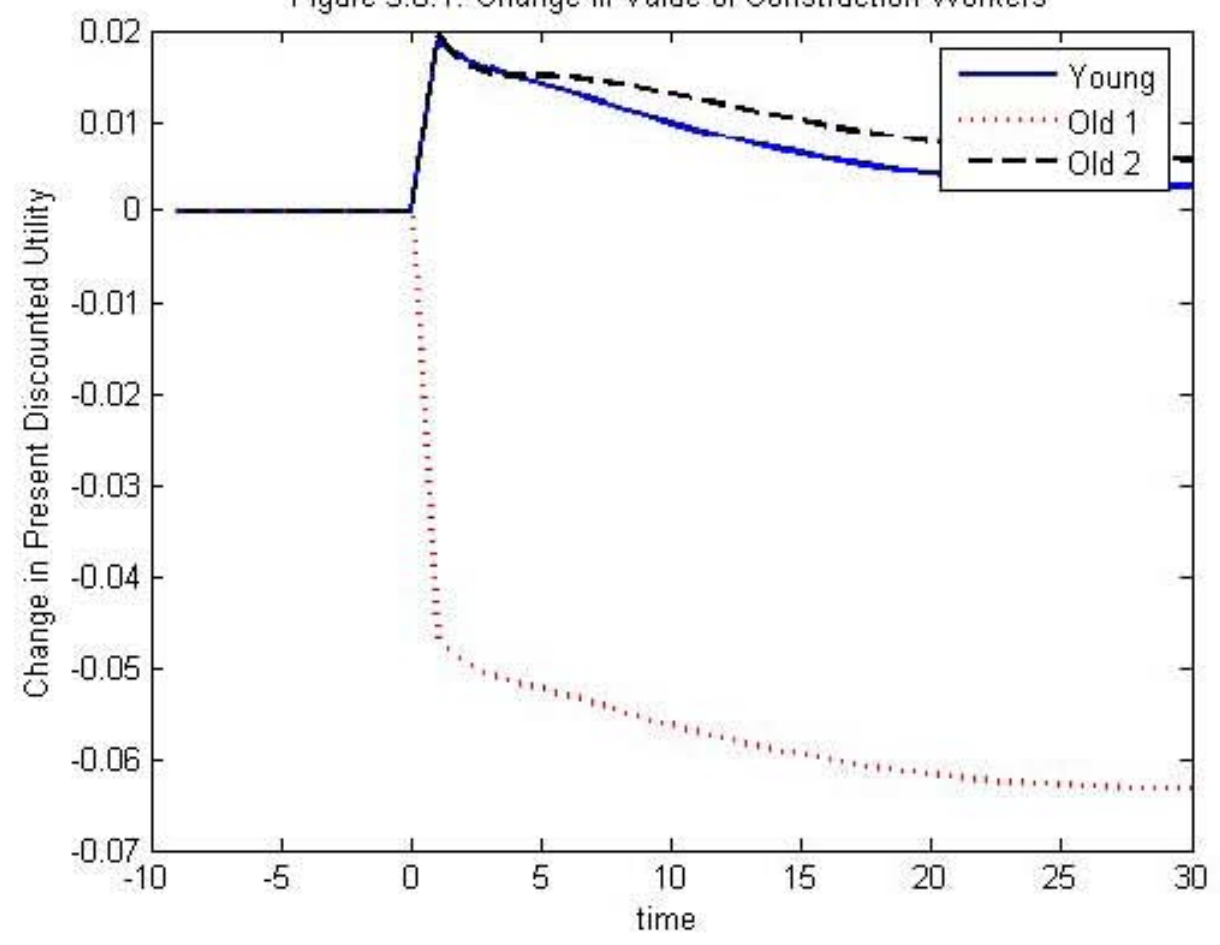




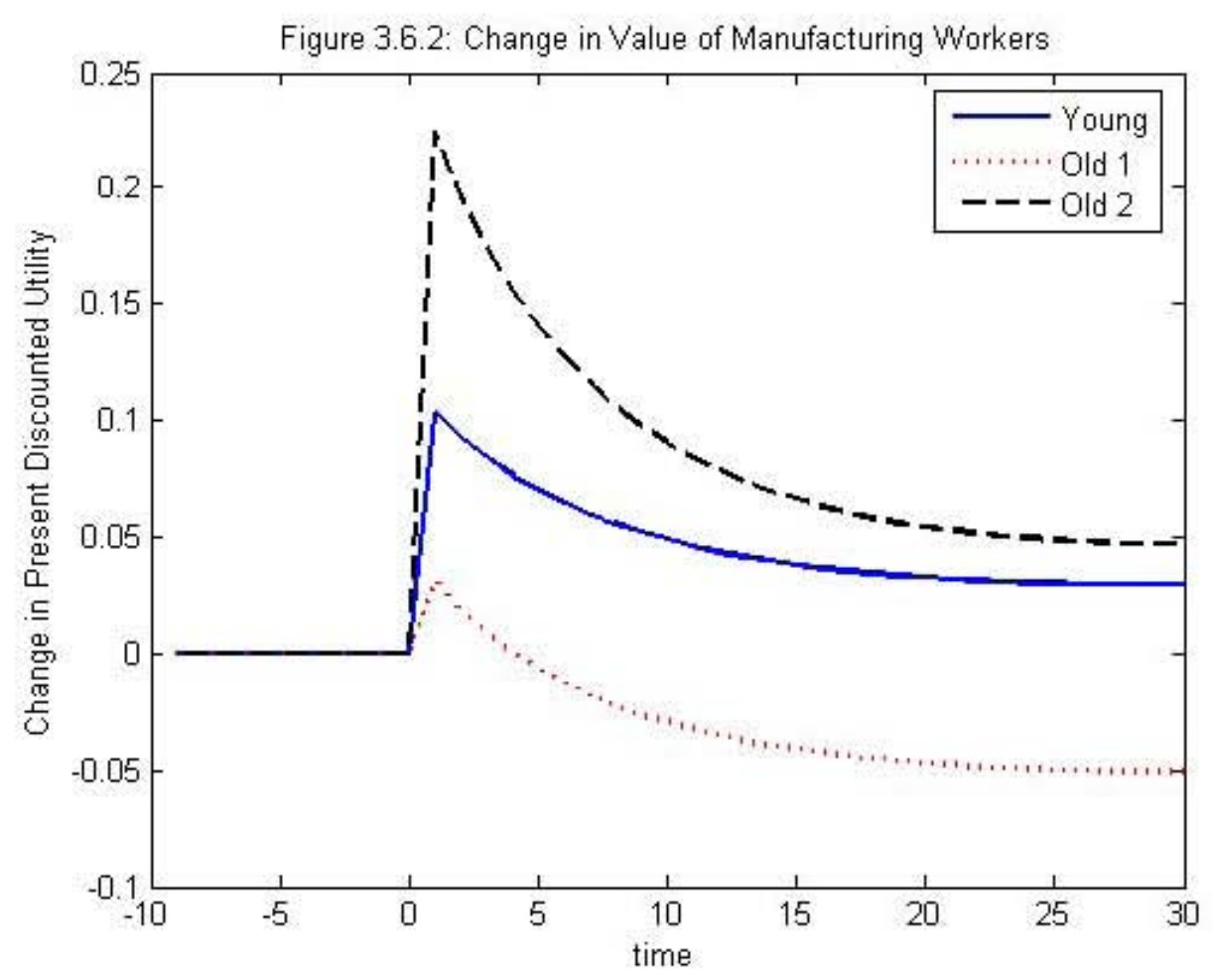

Figure 3.6.3: Chançe in Value of Metal Workers

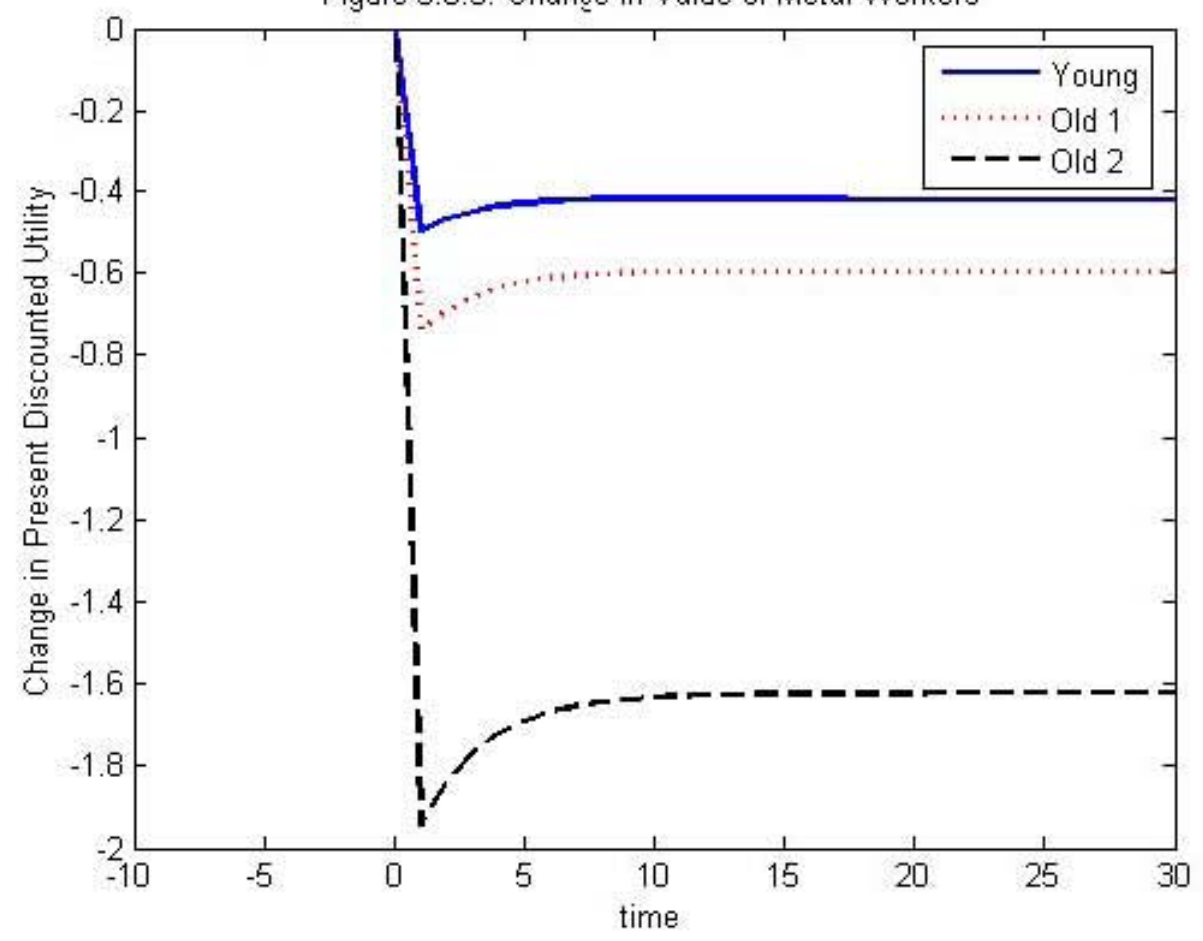




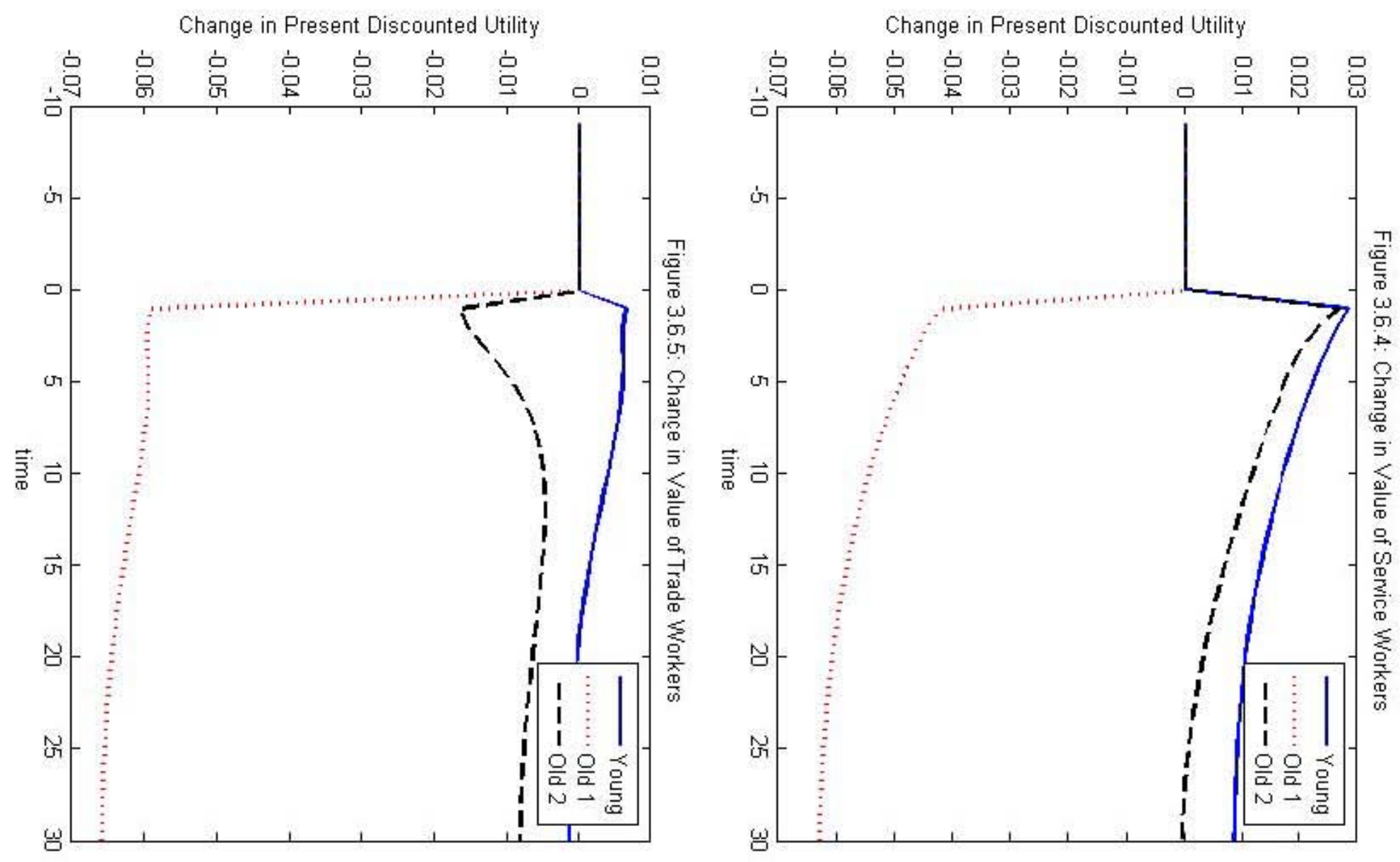


Figure 3.6.6: Change in Value of Non-Market Workers

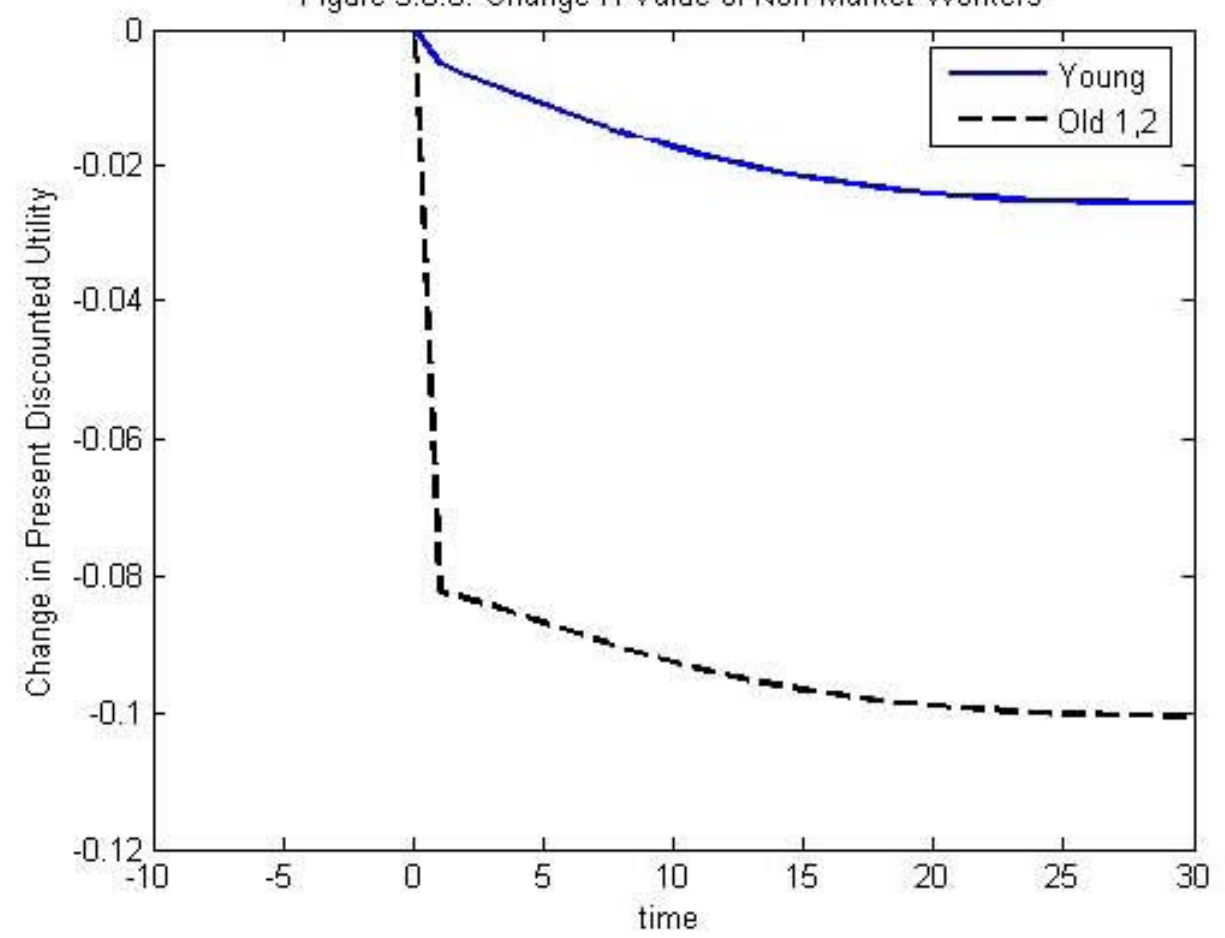

Figure 3.7.1: Change in Value of Construction Workers after Free Trade

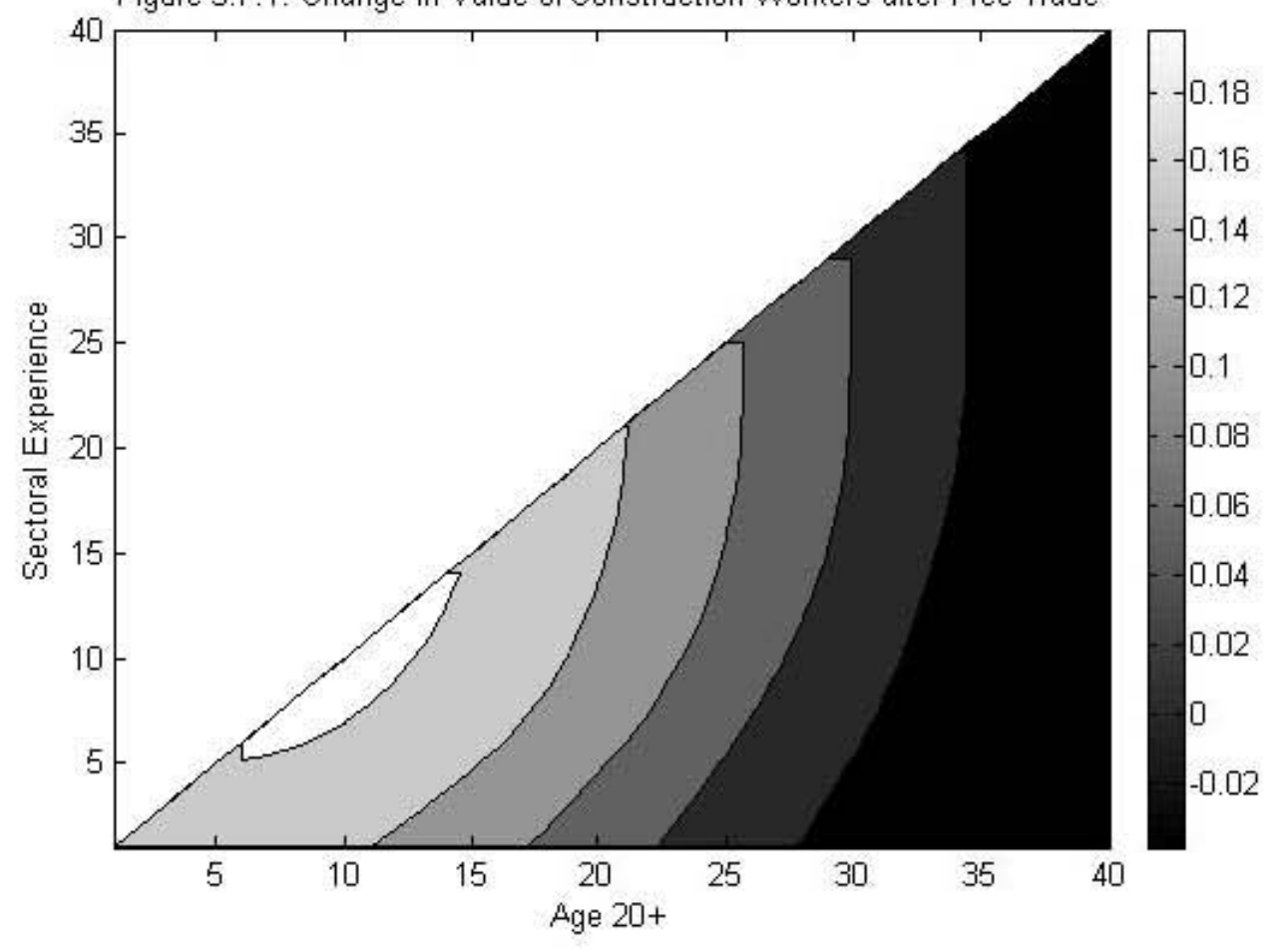


Figure 3.7.2: Change in Value of Manufacturing Workers after Free Trade

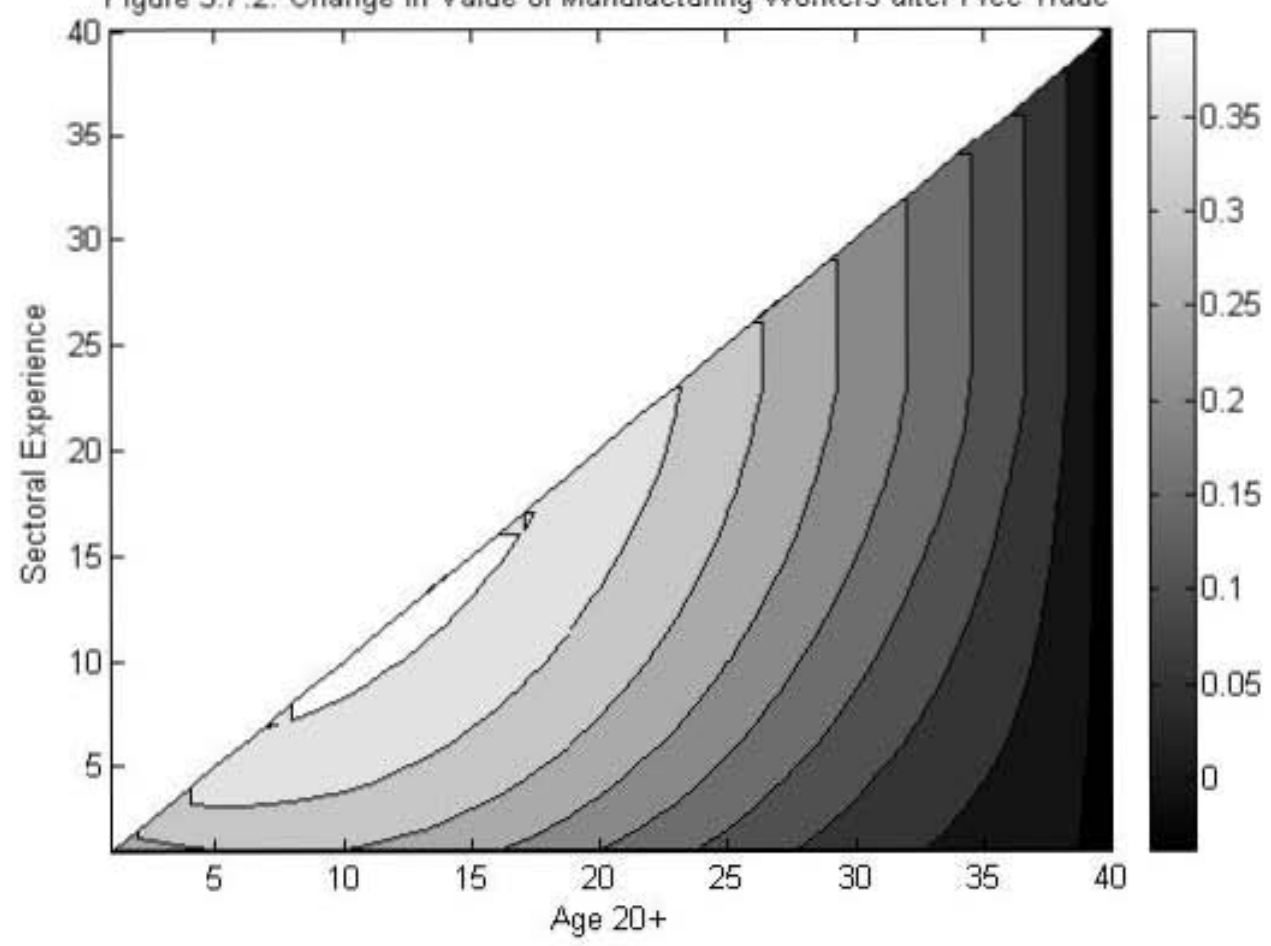

Figure 3.7.3: Change in Value of Metal Workers after Free Trade

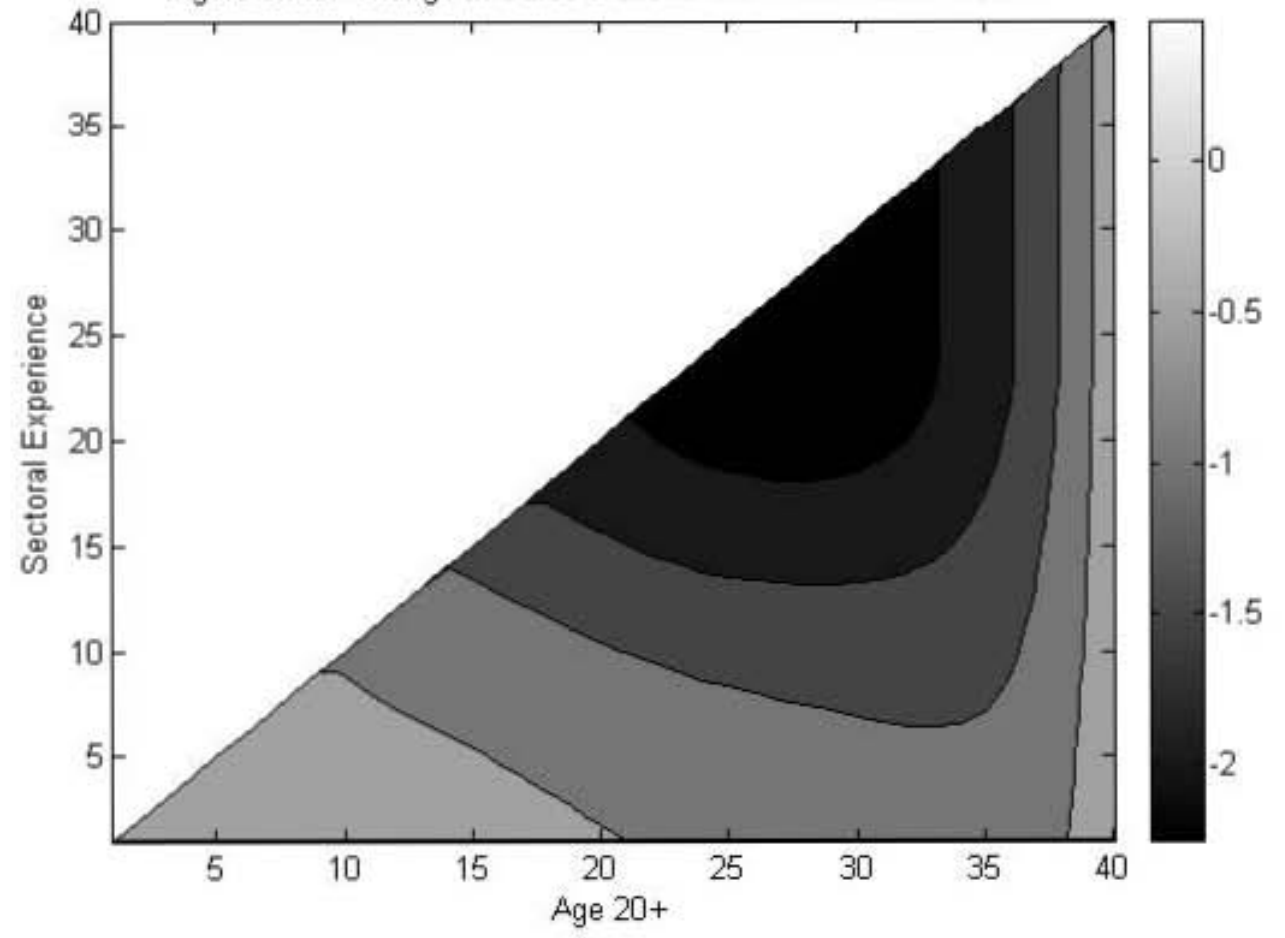


Figure 3.7.4: Change in Value of Service Workers after Free Trade

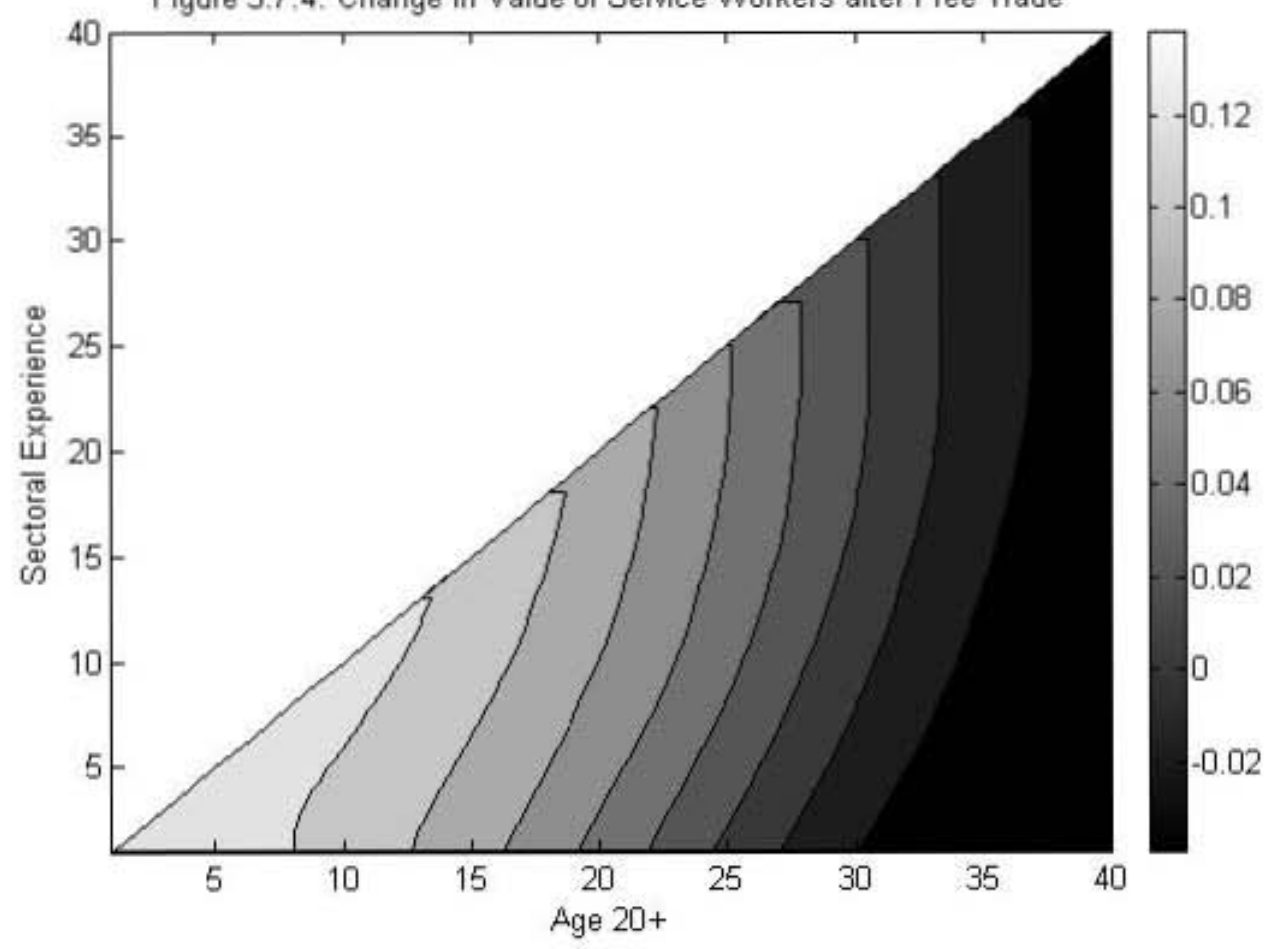

Figure 3.7.5: Change in Value of Trade Workers after Free Trade

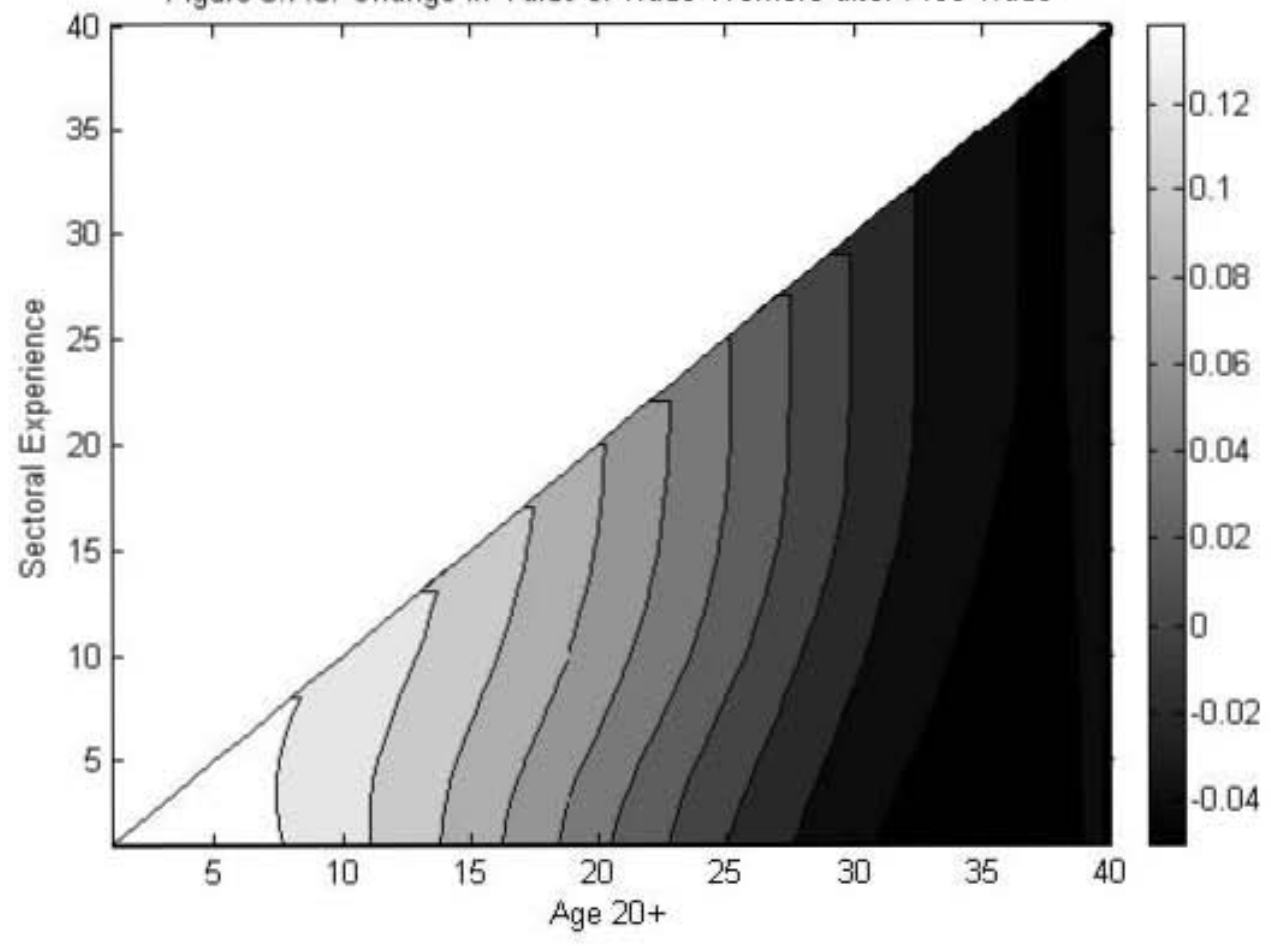


Figure 3.8.1: Change in Value of Construction Workers after Free Trade

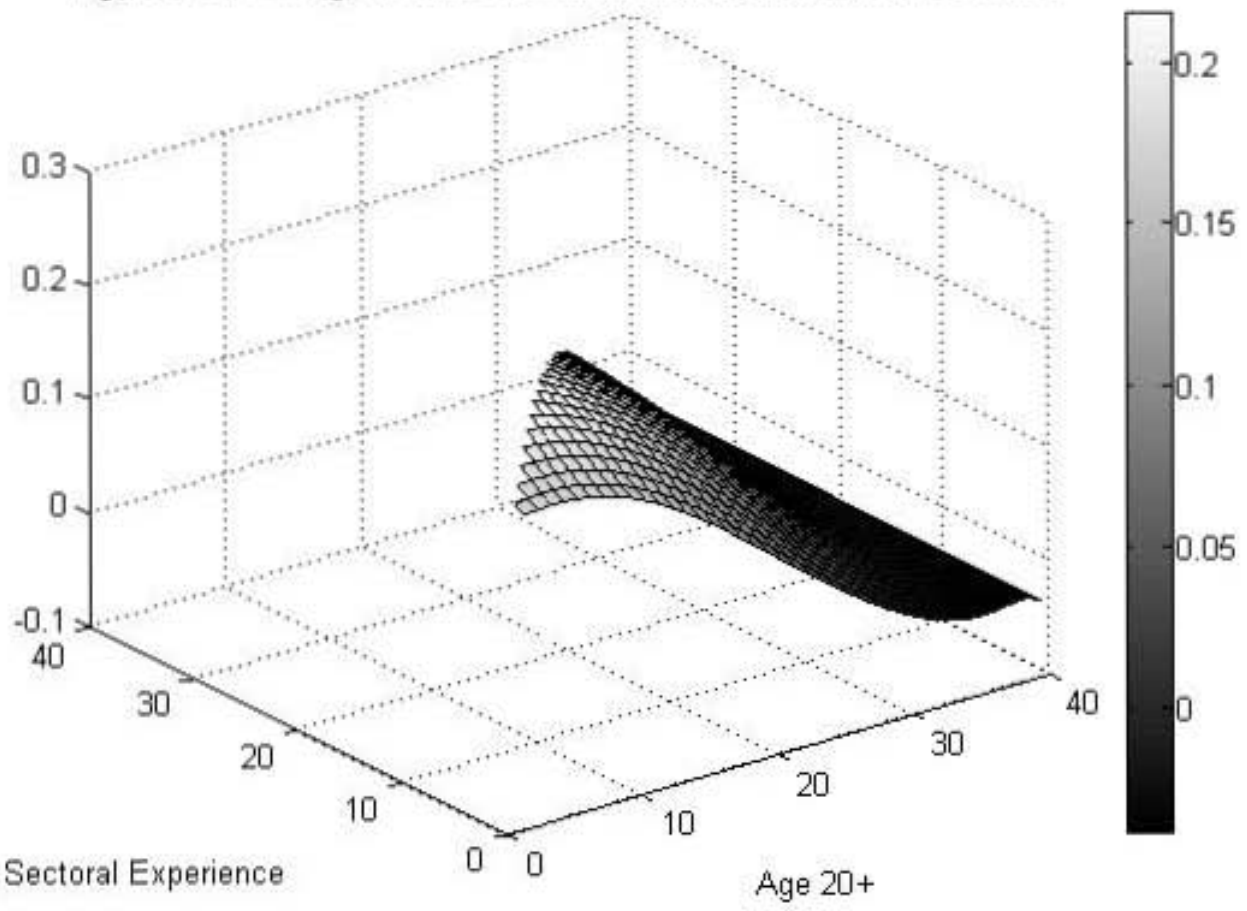

Figure 3.8.2: Change in Value of Manufacturing Workers after Free Trade

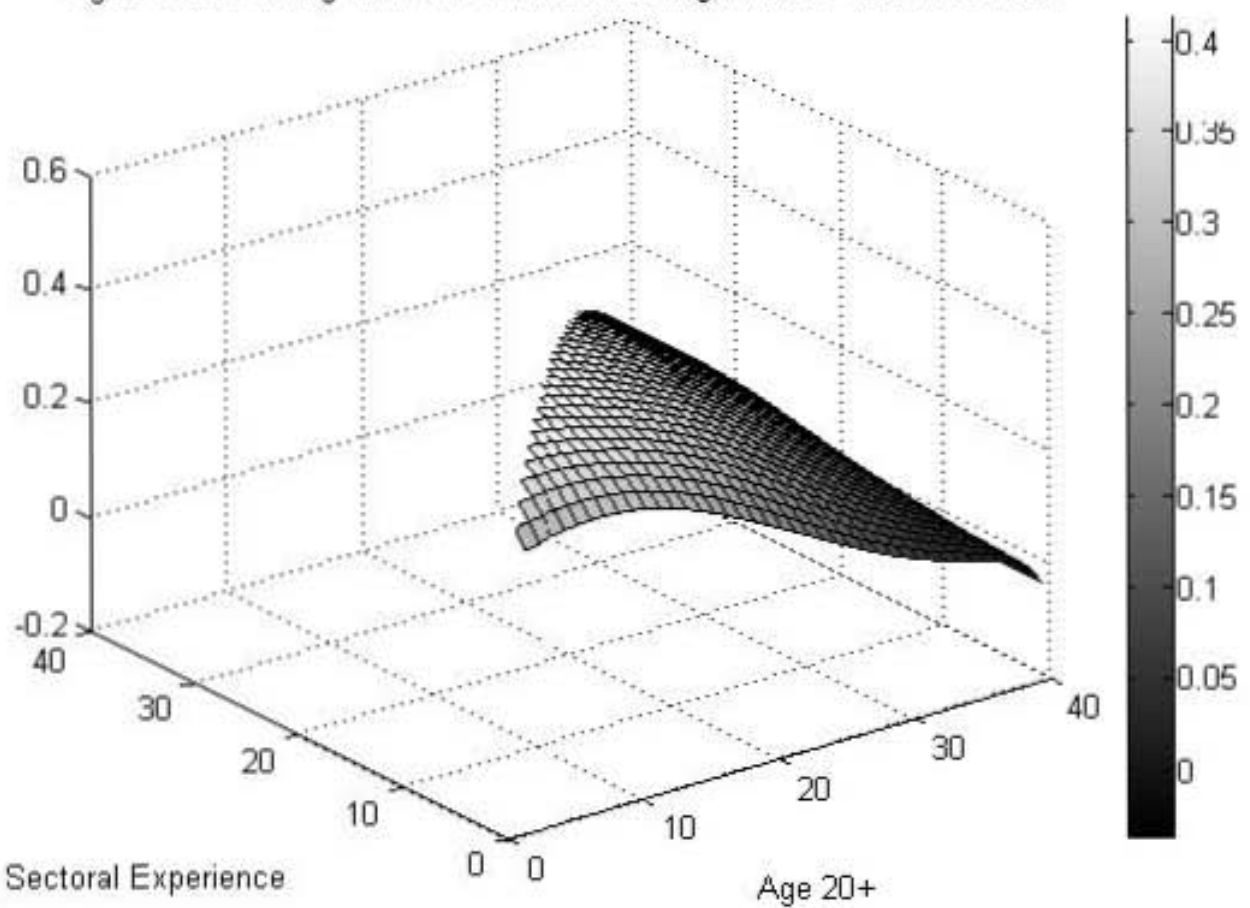


Figure 3.8.3: Change in Value of Metal Workers after Free Trade

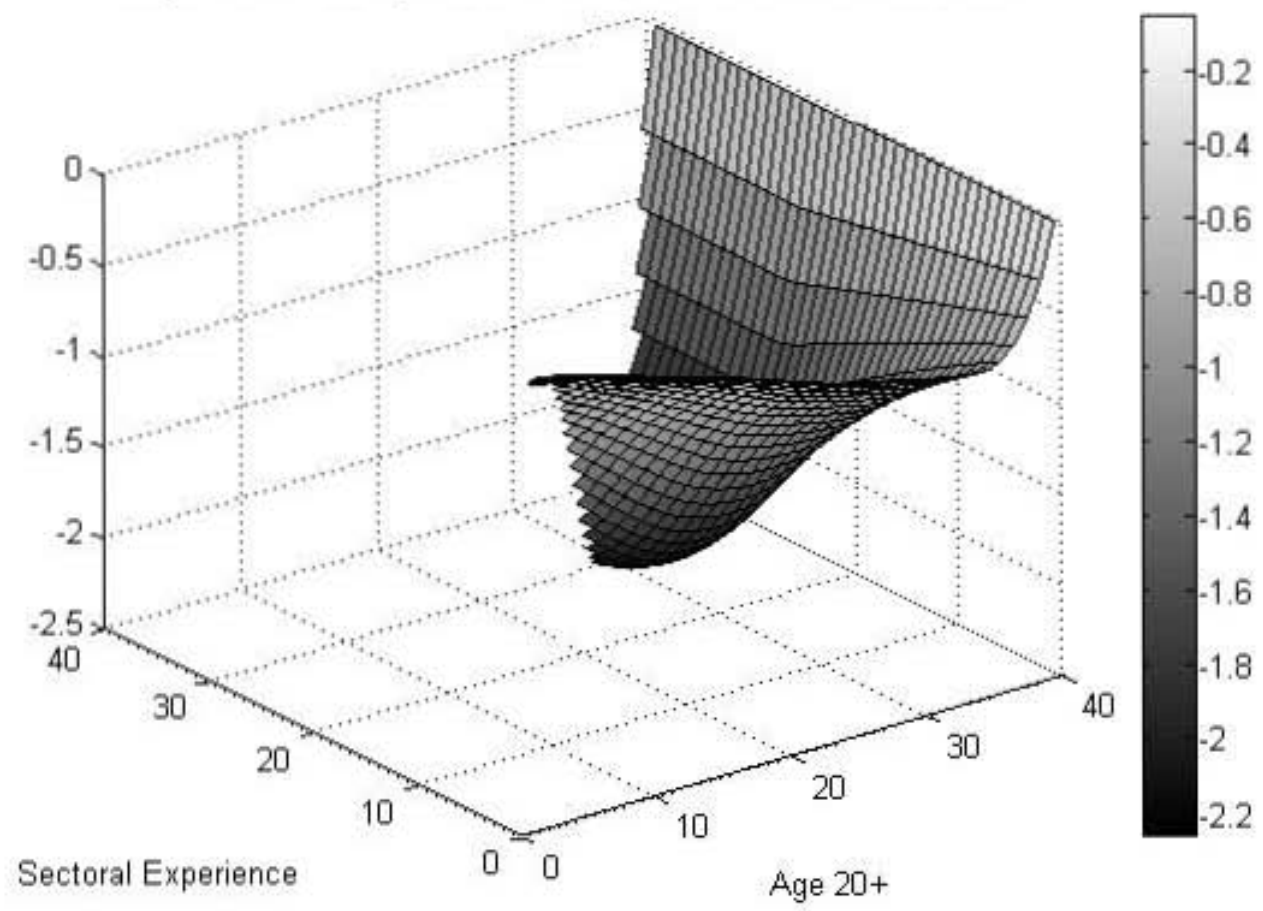

Figure 3.8.4: Change in Value of Service Workers after Free Trade

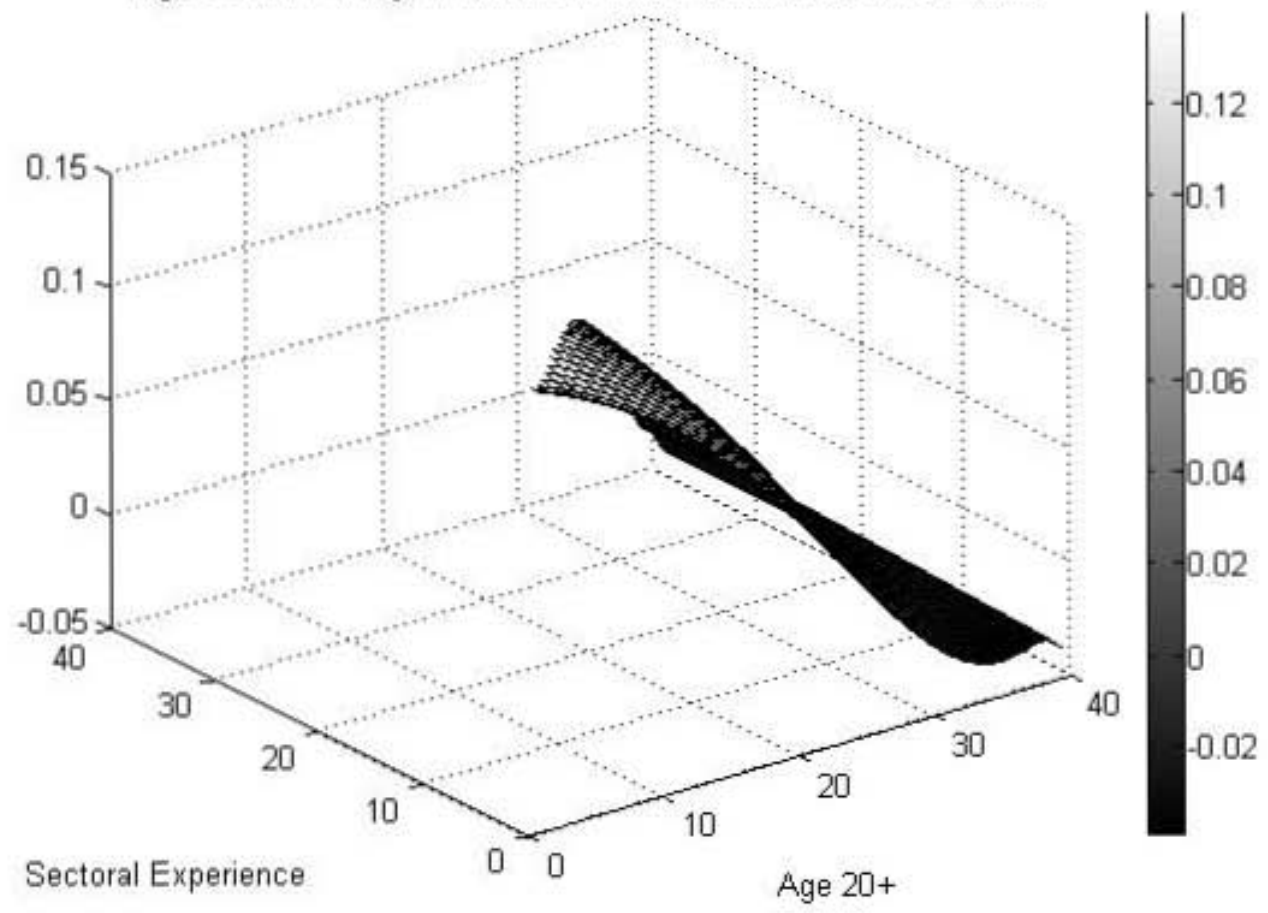


Figure 3.8.5: Change in Value of Trade Workers after Free Trade

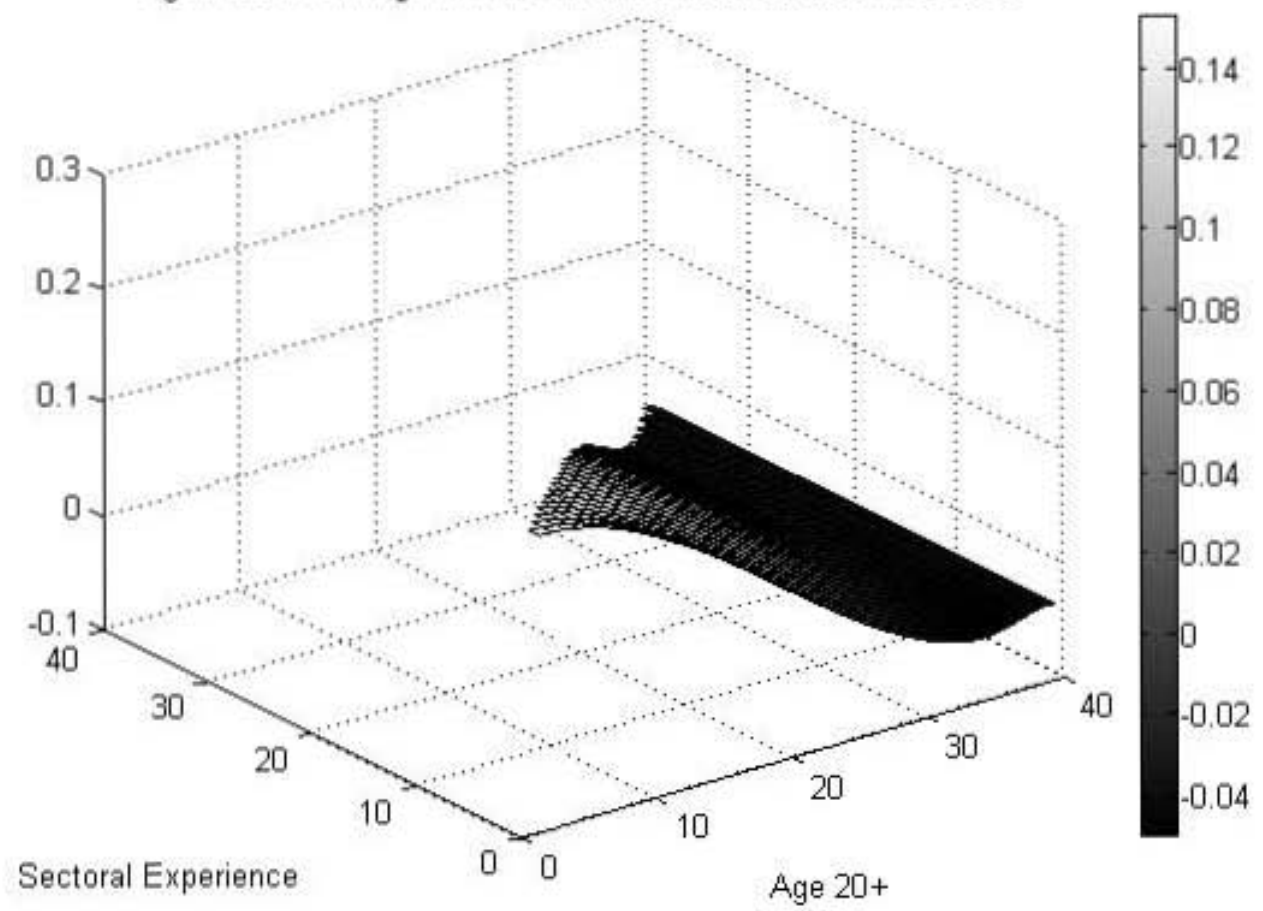

Figure 3.9.1: Change in Present Discounted Value of Wages - Construction

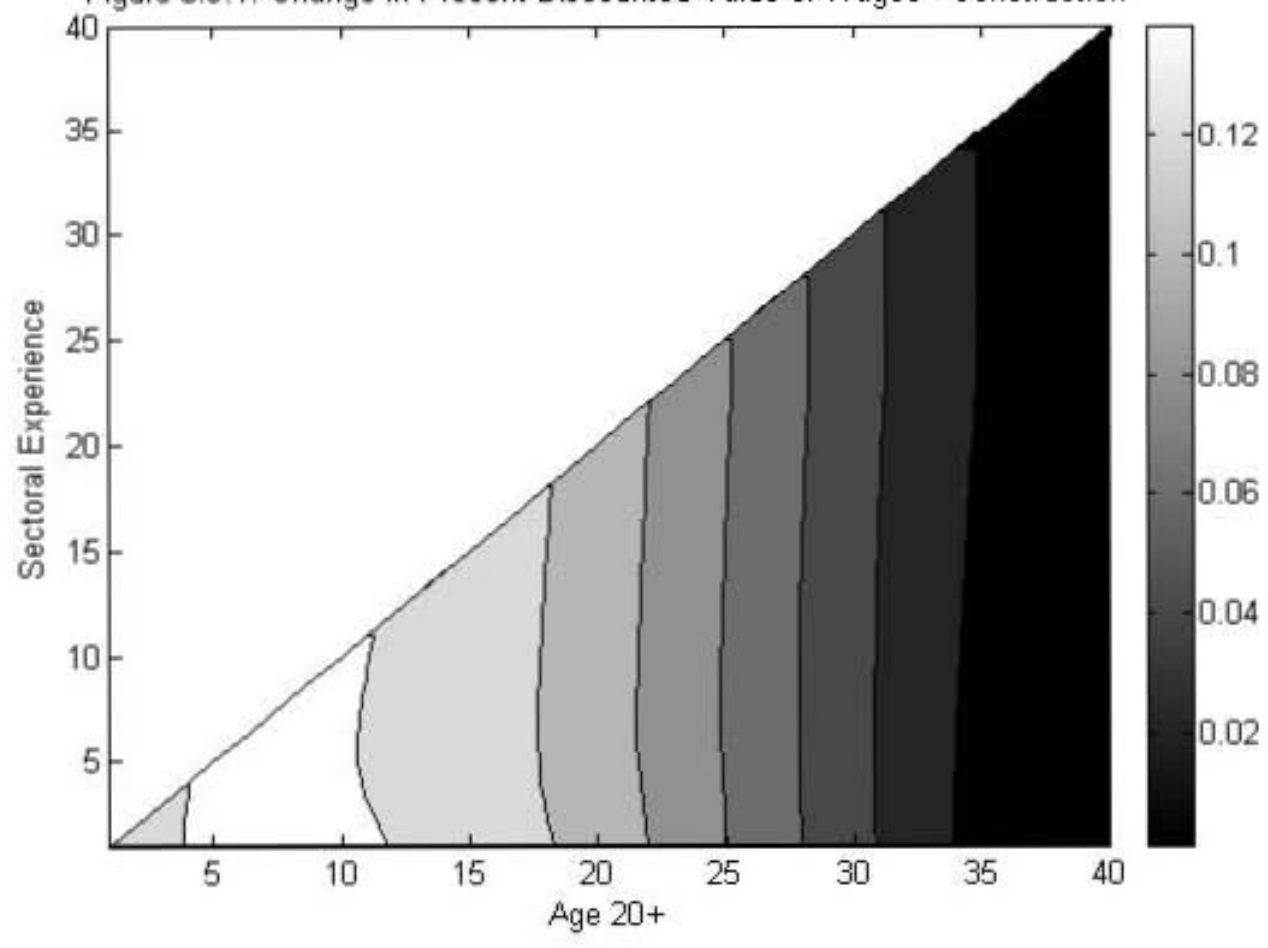




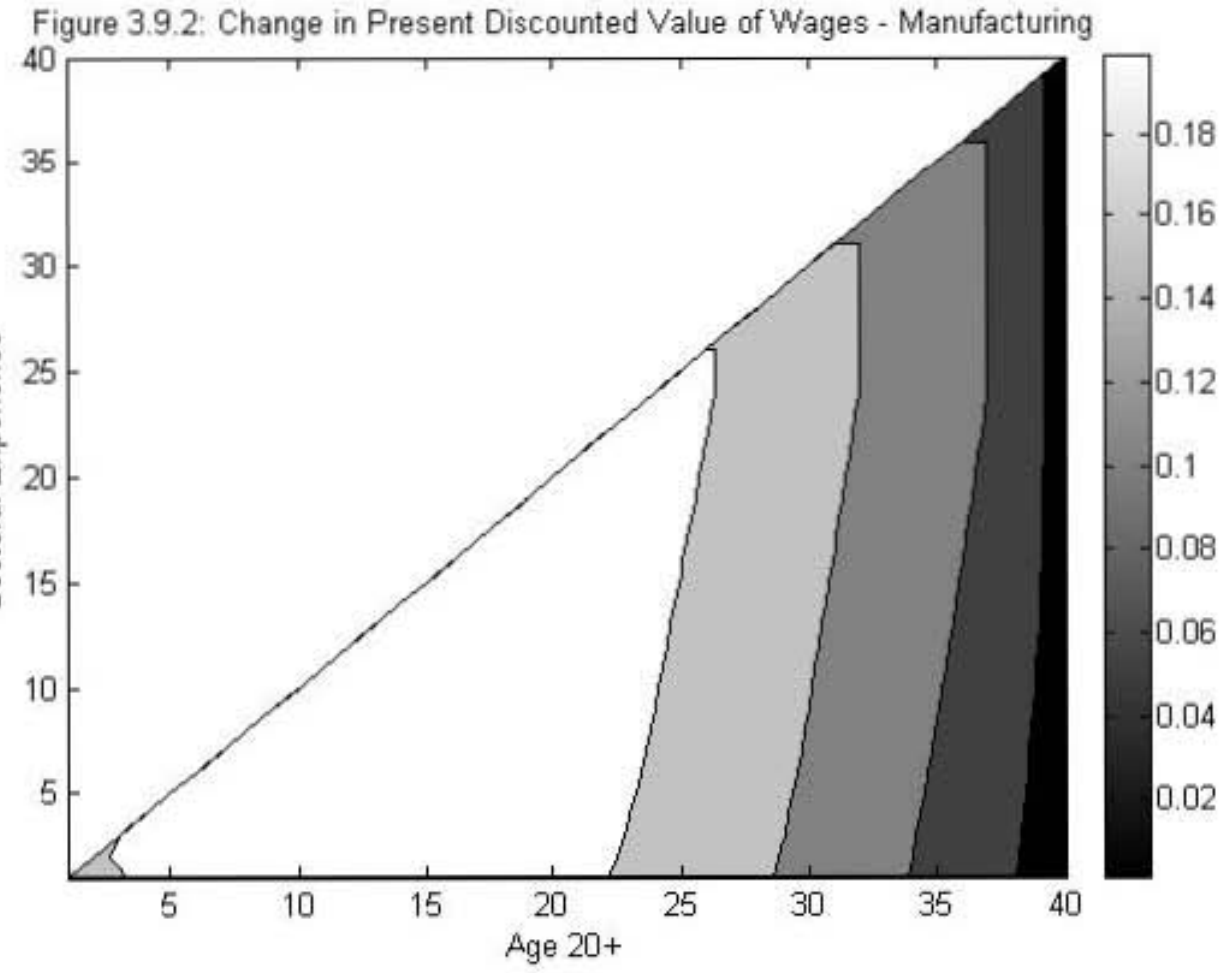

Figure 3.9.3: Change in Present Discounted Value of Wages - Metal

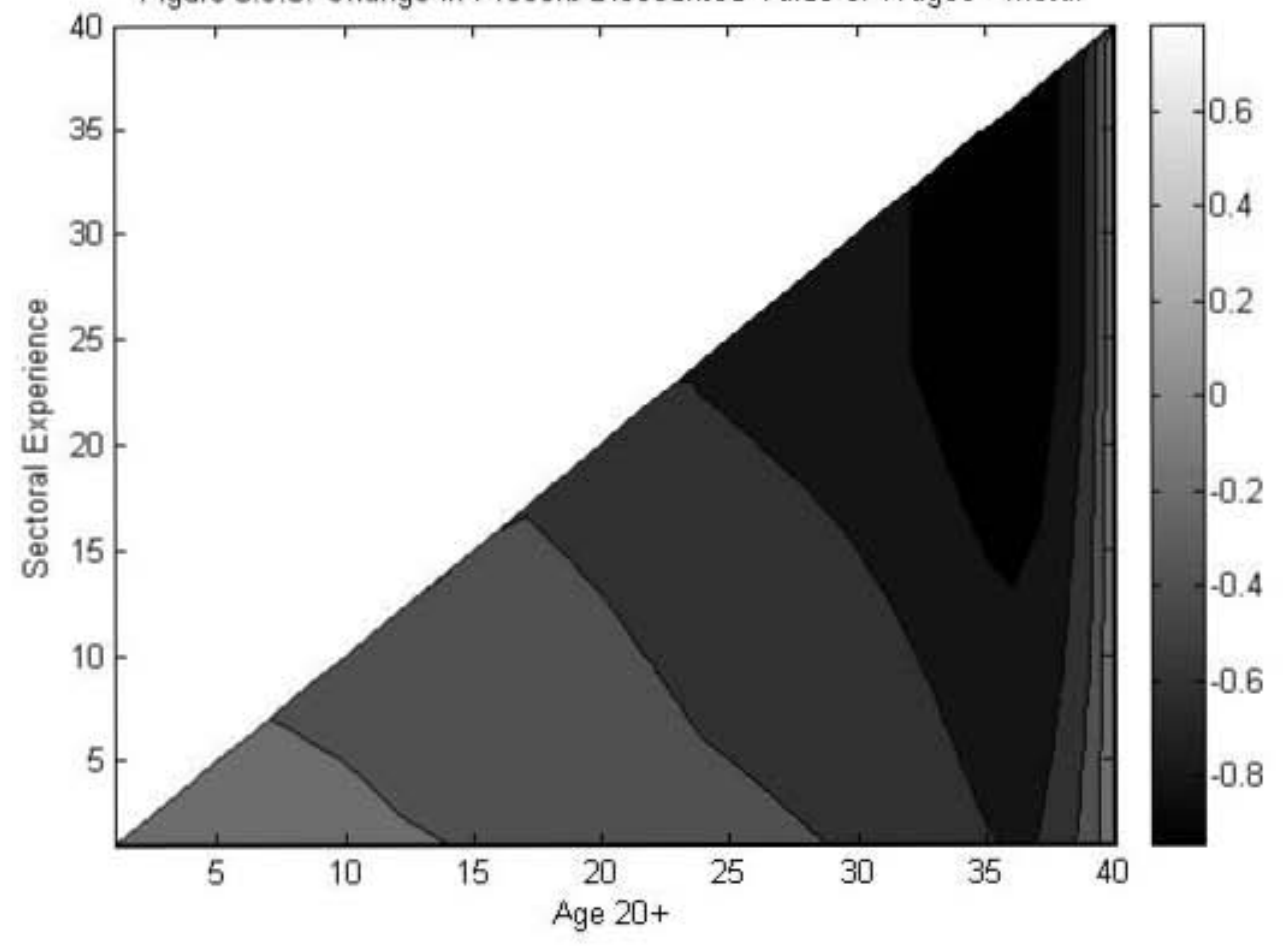


Figure 3.9.4: Change in Present Discounted Value of Wages - Service

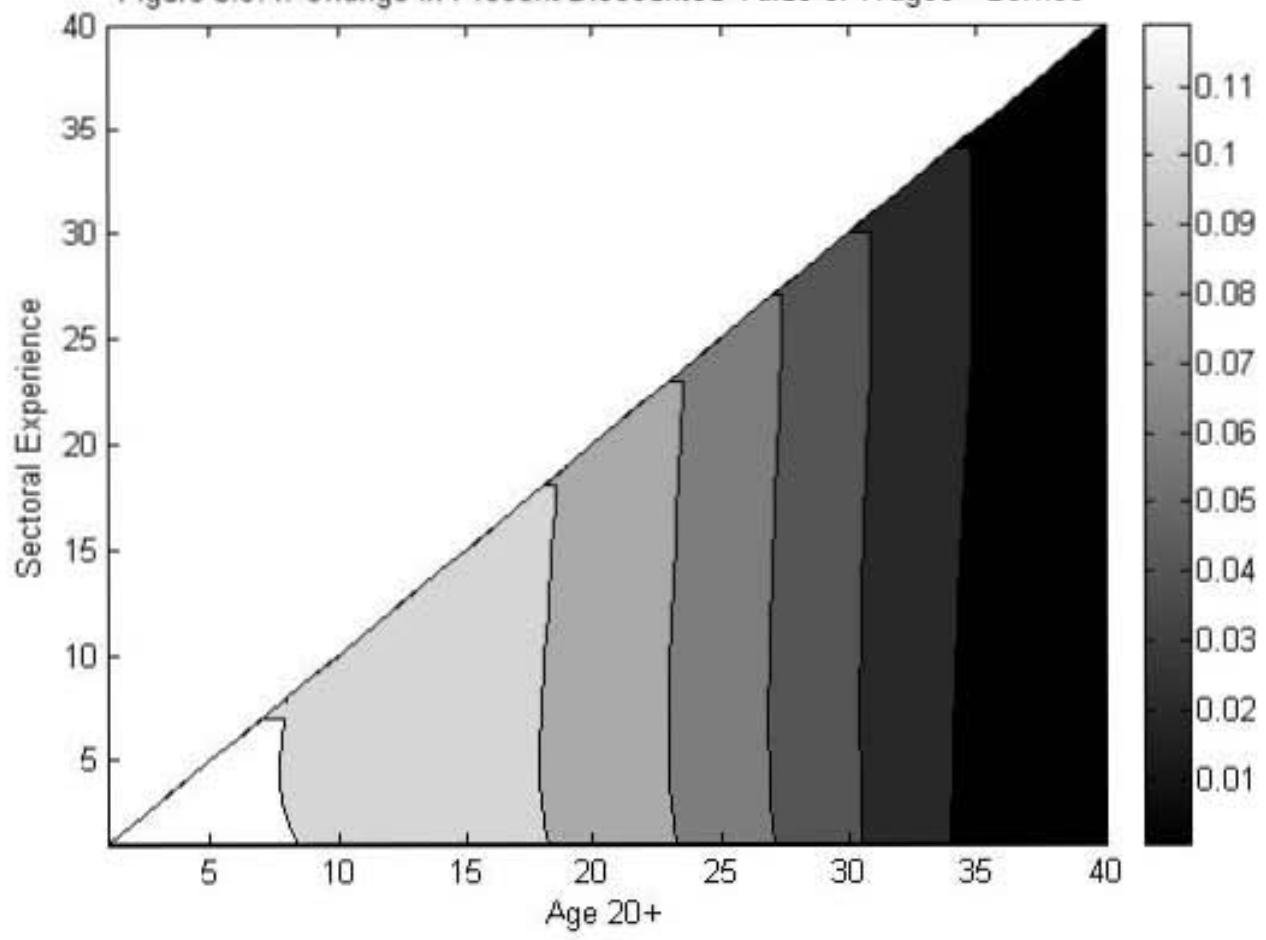

Figure 3.9.5: Change in Present Discounted Value of Wages - Trade

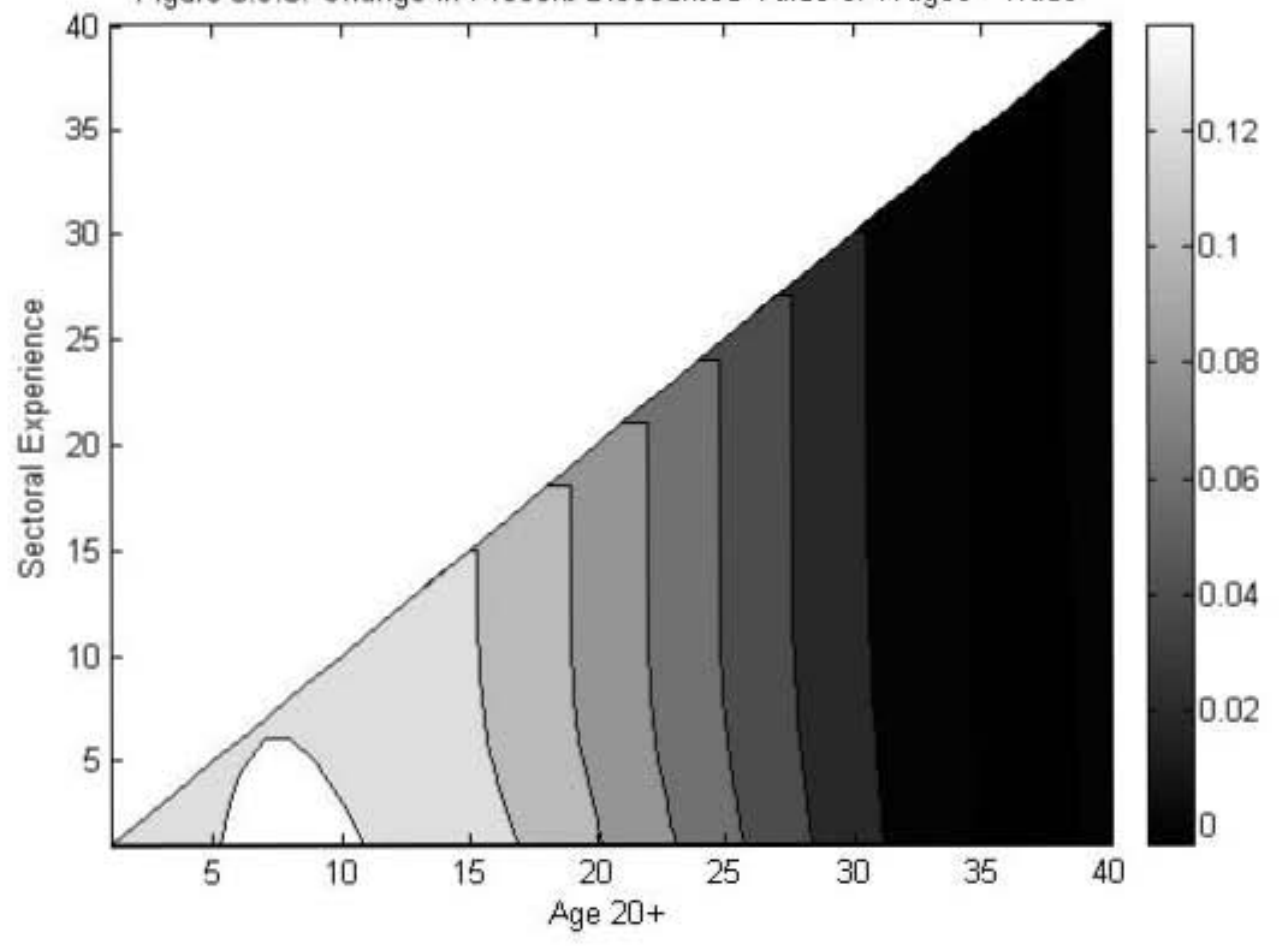


Figure 3.10.1: Change in Present Discounted Value of Wages - Construction

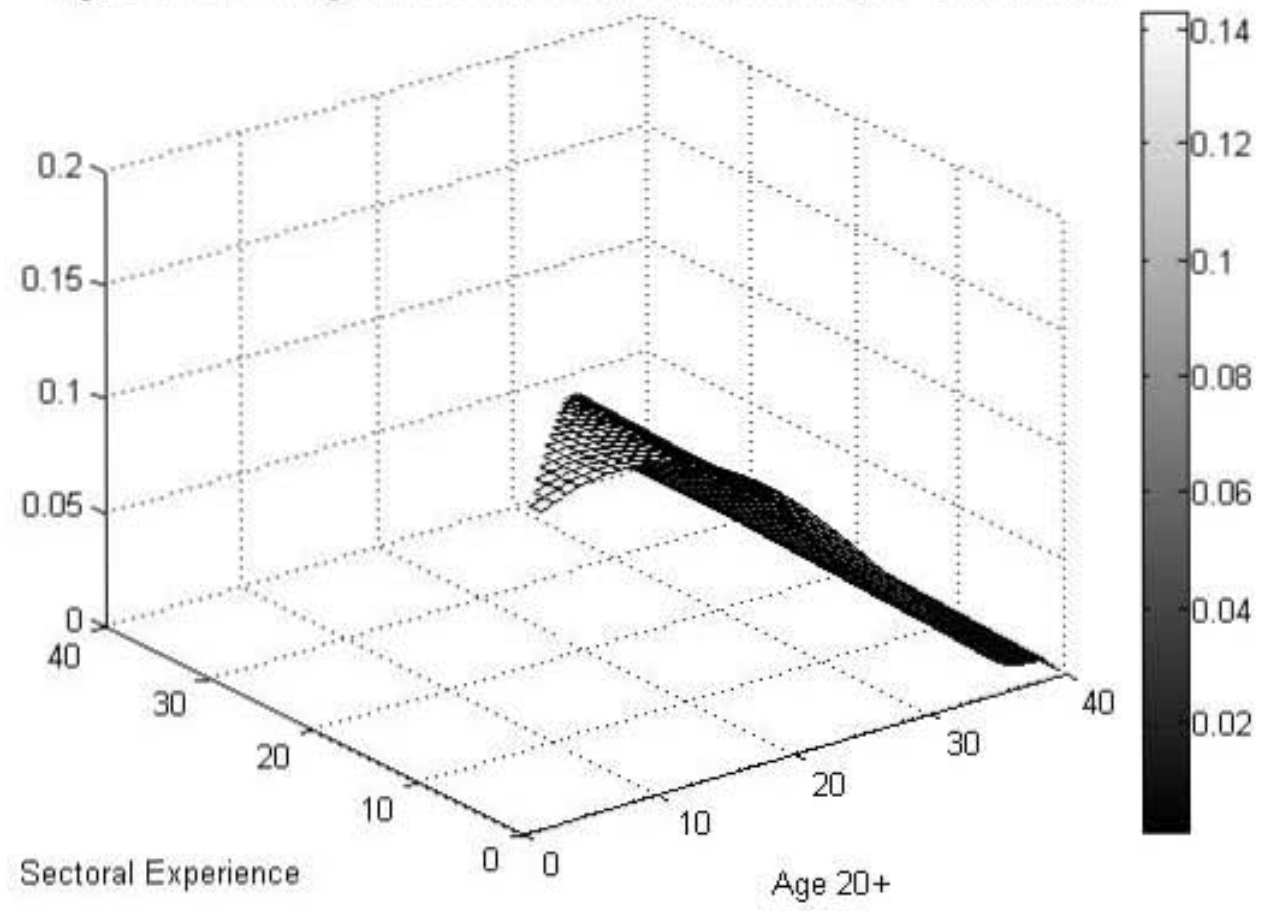

Figure 3.10.2: Change in Present Discounted Value of Wages - Manufacturing

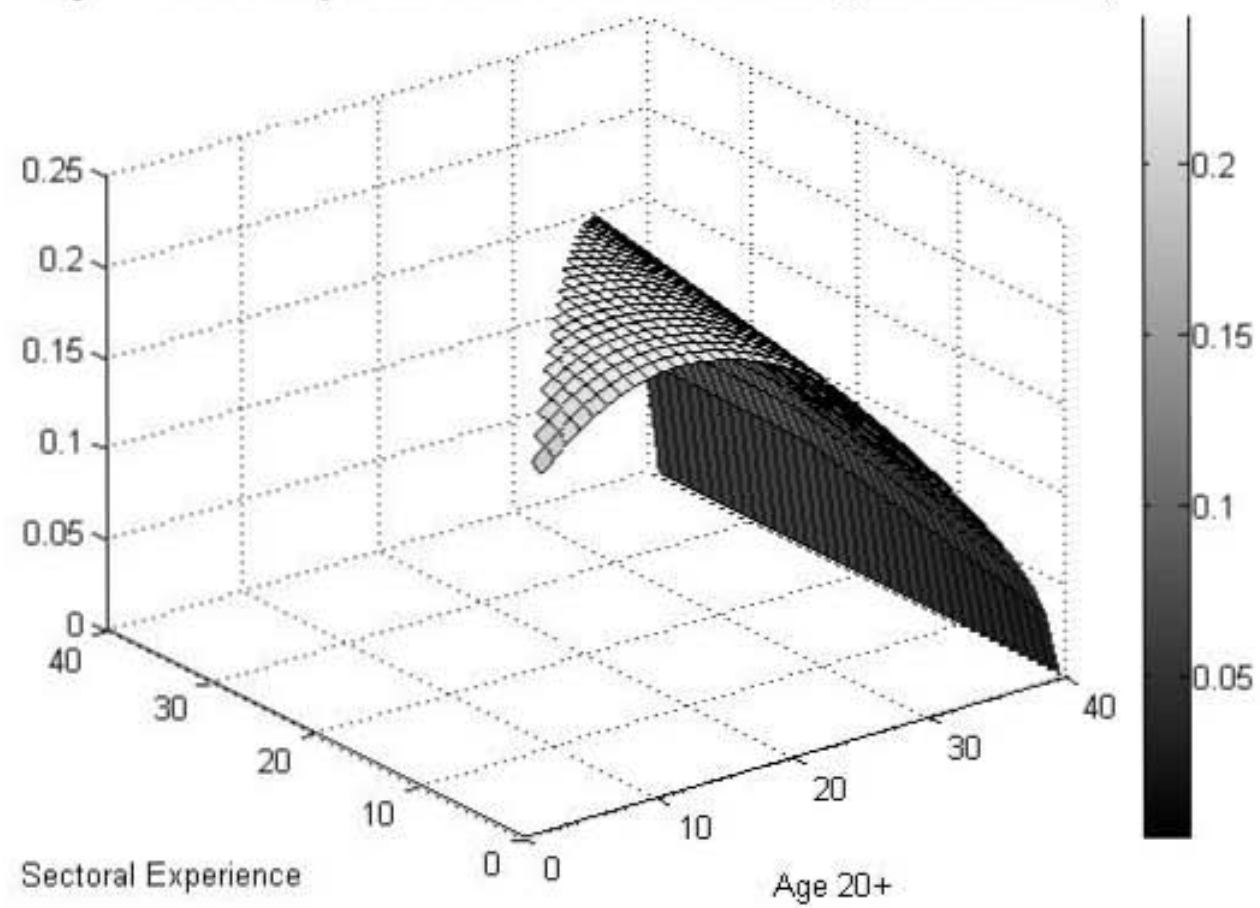


Figure 3.10.3: Change in Present Discounted Value of Wages - Metal

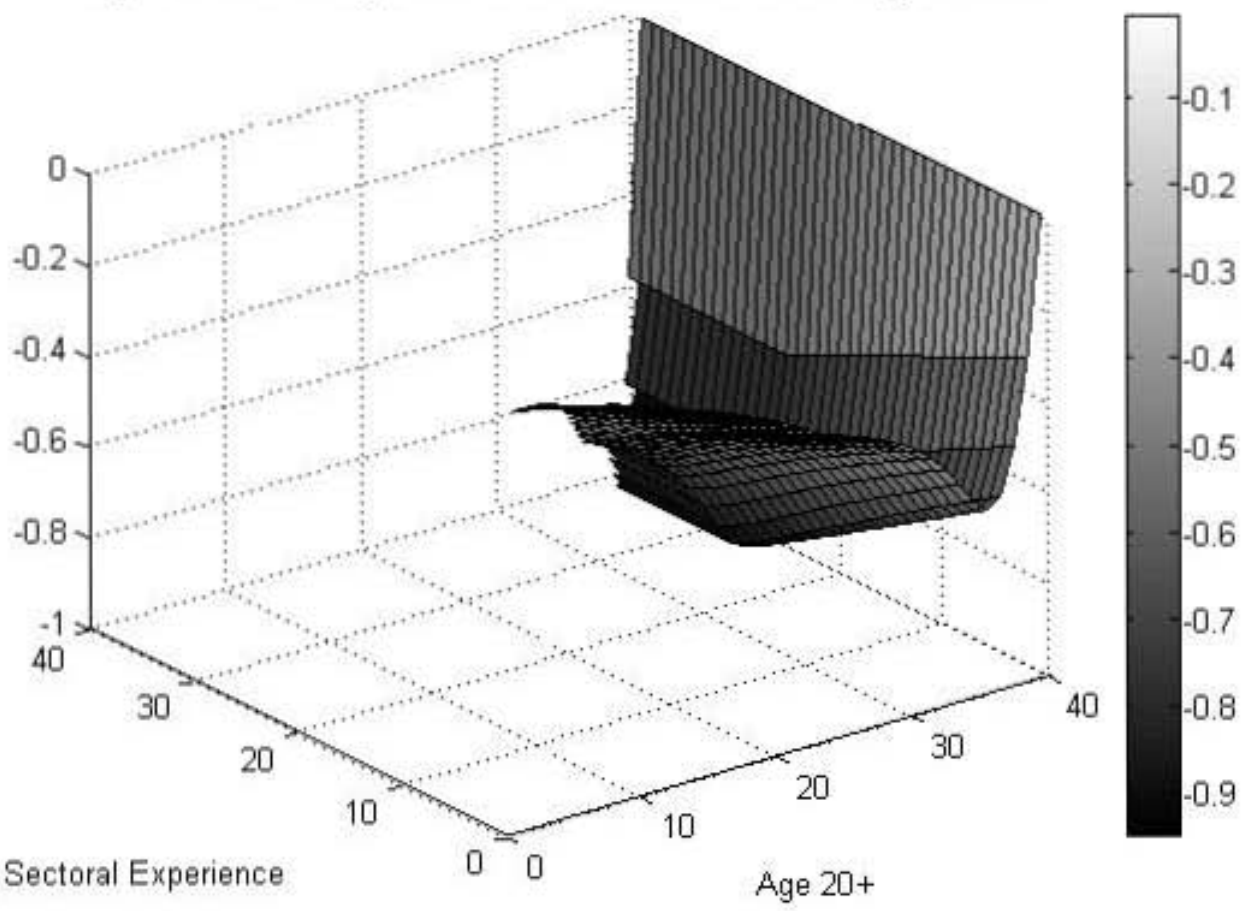

Figure 3.10.4: Change in Present Jiscounted Value of Wages - Service

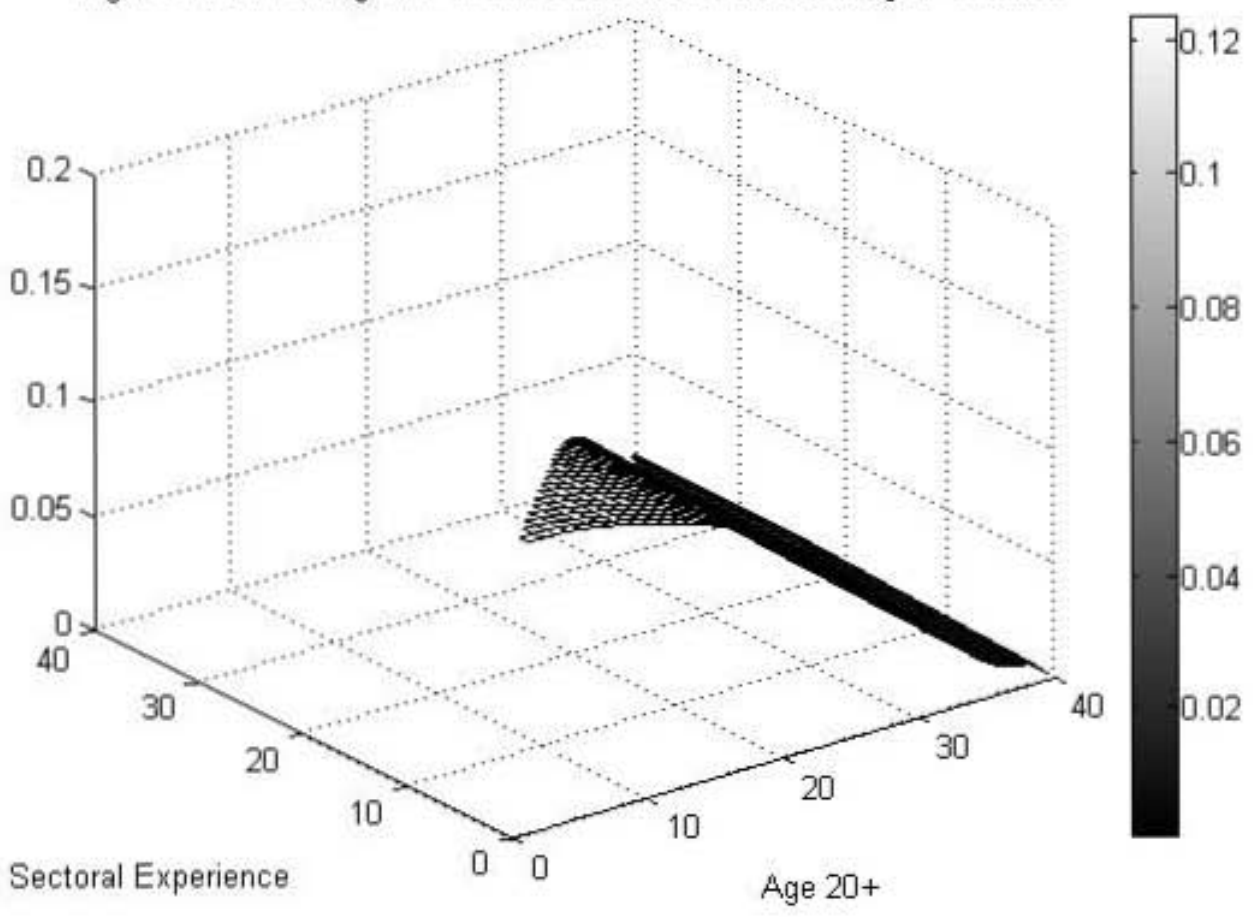


Figure 3.10.5: Change in Present Discounted Value of Wages - Trade
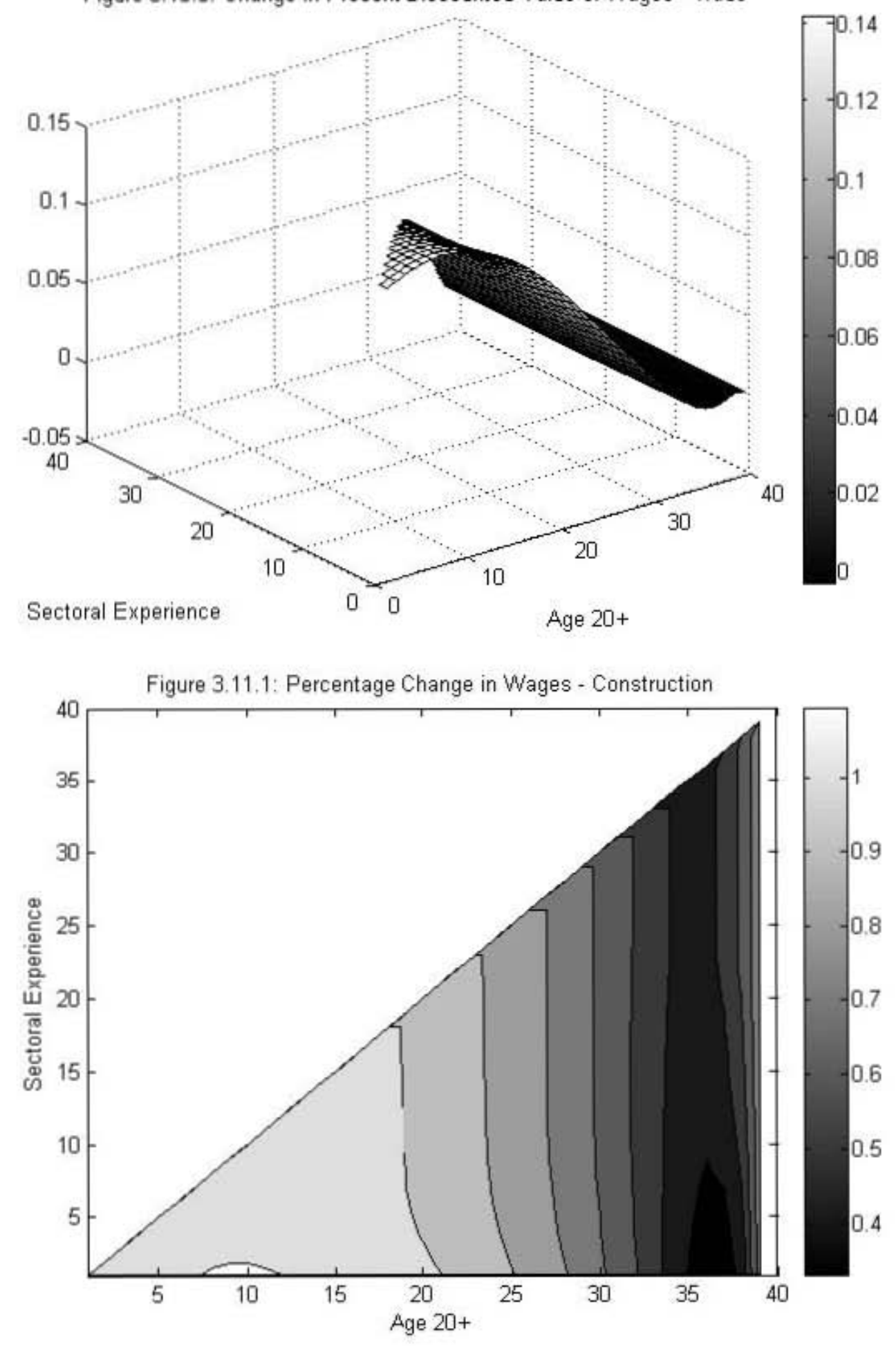
Figure 3.11.2: Percentage Change in Wages - Manufacturing

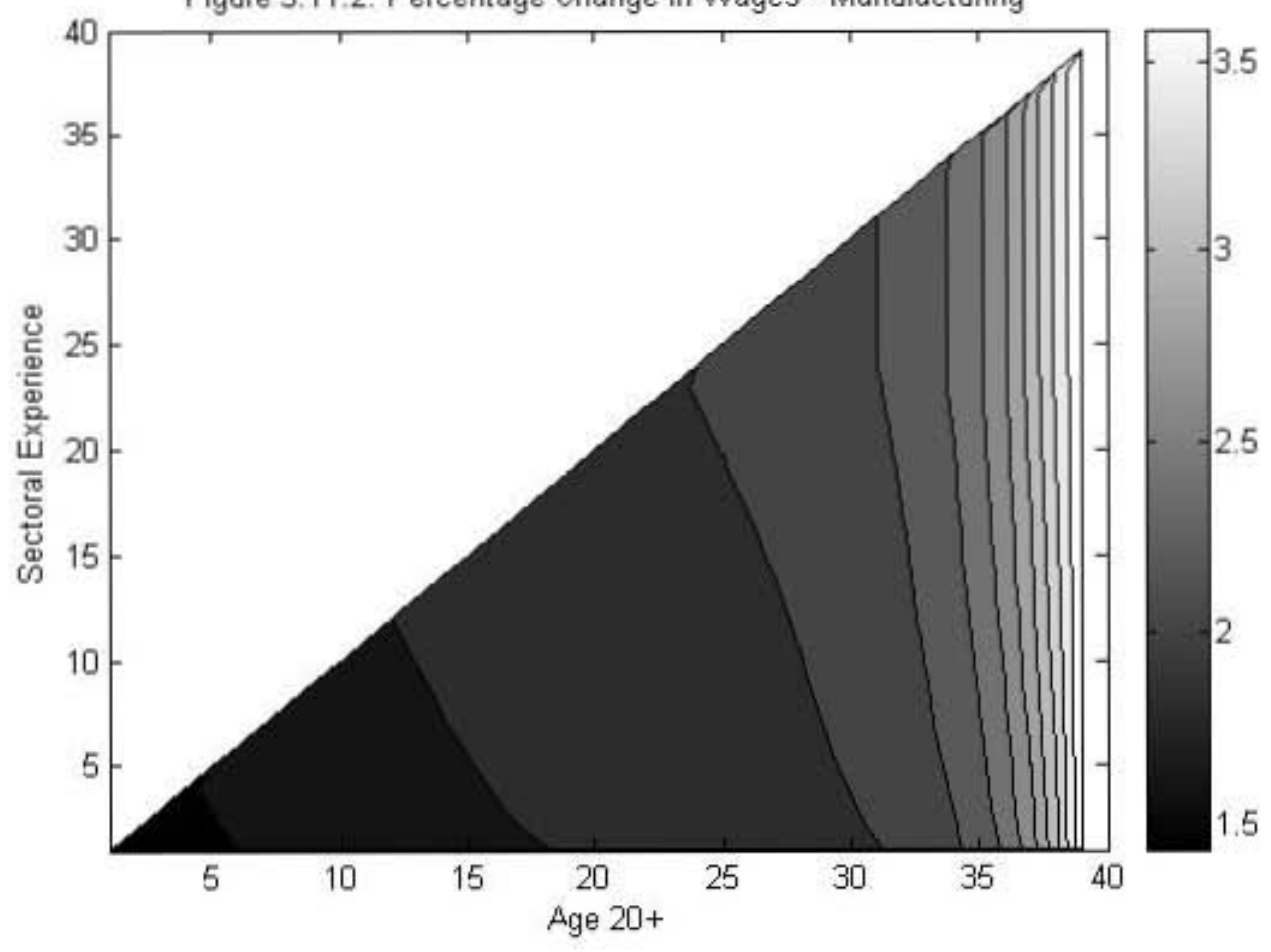

Figure 3.11.3: Percentage Change in Wages - Metal

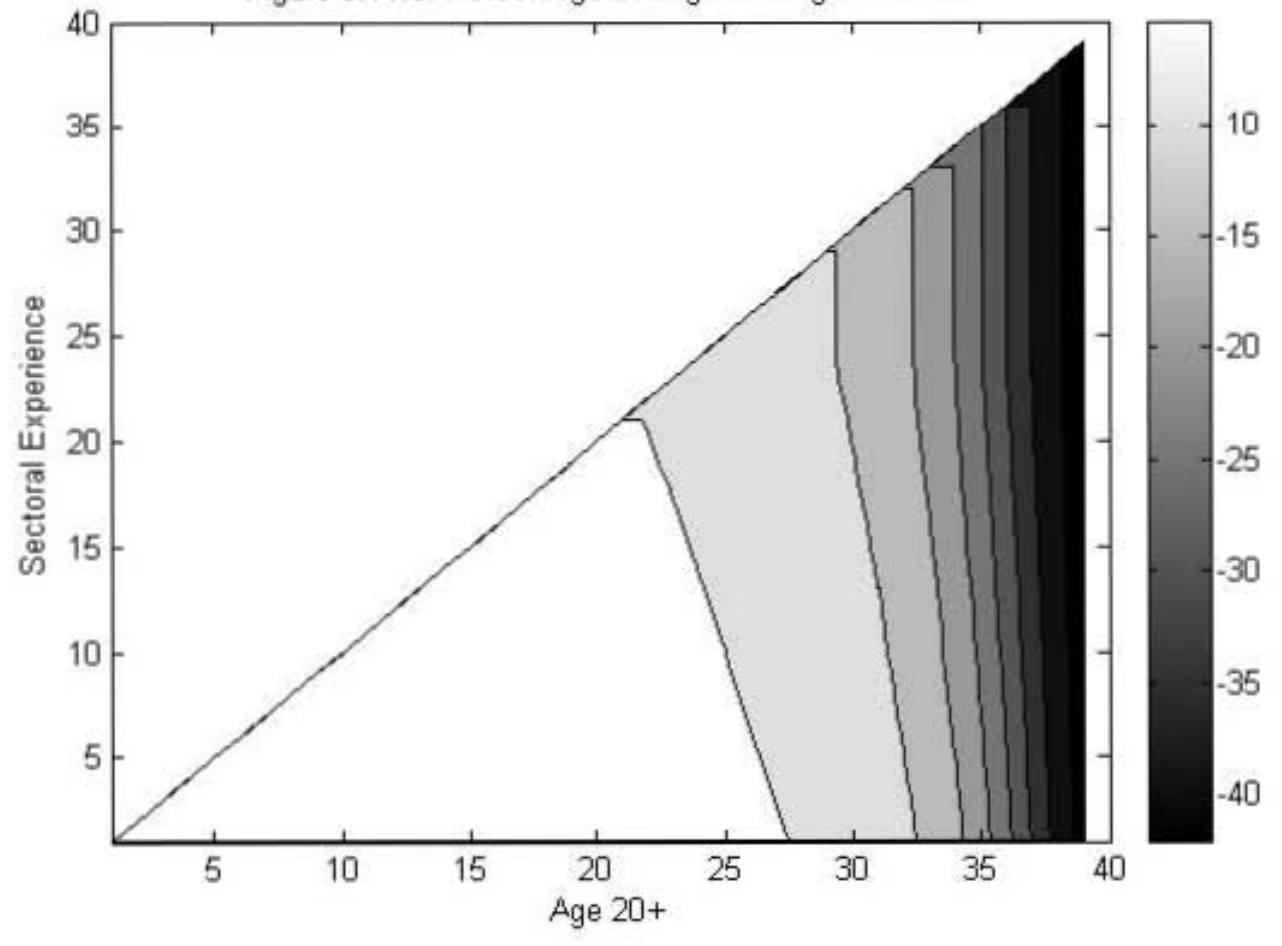


Figure 3.11.4: Percentage Change in Wages - Service

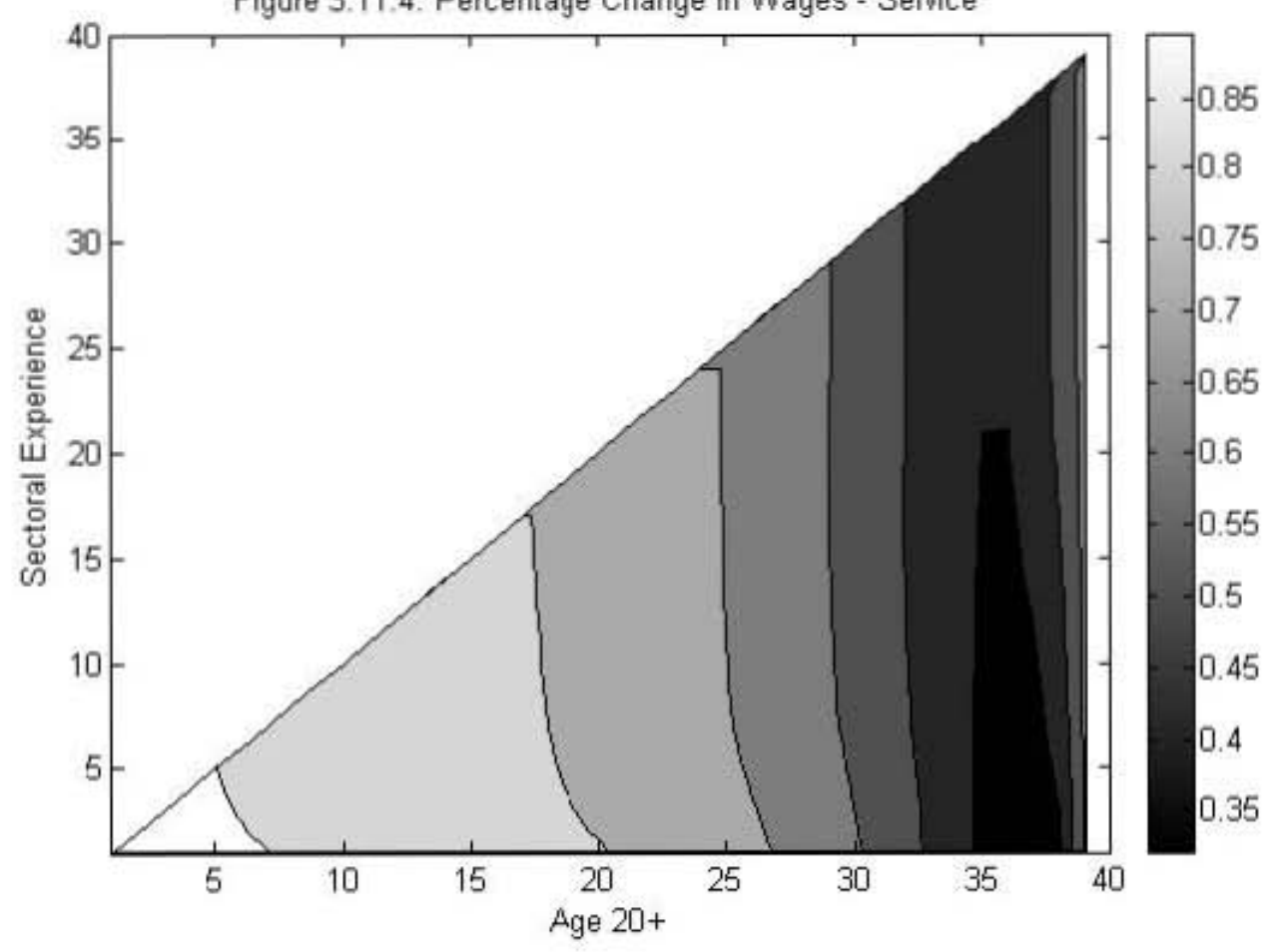

Figure 3.11.5: Percentage Change in Wages - Trade

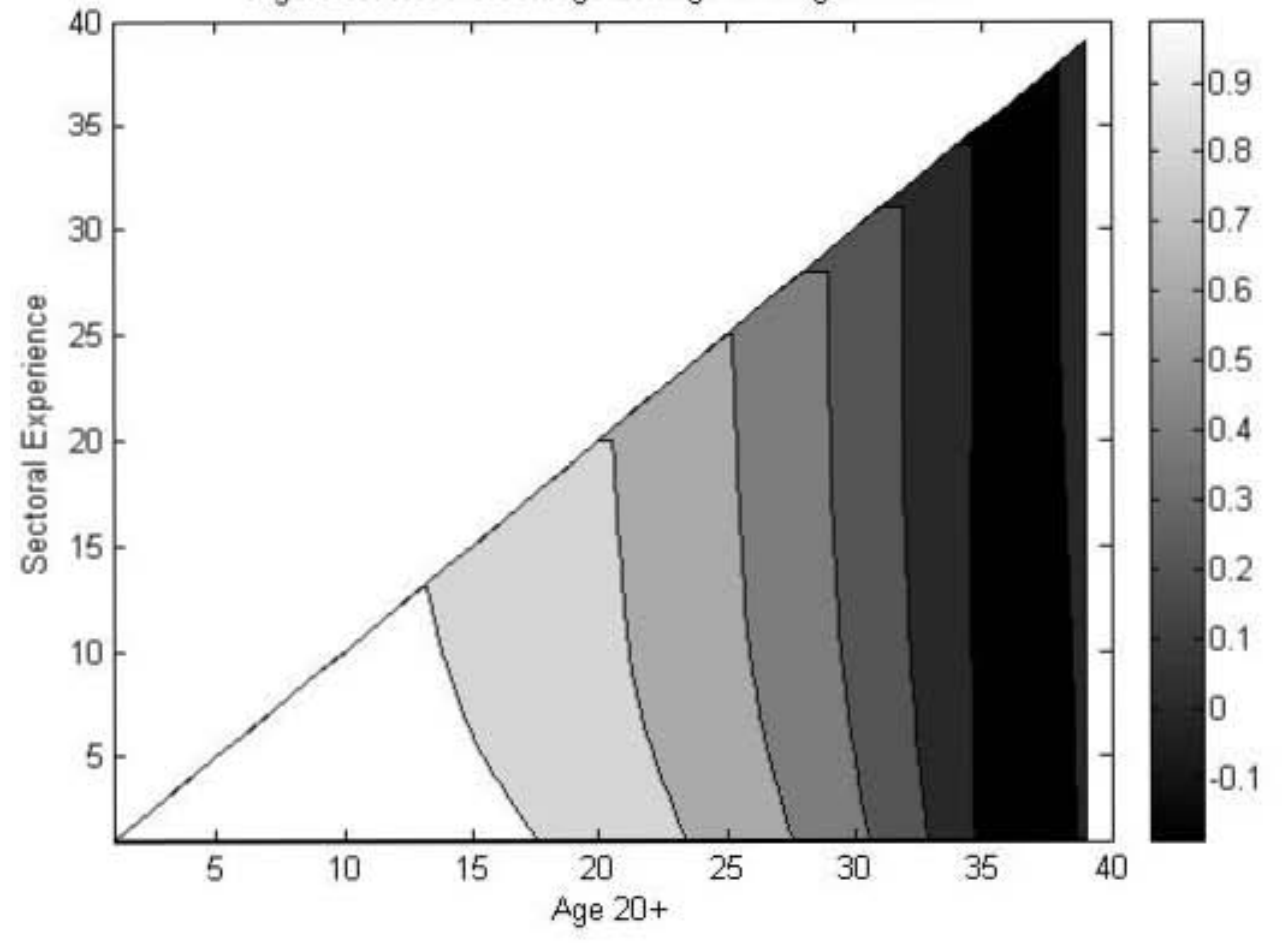


Figure 3.12.1: Percentage Change in Wages - Construction

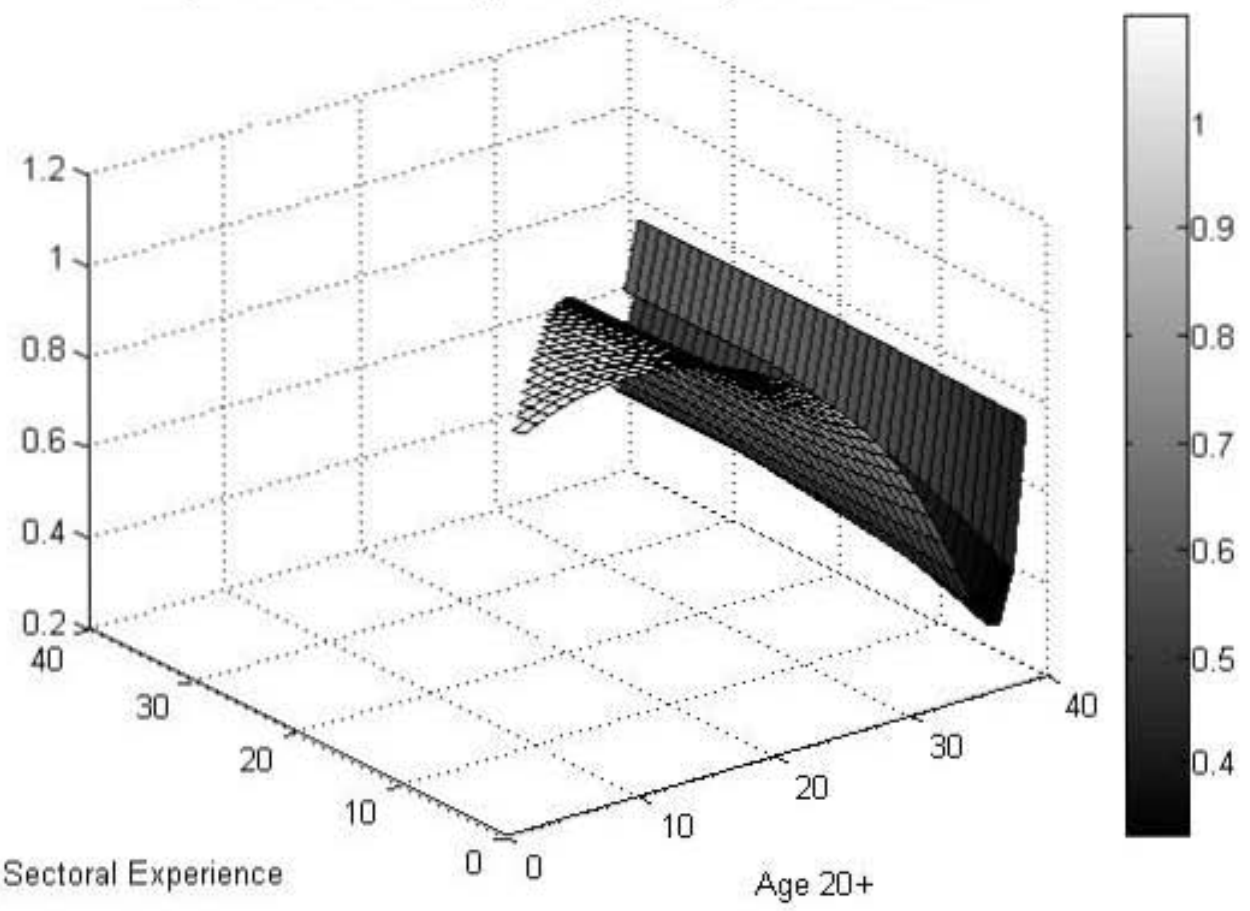

Figure 3.12.2: Percentage Change in Wages - Manufacturing

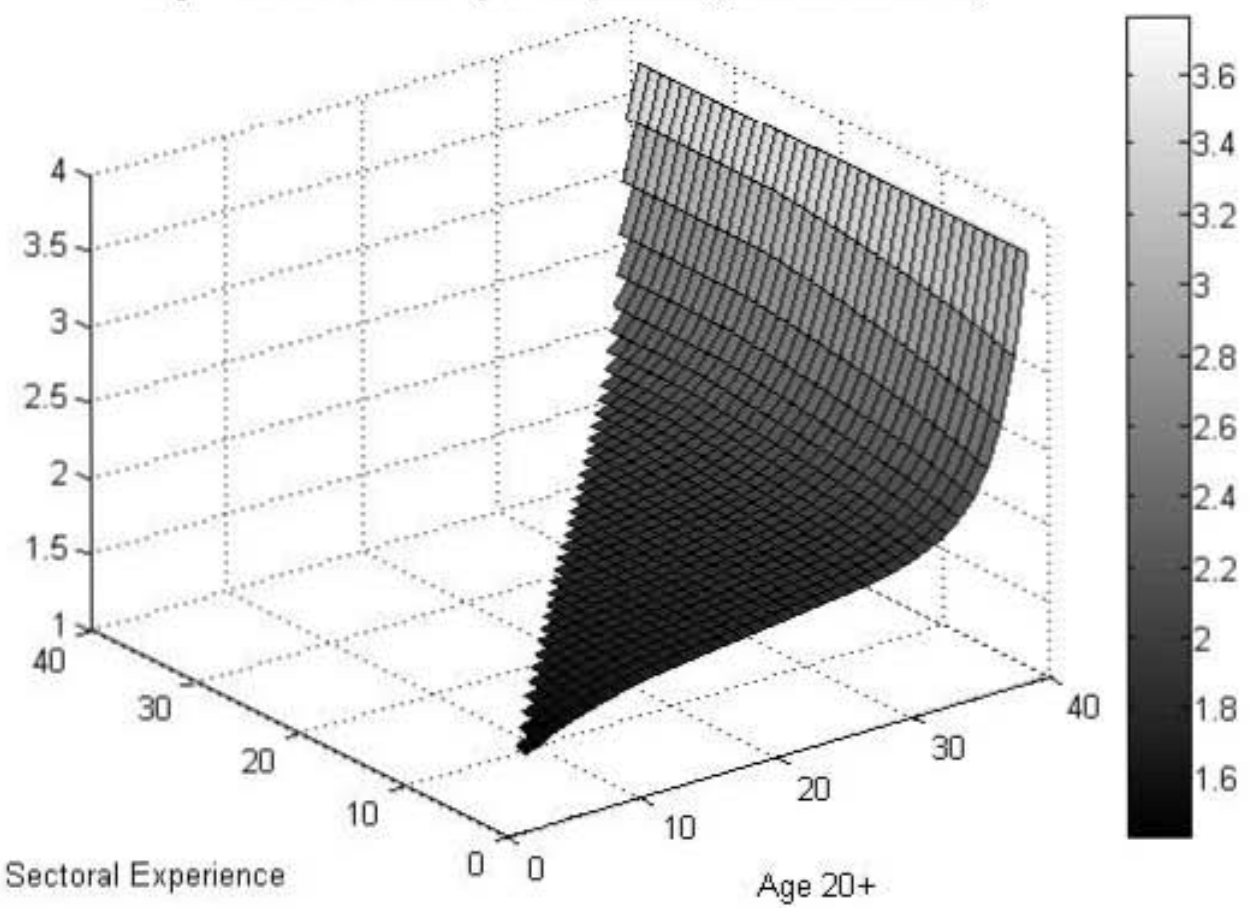


Figure 3.12.3: Percentagz Change in Wages - Metal

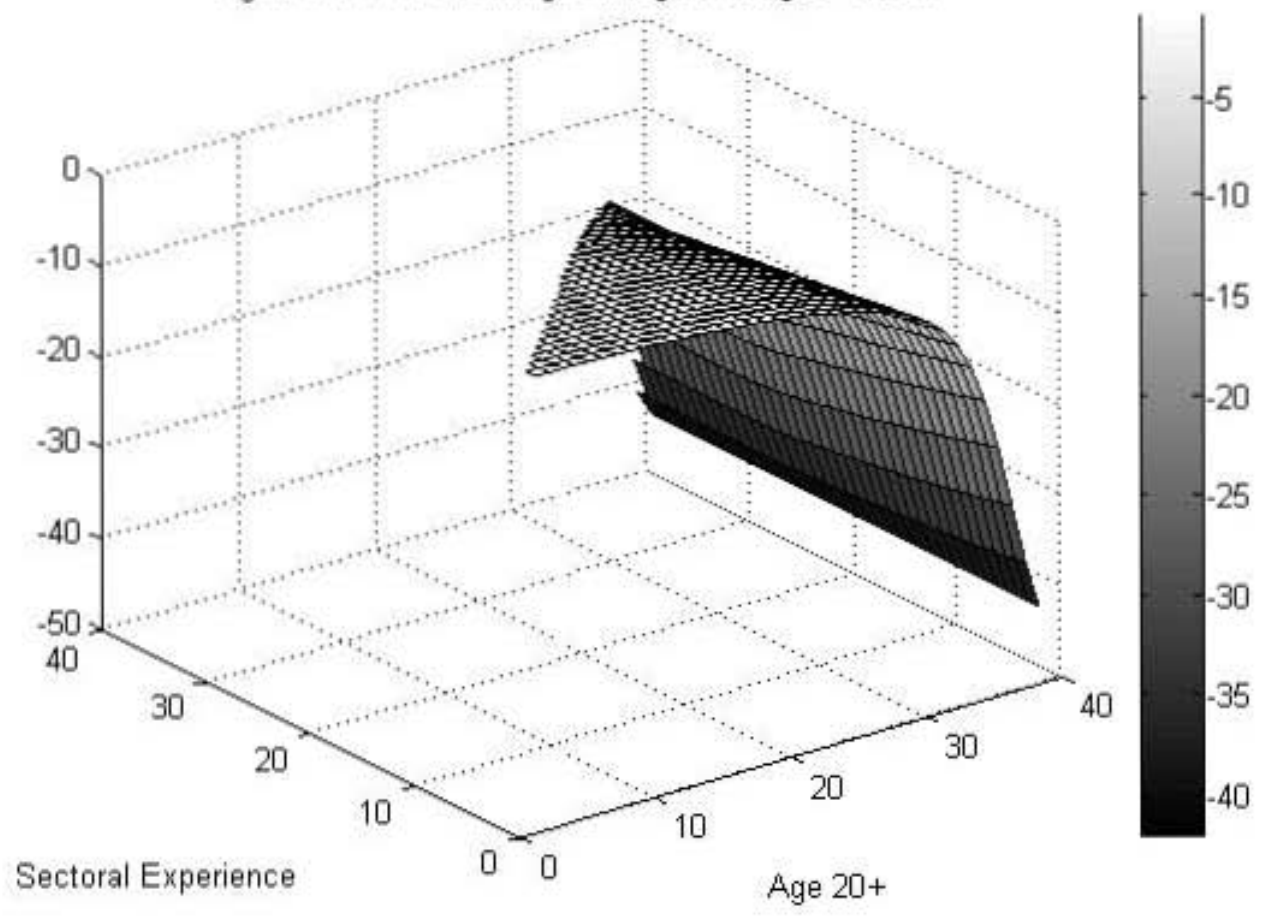

Figure 3.12.4: Percentage Change in Wages - Service

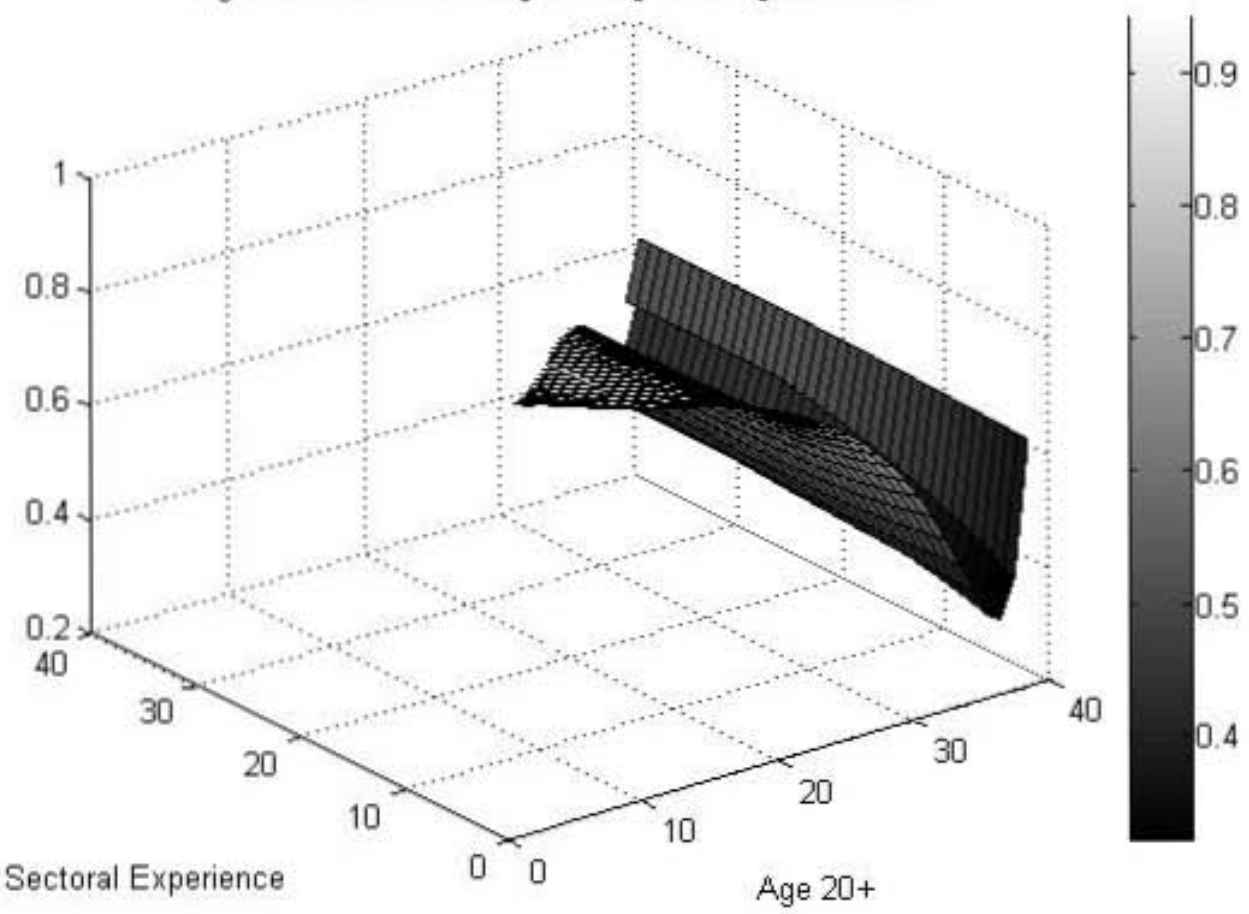


Figure 3.12.5: Percentage Change in Wages - Trade

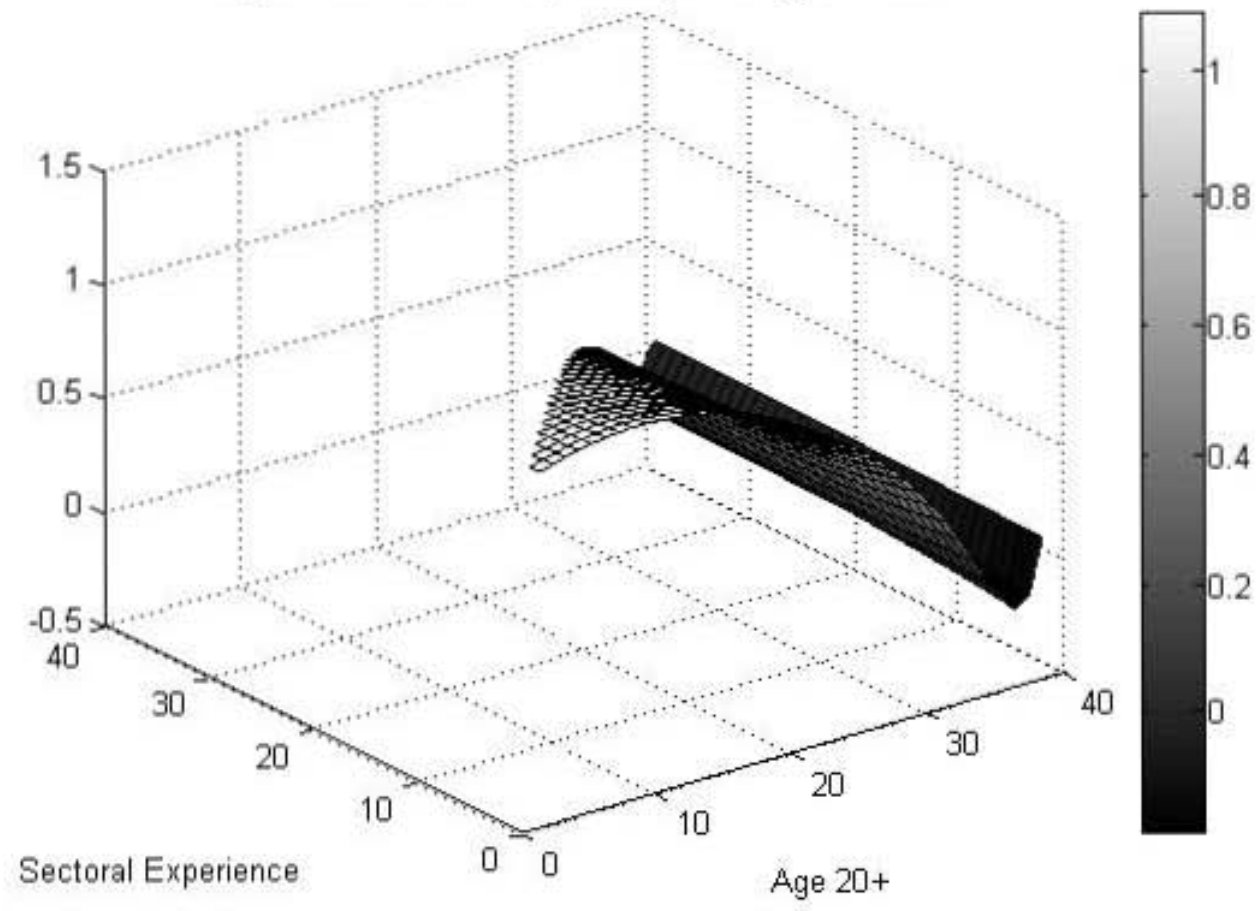

